\title{
LOW BACK PAIN INCIDENCE IN
}

NEW ZEALAND ROWERS AND ITS

RELATIONSHIP WITH FUNCTIONAL MOVEMENT PATTERNS

\section{Craig Newlands}

\author{
Supervisor: Duncan Reid
}

\author{
A thesis submitted to Auckland University of \\ Technology in partial fulfillment of the requirements \\ for the degree of Master of Health Science
}

October 2013 


\section{TABLE OF CONTENTS}

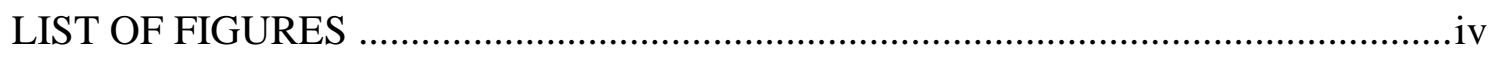

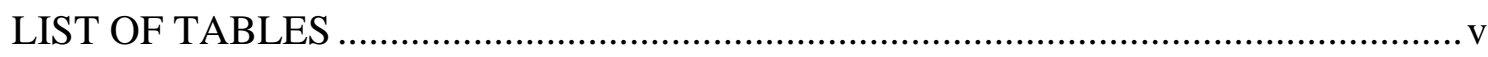

CERTIFICATE OF AUTHORSHIP ...................................................................

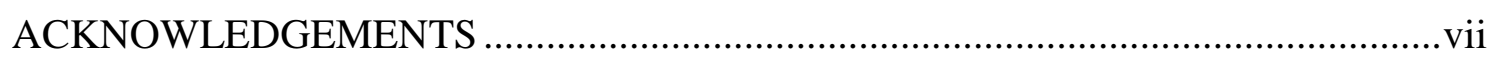

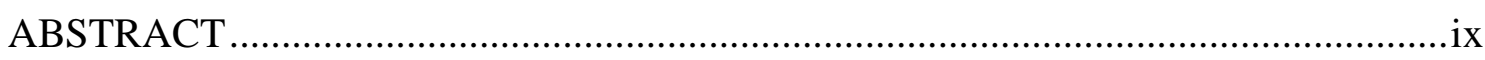

Chapter One Introduction.....................................................................................................1

$1.1 \quad$ Statement of the problem ………………………..................................... 1

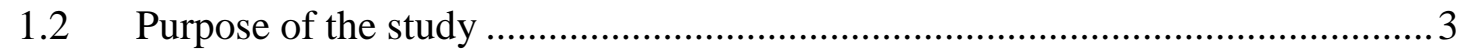

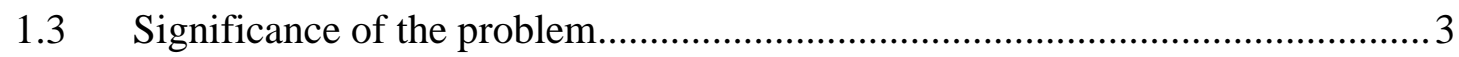

Chapter Two Review of Literature ...........................................................................................5

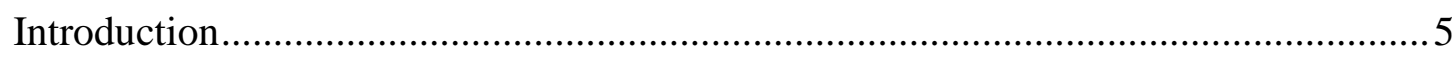

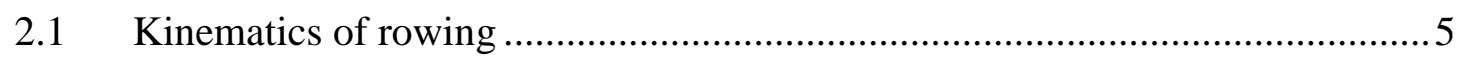

2.2 Low back pain in rowing ...................................................................

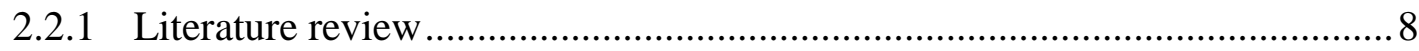

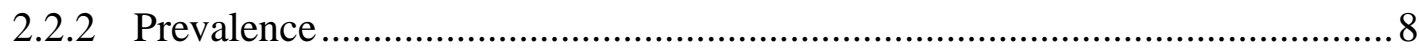

2.2.3 Possible risk factors associated with low back pain ……………………...... 17

2.2.4 Relationship between training volume and low back pain ............................ 18

2.2.5 Effect of low back pain on training ........................................................... 19

2.2.6 Intervention studies on low back pain in rowing .........................................2 20

2.3 Functional movement screening ................................................................2

2.3.1 Movement competency screen................................................................. 25

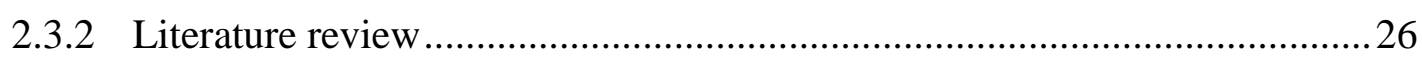

2.3.3 Functional movement screening tools reliability..........................................2

2.3.4 The relationship between functional screening tools and injury …….............38

2.3.5 The relationship between functional screening tools and performance.........50

2.3.6 Screening tools intervention studies ............................................................53

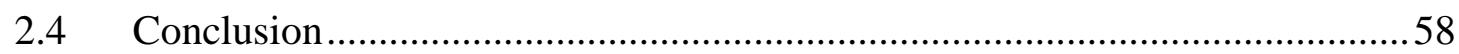

Chapter Three Methods ............................................................................................60

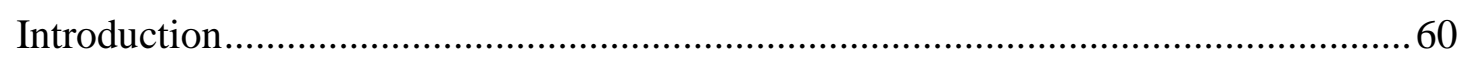

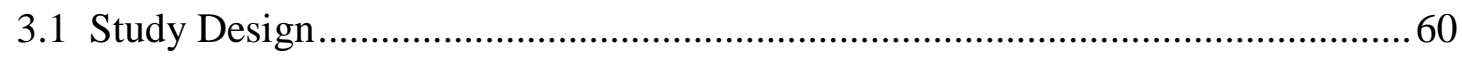

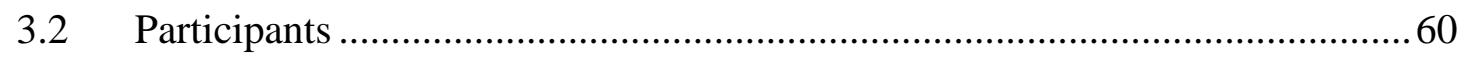




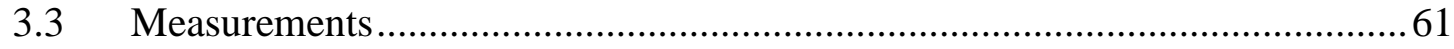

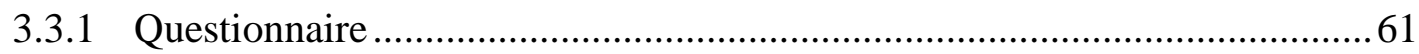

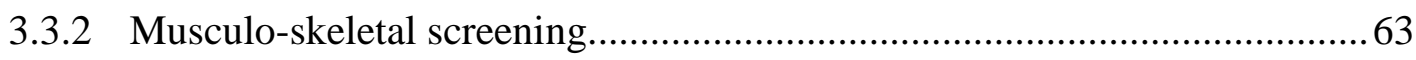

3.4 Movement Competency Screen reliability study ........................................ 71

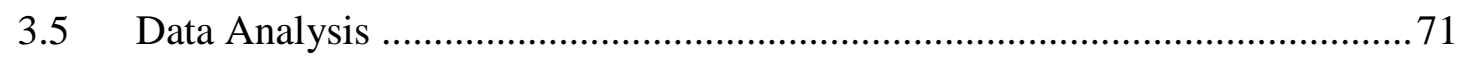

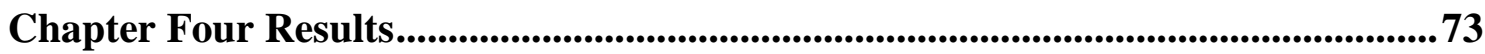

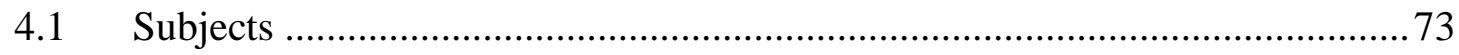

4.2 Injury Incidence, Prevalence and Severity ................................................... 77

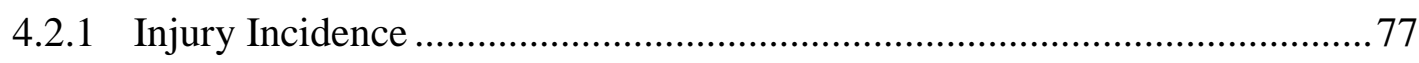

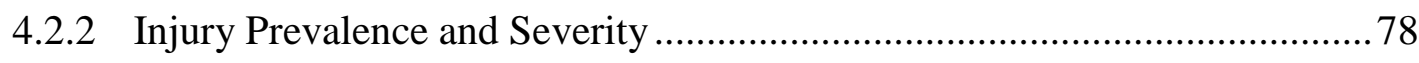

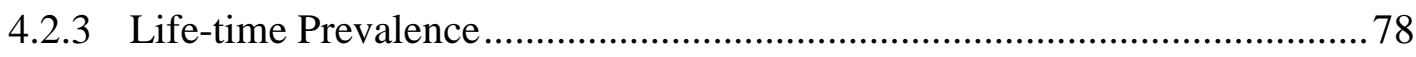

4.3 Relationship between training load and low back pain .................................. 79

4.3.1 Relationship between training hours and distance rowed...........................79

4.3.2 Relationship between new low back injuries and subjects currently

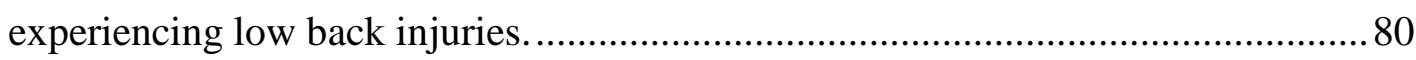

4.3.3 Relationship between training hours and low back injury .......................... 80

4.4 Association between possible risk factors, movement competency and low

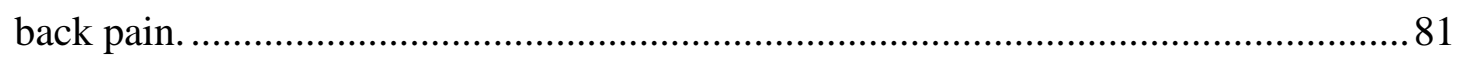

4.4.1 Association between new low back injuries and possible risk factors. ........ 81

4.4.2 Association between any low back injury and possible risk factors............ 82

4.4.3 Association between previous history of low back pain and possible risk factors 83

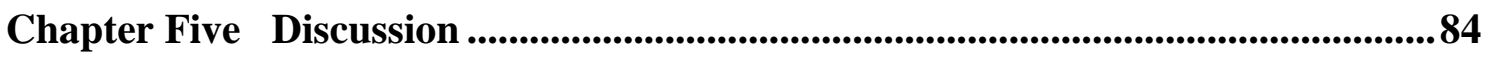

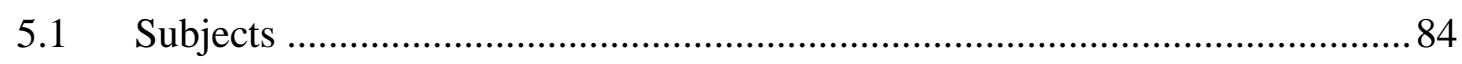

5.2 Incidence, Prevalence and Severity of Low Back Pain ................................... 86

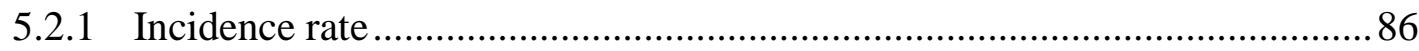

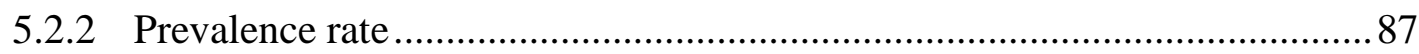

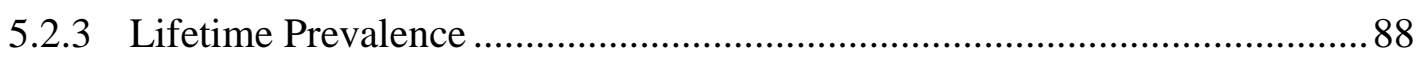

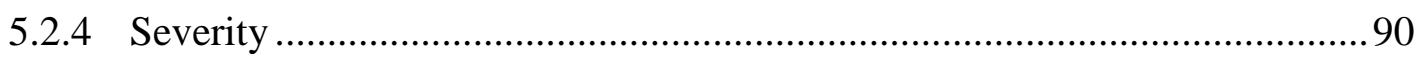

5.3 Relationship between training load and low back pain..................................93

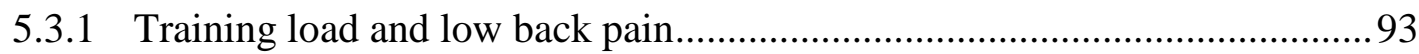

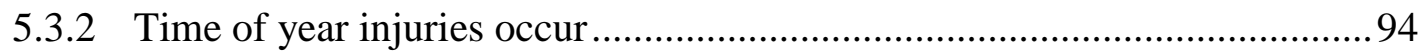

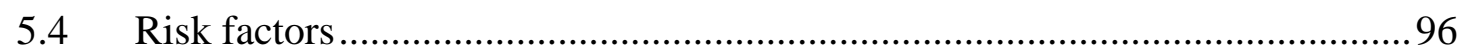

5.4.1 Correlation between movement competency and the development of low back pain .96 
5.4.2 Correlation between previous history of low back pain and age on the

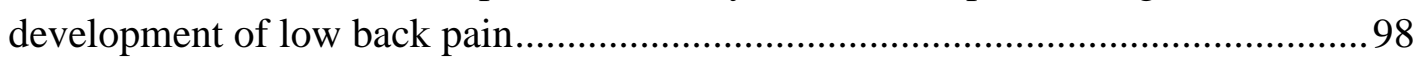

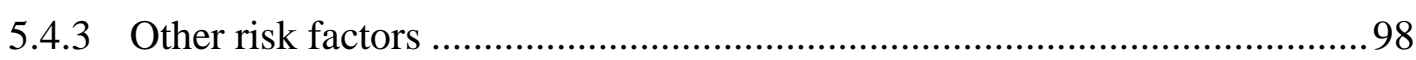

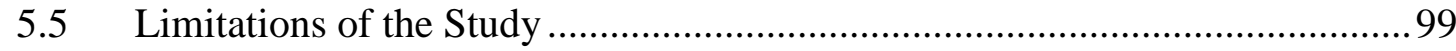

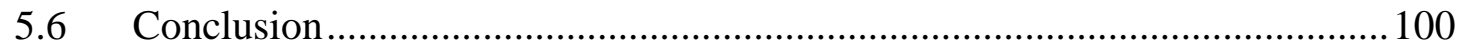

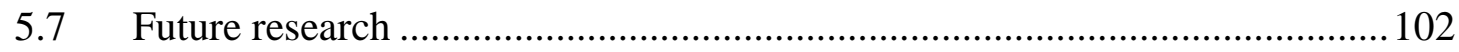

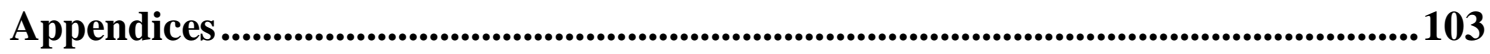

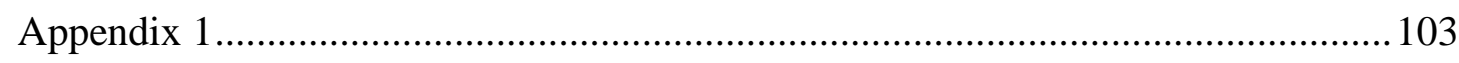

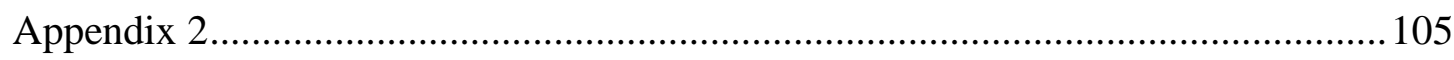

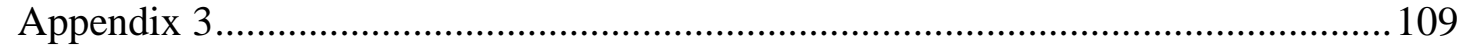

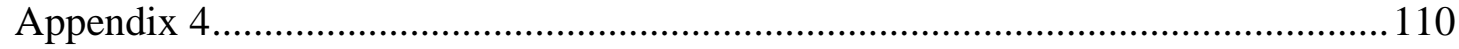

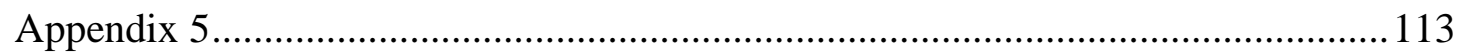

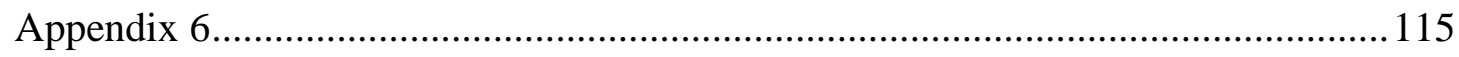

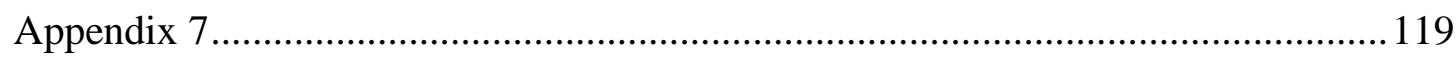

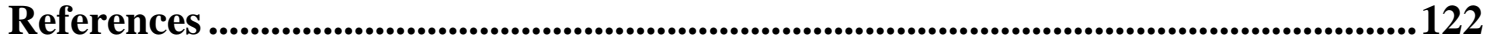




\section{LIST OF FIGURES}

Figure 2.1 The drive phase of the rowing stroke. ................................................... 7

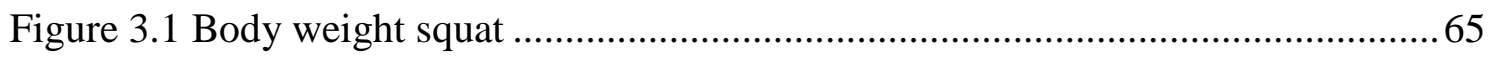

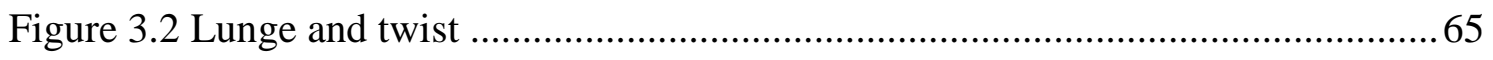

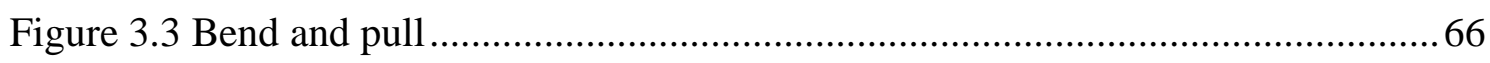

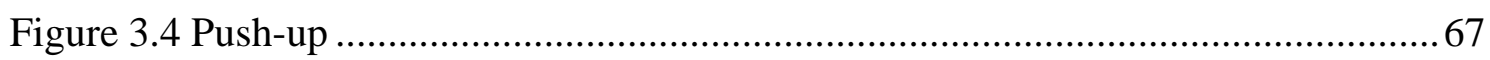

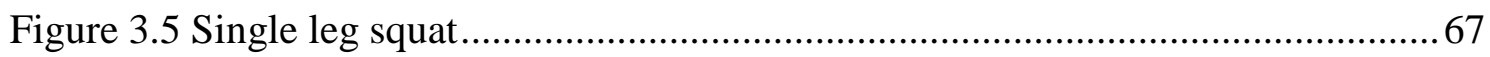

Figure 3.6 Active straight leg raise test used to assess hamstring flexibility................69

Figure 3.7 Modified Biering-Sorensen test over a roman chair used to assess trunk

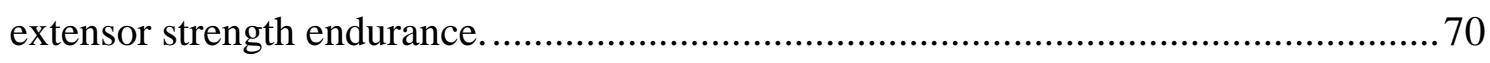

Figure 3.8 Modified flexor endurance test used to assess trunk flexor strength endurance

Figure 4.1 Severity of current and previous low back injuries as determined by number

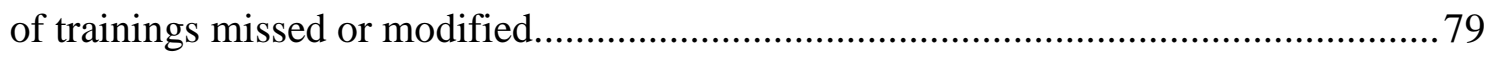

Figure 4.2 Relationship between total monthly training hours and number of low back pain cases per month over the twelve-month period. 


\section{LIST OF TABLES}

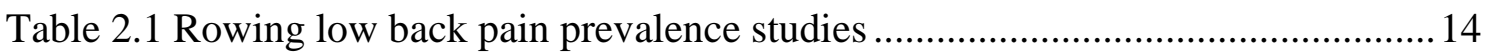

Table 2.2 Rowing low back pain intervention studies .............................................23

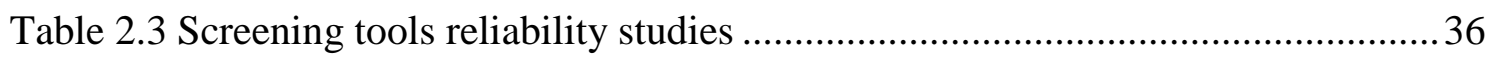

Table 2.4 Studies investigating the relationship between screening tools and injury..... 48

Table 2.5 Studies investigating the relationship between screening tools and

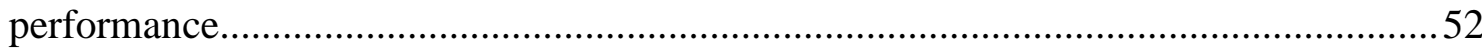

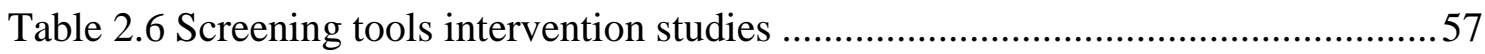

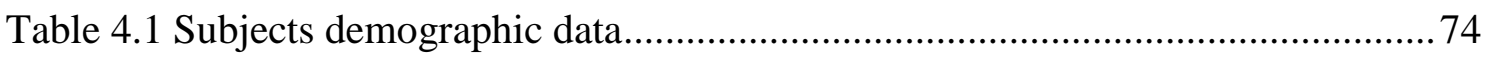

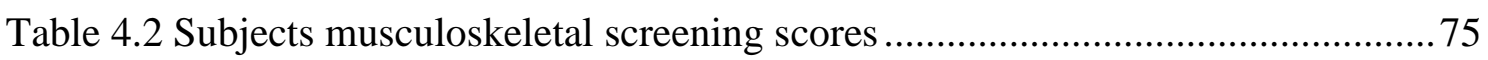

Table 4.3 Descriptive characteristics of elite and non-elite athletes ............................. 75

Table 4.4 Musculoskeletal screening scores of elite and non-elite athletes....................75

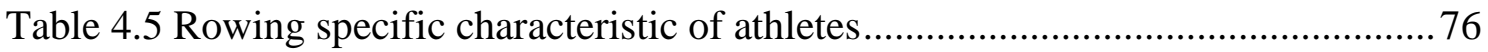

Table 4.6 Descriptive characteristics of low back pain and no low back pain groups ... 76

Table 4.7 Rowing specific characteristics of the low back pain and no low back pain

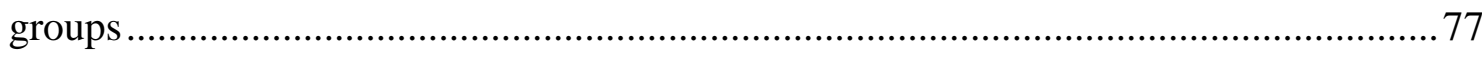

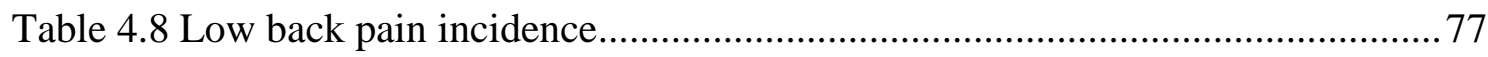

Table 4.9 Correlation between training hours and distance rowed ...............................79

Table 4.10 Relationship between new low back pain and risk factors ......................... 82

Table 4.11 Relationship between any low back pain and risk factors ......................... 83

Table 4.12 Relationship between previous low back pain and risk factors .................... 83 


\section{CERTIFICATE OF AUTHORSHIP}

"I hereby declare that this submission is my own work and that, to the best of my

knowledge and belief, it contains no material previously published or written by another person nor material which to a substantial extent has been accepted for publication for the qualification of any other degree or diploma of a university or other institution of higher learning, except where due acknowledgement is made in the acknowledgements".

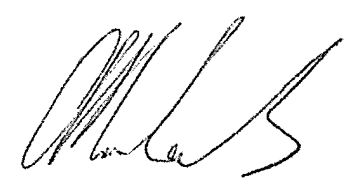




\section{ACKNOWLEDGEMENTS}

Firstly, I would like to thank my family, my wife Hannah and my children Isla, Bede and Thea for their love and support over the course of this project. Your understanding, encouragement and amazing ability to get on and not only survive, but thrive in my absence, has made it possible for me to be able to do the things I do as part of my work and study. You have all had to sacrifice important family time over the past few years, and please know that this has not been lost on me and is greatly appreciated. I will always love you.

To my parents, Helen and Donald, and brother Bevan, thank you for you love and support in everything I do. Your encouragement to always do my best has helped me to where I am today.

I would like to thank my colleagues both within High Performance Sport New Zealand and within Rowing New Zealand for your support and friendship. The words of wisdom while undertaking this thesis have been invaluable. In particular, I would like to acknowledge Alan Cotter for yours and Rowing New Zealand's support in this project.

To all the participants who completed surveys and underwent the testing at the start of the year, a big thank you. Without your ongoing commitment to the project, it would not have been possible.

I would also like to acknowledge High Performance Sport New Zealand whom through the Prime Minister's Scholarship Programme provided financial support for this research.

To Priya Parmar, your expertise and advice in the statistical analysis and results sections of this thesis has been invaluable. Your ability to explain, and educate me as to how to 
run the analysis and interpret the results has made the part of this project that I feared the most at the beginning, valuable and satisfying. It has also stimulated my interest in continuing with further research.

Finally, I would like to say a huge thank you to my supervisor, Duncan Reid. Your guidance, support and patience throughout this thesis have been remarkable and constant. I must admit that at the beginning of the project I was somewhat intimidated due to your standing and Mana within the physiotherapy profession. However, your ability to teach, lead and somehow make a very daunting task seem achievable has helped make this project an enjoyable and rewarding experience.

The Auckland University of Technology Ethics Committee (AUTEC) granted ethical approval for this research on 26 August 2011. Ethics Application Number 11/186 (see Appendix 1). 


\section{ABSTRACT}

Introduction: Low back pain (LBP) is frequently reported as the most common injury affecting rowers, accounting for $15-40 \%$ of all rowing injuries. It is generally believed and promoted within the sports medicine community that screening functional movement patterns is important as an injury prevention strategy and performance strategy. The Movement Competency Screen (MCS) is a tool that consists of five functional movement patterns. It has been shown to be reliable in uninjured subjects but has not been used in injured populations or linked to the injury prevalence and incidence of sporting populations.

Purpose: To investigate the incidence of LBP among New Zealand rowers and its relationship with the type and volume of training undertaken, as well as studying the effect LBP has on rowers' ability to train and compete. A secondary aspect of the study was to investigate the relationship between functional movement patterns as assessed by the MCS and the LBP injury data.

Methods: New Zealand representative rowers, 46 males (mean age 22 years, SD 4) and 30 females (mean age 21 years, SD 4) undertook a longitudinal prospective cohort study using a self-reported on-line questionnaire, repeated monthly over a full year, therefore including off-season as well as training and competition phases. The MCS was undertaken at the beginning of the study.

Results: 817 (90\%) questionnaires were completed, 59 (78\%) subjects completed all twelve questionnaires. Injury incidence rate equaled 1.68 per 1000 exposure hours. The cumulative incidence was $95 \%$ with 72 new LBP episodes reported. Fifty two percent of subjects experienced at least one new episode of LBP. The point prevalence of LBP was $13.7 \%$. Of these injuries, $45 \%$ were incidental, $29 \%$ were minor, $18 \%$ were 
moderate and $9 \%$ were severe. There was a significantly positive high correlation between new LBP and total training hours per month $(\mathrm{r}=0.83, \mathrm{p}=0.001)$.

A previous history of LBP was found to be the most significant risk factor in developing new LBP (OR 2.03, p=0.01). Age of the subjects was also a risk factor with the likelihood of developing a new low back injury increasing for every year in age (OR 1.07, $\mathrm{p}=0.04)$. Subjects who had an MCS score of 16 or more out of 21 were more likely to develop LBP than those with a score of 15 or less out of 21; however this was not a statistically significant finding (OR $1.58, \mathrm{p}=0.08)$.

Conclusion: LBP is a common injury among New Zealand representative rowers. There is a strong relationship between training load and the development of LBP. Previous history of injury and subject age are the strongest indicators of risk of LBP. The MCS screening results imply that those subjects who had a better MCS score, and therefore moved better, were more at risk of LBP. Further research is warranted to assess the ability of the MCS to determine risk of any injury in other sports. 


\section{Chapter One}

\section{Introduction}

\subsection{Statement of the problem}

The sport of rowing is popular in New Zealand and worldwide and is one of the original sports of the modern Olympic Games (Timm, 1999). It is one of this country's most successful Olympic sports and requires outstanding physiological attributes and places high demands on the muscular system (Hagerman et al., 1996).

Low back pain is frequently reported as the most common injury affecting rowers with incidence rates described between 25\% (Hickey, Fricker, \& McDonald, 1997) and 81\% (Howell, 1984) and accounting for 15-25\% of all reported injuries in rowing (Rumball, Lebrun, Ciacca, \& Orlando, 2005). There is a correlation between the early development of low back pain and the incidence of recurrent problems later in life with the strongest predictor of future low back pain being a prior history of low back pain (Hestbaek, Leboeuf-Yde, Kyvik, \& Manniche, 2006). It is therefore concerning that the incidence of low back pain is reported as being higher in the young rowing population than the general population (Perich, Burnett, \& O'Sullivan, 2006). Previous research has suggested a number of sports specific risk factors associated with rowing that can potentially increase the risk of low back pain (Caldwell, McNair, \& Williams, 2003; Perich, Burnett, O’Sullivan, \& Perkin, 2011; Reid \& McNair, 2000). High levels of training times and volumes may also represent potential mechanisms for strain to the lumbar spine structures (Reid \& McNair, 2000).

The New Zealand Rowing Association has 4200 members and estimates there are over 6500 people who row regularly in 65 rowing clubs nationwide. New Zealand rowing 
especially enjoys high participation numbers at a secondary school level, with over 3000 students rowing (www.nzsssc.org.nz). The New Zealand secondary Schools Rowing Regatta, more colloquially known and as the Maadi Cup is the largest school sports event in the Southern Hemisphere with approximately 2000 competitors from more than 100 schools (www.maadi.co.nz).

At an international competitive level, rowing in the Southern Hemisphere is unique as the major regattas are predominantly held in the Northern Hemisphere, and therefore during the New Zealand winter. The training year is therefore long and will differ significantly from Northern Hemisphere countries. This will possibly affect the development of rowing injuries. At present incidence data on the extent of the problem of low back pain in New Zealand rowing is lacking.

The screening of athletes is seen as an important component of the sports medicine team's job (Brukner \& Khan, 2011) and is promoted as both a strategy to minimise injury risk and to enhance performance (Comerford, 2006; Mottram \& Comerford, 2008). Functional screening tools aim to evaluate an individual's dynamic and functional capacity and are based on fundamental proprioceptive and kinaesthetic awareness principles (Cook, Burton, \& Hoogenboom, 2006). It is assumed that identifiable deficits in fundamental movement patterns may increase the risk of injury and have the potential to limit performance.

A tool has recently been developed called the Movement Competency Screen (MCS) (Kritz, Cronin, \& Hume, 2009b; Kritz, Cronin, \& Hume, 2009c; Kritz, Cronin, \& Hume, 2010). The MCS screen consists of five functional movement patterns; squat, lunge, push up, bent over pull and single leg squat. These movements assess the athletes normal and abnormal movement patterns across key movements used in sport and training. The MCS is a movement-screening tool that was developed to provide strength 
and conditioning professionals with a straightforward understanding of an individual's movement competency related to fundamental movement patterns performed in activities of daily living, sport and sport specific training (Kritz, 2012). The MCS is currently used by High Performance Sport New Zealand as part of its minimising injury risk strategy as well as guiding its strength training and rehabilitation exercise prescription (Kritz, 2012). The tool has been shown to be reliable in uninjured subjects (Kritz, 2012) but has not been used in injured populations. Neither has it been used in specific sports populations such as rowing. The ability to correlate the injury data with the screening data would be of interest to help identify factors contributing to low back pain in rowers.

\subsection{Purpose of the study}

The primary objectives of this study are twofold. Firstly, to provide good quality incidence and prevalence data on lower back pain amongst New Zealand rowers, as well as establishing whether a relationship between type of training, high level of training times and volumes and the development of lower back pain exists. This study will also establish severity of low back pain in regards to the extent it affects an athlete's ability to train and compete, and therefore whether further research is warranted. A secondary aspect of the study is to investigate the relationship between functional movement patterns as assessed by the MCS and the low back pain injury data.

\subsection{Significance of the problem}

Low back pain is frequently reported as the most common injury effecting rowers (O'Kane, Teitz, \& Lind, 2003; Rumball et al., 2005; Teitz, O'Kane, Lind, \& Hannafin, 2002). Low back pain is a source of considerable frustration to the rower, other crew members and coaching and support staff, especially when this occurs in the build-up to 
a major regatta (Warden, Gutschlag, Wajswelner, \& Crossley, 2002). At an elite level, a low back injury that affects an athlete's ability to train for a period can have a significant impact on their performance. This will not only affect the individual athlete, but potentially their crew and coach, and when the sports funding model is based on performance, the national sporting organisation itself. In order to implement high quality intervention research, knowledge of the extent of the problem of lower back pain in New Zealand through incidence data is vital. To the authors knowledge no studies in New Zealand have compared the incidence rates of low back pain between different competitive levels; and the relationship between the onset of low back pain and the intensity or volume of training, or the effect back pain has on the athletes' ability to train.

The identification of potential individual injury risk factors through the implementation of a screening programme may be an important component of a successful sporting organisation. At present, it is not known whether there is any correlation between the screening tool currently employed by Rowing New Zealand at a high performance level and low back pain. As low back pain is the most prevalent injury in the sport of rowing, and the time and cost involved in screening athletes, it is important that a screening tool used is effective at establishing a correlation between its findings and low back pain. 


\section{Chapter Two}

\section{Review of Literature}

\section{Introduction}

This chapter begins with a kinematic description of the rowing stroke. A review of the literature investigating low back pain in the sport of rowing follows. This includes prevalence studies, possible risk factors, the relationship between training and low back pain, the effect the injury has on training and competition and potential intervention programmes. The third section of this chapter is discussion on functional movement screening tools, including the Movement Competency Screen (MCS). A review of the literature starts with the reliability of the screening tools, followed by their ability to predict injury and performance and finally the effect of exercise intervention programmes have on the tools and injury. The chapter concludes with a summary.

\subsection{Kinematics of rowing}

Rowing is a sport that includes events for both men and women, is divided into heavy weight and lightweight classes for both genders, and has a number of different boat classes depending on the number of athletes in each crew and the presence or absence of a coxswain. Rowing is a motor skill that demands a high level of consistency, coherence and accuracy, especially at an elite level (McGregor, Anderton, \& Gedroyc, 2002).

There are two types of rowing, sculling and sweep oar rowing. Sculling involves the rower using two oars simultaneously, while in sweep rowing the rower will pull on one oar. However, the basic components of the rowing stroke remain the same in the two 
rowing types and consist of four distinct but interrelated phases (McGregor et al., 2002). These are the catch, drive, finish and recovery phases of the stroke. The finer details of the rowing stroke differ from rower to rower, crew to crew, and at present the definition of a good rowing technique is highly descriptive, and coaches rely predominantly on the aesthetic appearance of technique (McGregor et al., 2002).

The rowing stroke begins with the catch phase. At this point, the oar or oars enter the water and the rowers' hips and knees are maximally flexed, the lumbar spine is flexed and the arms are extended. There is a sudden increase in load on the rower as the aim is to "catch" the water with the oar blade and propel the boat. The drive phase requires the rower to extend the hips and knees and, depending on the rower's technique and timing, the trunk will move from flexion into an extended position. The drive phase of the stroke concludes with the arms flexing at the elbows and extending at the shoulders to further draw the oar through the water. It is during the drive phase that the load through the oar reaches is maximum point. At the finish point of the drive phase, the rower pulls the hands to the chest then drops the hands towards his or her lap while extending the wrist, which feathers the oar to remove the blade for the water. The recovery phase of the rowing stroke is when the blade is out of the water and the rower comes back up the slide as the boats seat moves back towards the stern of the boat, thereby returning back to start position ready to take the next stroke. In this phase, the rower first extends the arms over the knees, and then moves from a position of trunk, hip and knee extension to trunk, hip and knee flexion. The stroke rate may vary from as low as 18-20 strokes per minute in a training situation up to $35-40$ strokes per minute in a race situation. 


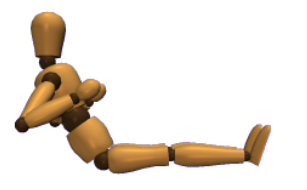

(c) finish point

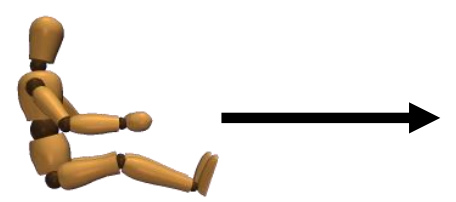

(d) recovery point

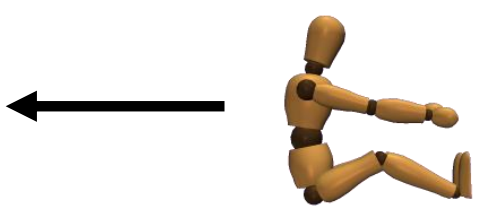

(b) mid drive

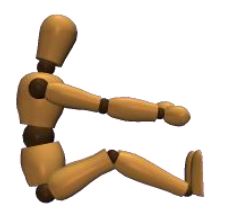

(e) mid recovery

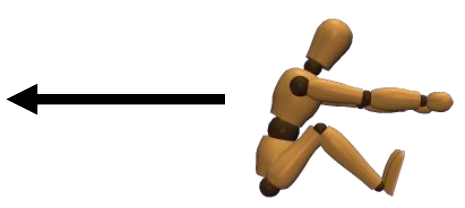

(a) catch point

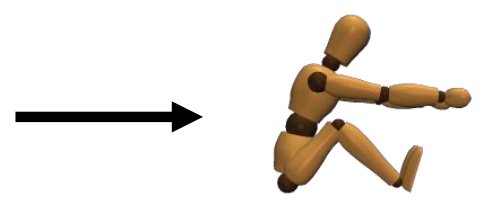

(f) catch point

Figure 2.1 The drive phase of the rowing stroke. The arrow indicates the direction of movement. Reproduced with permission from Reid, D. (2001). The influence of hamstring extensibility on lumbar and pelvic angles in rowers. Unpublished Master's thesis AUT aut.researchgateway.ac.nz

Previous research has reported that the amount of trunk movement during the rowing stroke can range from 30 degrees flexion at the catch to 30 degrees extension at the finish (McGregor et al., 2002).

\subsection{Low back pain in rowing}

Low back pain was first reported in the literature as a significant problem among rowers by Stallard in 1980, when he noted he had seen a growing number of athletes with low back pain over a five year period. Since then a number of studies have reported a relatively high incidence of back pain in this population (Bahr et al., 2004; Hickey et al., 1997; Howell, 1984; Perich et al., 2011; Smoljanovic et al., 2009; Stutchfield \& Coleman, 2006; Teitz et al., 2002; Wilson, Gissane, Gormley, \& Simms, 2010). A literature review was performed to compare the studies that have investigated low back pain among different rowing populations. The following sections are the results of this review. 


\subsubsection{Literature review}

\subsubsection{Search strategy}

The papers reviewed in this work were selected from a comprehensive Medline, CINAHL, and SPORT Discus database search from the year 1980 to 2012 using combinations of the following the key words and terms: low back pain, low back injury, rowing, prevalence, incidence and risk factors. The titles and abstracts of the articles that were identified in the search were reviewed by the author $(\mathrm{CN})$ for potential relevance. In addition, a further search was undertaken on the reference lists of the included articles. The full text of possibly relevant articles was then analysed for final inclusion based on the criteria that the article was related low back pain in rowing.

\subsubsection{Prevalence}

A review of the literature on lower back pain in the rowing population revealed two prospective cohort studies (Table 2.1) (Foss, Holme, \& Bahr, 2012; Wilson et al., 2010). The study by Wilson et al. (2010) was conducted over a twelve-month period on twenty elite international rowers competing as part of the Irish Amateur rowing Union squad system. The investigators carried out a monthly telephone questionnaire, and collected data on all injuries sustained over the year by the twenty participants; therefore it did not exclusively look at low back injuries. The authors reported 14 injuries to the lumbar spine $(31.8 \%)$ of the total number of injuries sustained, and three injuries of the sacroiliac joints (6.8\%) (Wilson et al., 2010). If this injury data were combined, low back pain would have equaled $38.6 \%$ of all the injuries sustained, a prevalence of 0.85 injuries per athlete. This study was the only one found in this literature review that reported injury as a standardised incidence rate per 1000 hours; unfortunately, it only reported the total injury incidence rate, not low back pain incidence rates. The total training and racing hours was 
reported however, and therefore the low back pain incidence rate can be calculated as 1.31 per 1000 exposure hours.

The second prospective study identified in this review was a recent 10 -year follow-up investigation taken from a cohort of endurance sport athletes, based on a cross-sectional survey from 2000 by Bahr et al. (2004) (Foss et al., 2012). The original cross-sectional study is reviewed below (Bahr et al., 2004). The aim of their study was to compare the prevalence of low back symptoms among former endurance athletes, in sports with different loading characteristics on the lumbar spine, and that of a nonathletic control group. Foss et al. (2012) undertook a follow-up questionnaire to those participants of the original cohort. This resulted in a final sample of 740 participants (88\% of the original cohort.) They found that there were no significant differences between the athletic groups and the control group in regards to the prevalence of any or frequent low back pain over the previous twelve months. They concluded that years of prolonged and repetitive low back loading in endurance sports does not lead to more low back pain later in life. However, more rowers reported occupational changes due to low back pain than the former athletes from the other sports and more rowers and skiers reported having received treatment for low back pain than the orienteers and controls.

Three studies have reported the prevalence of low back pain in cross-sectional survey designs (Table 2.1) (Bahr et al., 2004; Howell, 1984; Stutchfield \& Coleman, 2006). Bahr et al. (2004) in a high quality cross-sectional survey compared the prevalence of symptoms of low back pain between endurance sports with different loading characteristics on the lumbar region. They compared athletes competing at the national elite level in crosscountry skiing, rowing, and orienteering, as well as a matched non-athletic control group. Their study included 841 participants, of which 199 were rowers. The survey was conducted during the National Championships of the respective sports in 2000. All athletes who had qualified for the championships were asked to complete a two-page questionnaire on low back pain. The results of this study found a low back pain point prevalence of 
$25.3 \%$, over the previous 12 months of $55.3 \%$ and a lifetime prevalence of $63.3 \%$ amongst the rowers in their study. Low back pain was reported to be more common among the rowers and cross-country skiers that the orienteers and non-athletic controls. The athletes also reported more low back pain during periods when training and competition loads were higher.

As part of their study on the effect of hamstring flexibility and lumbar flexion on low back pain in rowers, Stutchfield and Coleman (2006) undertook a cross-sectional questionnaire that revealed a $42 \%$ point prevalence of low back pain in their population of university rowers. They also reported that $81 \%$ of the participants had experienced low back pain at some point in their lifetime and that $40 \%$ of the rowers had experience more than five episodes of low back pain over the previous twelve months.

Howell (1984) found that 14 of 17 lightweight female rowers at a development camp complained of occasional or chronic low backache or discomfort indicating a lifetime prevalence of $82 \%$. Two of the 17 athletes also reported currently experiencing back pain, indicating a point prevalence of $12 \%$.

A number of retrospectively designed studies have investigated the prevalence of low back pain in rowing (Table 2.1) (Budgett \& Fuller, 1989; Hickey et al., 1997; O'Kane et al., 2003; Smoljanovic et al., 2009; Teitz et al., 2002; Teitz, O'Kane, \& Lind, 2003; Wilson, Kennedy, \& Meehan, 2004). Hickey et al. (1997) conducted a retrospective review of the medical records of elite Australian rowers (ages 14 to 36 years) from 1985 to 1994 to document injuries. In that review, lumbar injuries accounted for $25 \%$ of the injuries recorded for 88 male rowers (29 of 116 injuries) and $15.2 \%$ of the injuries recorded for 84 female rowers (31 of 204 injuries). They also recorded the time of year at which injuries occurred, the location of injuries, diagnosis, and whether the injury was acute or chronic. Time lost from sports as a result of injury was not quantified. 
The remainder of the retrospective studies identified in this literature review utilised self-reporting questionnaires to investigate the either the lifetime prevalence, point prevalence, or prevalence over a season or rowing career of low back pain. Budgett and Fuller (1989) surveyed 69 male rowers from the 1987 British national rowing team and reported a prevalence of low back pain of $43 \%$ over the previous twelve months. Low back pain accounted for $52 \%$ of all the injuries sustained by this cohort.

Smoljanovic et al. (2009) completed a retrospective survey among international elite junior rowers asking questions about injuries sustained over the current rowing season. They reported 127 low back injuries, or a prevalence rate of low back pain of $21.3 \%$. Low back injuries comprised $32.3 \%$ of all the injuries of elite junior rowers.

Wilson et al. (2004) completed a retrospective questionnaire amongst Irish rowers and their respondents represented $18.7 \%$ of the total rowing population of the nation's rowers. They found that $35.4 \%$ of respondents reported having suffered from low back injury.

A series of three studies have investigated low back pain among former intercollegiate rowers from five US schools with strong rowing programmes (O'Kane et al., 2003; Teitz et al., 2002; Teitz et al., 2003). The studies covered a 20-year period from between 1978 and 1998 and investigated the prevalence of low back pain and its effects and etiology prior to, during and following the subjects' intercollegiate rowing careers. In the first investigation of the series, Teitz et al. (2002) reported 526 out of 1632 or $32 \%$ of subjects developed back pain during intercollegiate rowing. Interestingly they found that the number of athletes that reported low back pain during college rowing steadily increased over the 20 years covered by the study. The second study in the series (O'Kane et al., 2003) investigated whether pre-existing low back pain was a significant risk factor for developing low back pain during college rowing, and how it 
related to the ability of the athletes to participate. The prevalence rate of low back pain during the college rowing career of this cohort was $38 \%$. The authors concluded that subjects with preexisting low back pain were more likely to develop pain while rowing at college than those without preexisting pain, however, this group was less likely to miss extended period of training or stop rowing because of back pain. The final study in the series investigated the presence of back pain and its severity before, during and following intercollegiate rowing (Teitz et al., 2003). The authors of this study found that the lifetime prevalence of low back pain in former rowers was $51.4 \%$ and was no different to that previously reported in the general population. Not surprisingly, they found that those rowers who had low back pain during their rowing careers were more likely to have subsequent back pain than those who were asymptomatic during their college rowing.

A limitation of these three studies was the low response rate among those athletes who were surveyed. Unfortunately, out of the 4680 former rowers who were sent questionnaires, only $46 \%$ responded. It is possible that those subjects who had experienced low back pain were more likely to complete the questionnaires, thereby leading to selection bias. Another limitation was that for some of the respondents, a 20year period had elapsed from the end of their rowing career until the time of the study. This could lead to recall bias in the studies.

The majority of the prevalence studies in this review the have investigated the prevalence and types of injuries seen in rowers rather than the prevalence of low back pain specifically (Budgett \& Fuller, 1989; Hickey et al., 1997; Howell, 1984; Smoljanovic et al., 2009; Wilson et al., 2010; Wilson et al., 2004) Therefore, no analysis of mechanism of onset, etiologic or associated factors or preexisting back problems was conducted. In the study by Hickey et al. (1997) injuries were culled from 
medical records, thereby excluding symptomatic rowers who chose not to report their back pain and asymptomatic rowers necessary to calculate prevalence rates.

A possible reason for the large variation in the reported prevalence of low back pain amongst epidemiological studies of the rowing population is the lack of a consistent definition of low back pain. The definitions used in the aforementioned studies range from occasional or chronic low backache or discomfort (Howell, 1984), to pain, ache, or discomfort in the low back with or without radiation to one or both legs (sciatica)(Bahr et al., 2004; Stutchfield \& Coleman, 2006), and pain that lasted for at least one week (O'Kane et al., 2003; Teitz et al., 2002; Teitz et al., 2003). Wilson et al (2010) defined injury as a problem which caused the athlete to miss at least one competition (regatta, head race or trial); or at least two training sessions; or required at least one visit to a health professional for treatment. A number of the studies did not define back pain at all (Budgett \& Fuller, 1989; Foss et al., 2012; Hickey et al., 1997; Smoljanovic et al., 2009). The lack of consistency amongst the studies definitions of low back pain make it difficult to make comparisons between them.

Another possible reason for the variability in prevalence reported is that each study has looked at an isolated competitive level of rower. To the author's knowledge the only study that has compared the prevalence or incidence rates of lower back pain among different competitive levels was that by Wilson (2004) whose retrospective study cohort consisted of $18 \%$ of Ireland's rowing population. As the number of years rowing experience (Smoljanovic et al., 2009), the age of the athlete, and the type and intensity of training (Teitz et al., 2002) have been suggested as possible factors associated with back pain, it would follow that limiting a studies inclusion criteria to one competitive level makes it difficult to draw conclusions across the whole rowing population. 
Table 2.1 Rowing low back pain prevalence studies

\begin{tabular}{|c|c|c|c|c|}
\hline Study & Participants & Study Design & Methods & Results \\
\hline $\begin{array}{l}\text { Bahr et al } \\
(2004)\end{array}$ & $\begin{array}{l}\text { National elite level athletes in } \\
\text { rowing, cross-country skiing, } \\
\text { orienteering \& a non-athletic } \\
\text { control group } \\
\mathrm{n}=931 \text { (199 rowers) }\end{array}$ & $\begin{array}{l}\text { Cross-sectional } \\
\text { survey }\end{array}$ & Self-reported questionnaire & $\begin{array}{l}\text { LBP point prevalence }=25.3 \% \\
\text { LBP over previous } 12 \text { months }=55.3 \% \\
\text { LBP lifetime prevalence }=63.3 \% \\
\text { LBP more frequent during periods of high training and competition } \\
\text { load }\end{array}$ \\
\hline $\begin{array}{l}\text { Budgett \& Fuller } \\
(1989)\end{array}$ & $\begin{array}{l}1987 \text { British national rowing } \\
\text { team } \\
\mathrm{n}=69 \text { (males) }\end{array}$ & $\begin{array}{l}\text { Retrospective } \\
\text { survey }\end{array}$ & Self-reported questionnaire & $\begin{array}{l}\text { LBP over previous } 12 \text { months }=43 \% \\
\text { LBP } 52 \% \text { of all injuries over previous } 12 \text { months } \\
\text { LBP resulted in } 486 \text { days off training. }\end{array}$ \\
\hline $\begin{array}{l}\text { Foss et al } \\
(2012)\end{array}$ & $\begin{array}{l}\text { Athletes from the sports of } \\
\text { rowing, cross-country skiing, } \\
\text { orienteering \& a non-athletic } \\
\text { control group } \\
\mathrm{n}=740 \text { (173 rowers) }\end{array}$ & $\begin{array}{l}\text { Prospective } \\
\text { cohort study }\end{array}$ & $\begin{array}{l}\text { 10-year follow-up } \\
\text { questionnaire to the remainder } \\
\text { of the cohort from the Bahr et } \\
\text { al (2004) study }\end{array}$ & $\begin{array}{l}\text { LBP point prevalence }=19 \% \\
\text { LBP over previous } 12 \text { months }=57 \% \\
\text { LBP lifetime prevalence }=68 \% \\
\text { No difference between the athletic groups \& control group in regard } \\
\text { to LBP over previous } 12 \text { months or frequent LBP. } \\
\text { Training volume }>550 \text { hour/year risk factor for LBP c.f. }<200 \\
\text { hour/year }(\mathrm{OR}=2.51, \mathrm{CI} 1.26-5.02) \\
\text { PHx LBP related to LBP later in life }(\mathrm{OR}=3.02 \text {, CI } 2.22-4.10)\end{array}$ \\
\hline $\begin{array}{l}\text { Hickey et al } \\
(1997)\end{array}$ & $\begin{array}{l}\text { All rowers at the AIS from } \\
1985-1994 \\
n=172 \text { ( } 88 \text { males, } 84 \text { females })\end{array}$ & $\begin{array}{l}\text { Retrospective } \\
\text { study }\end{array}$ & $\begin{array}{l}\text { Review of medical records } \\
\text { over the previous } 10 \text {-year } \\
\text { period }\end{array}$ & $\begin{array}{l}\text { LBP } 25 \% \text { of all injuries recorded among male rowers } \\
\text { LBP } 15 \% \text { of all injuries recorded among female rowers }\end{array}$ \\
\hline $\begin{array}{l}\text { Howell } \\
(1984)\end{array}$ & $\begin{array}{l}\text { National elite lightweight } \\
\text { rowers } \\
\mathrm{n}=17 \text { (females) }\end{array}$ & $\begin{array}{l}\text { Cross-sectional } \\
\text { study }\end{array}$ & $\begin{array}{l}\text { Self-reported questionnaire }+ \\
\text { strength and flexibility testing }\end{array}$ & $\begin{array}{l}\text { LBP point prevalence }=12 \% \\
\text { LBP lifetime prevalence } 82 \% \\
75 \% \text { had hyper-flexion of Lx \& } 58 \% \text { had hyper flexible hamstrings } \\
\text { High +'ve correlation between Lx hyper-flexion \& LBP } \\
\text { High -'ve correlation between regular stretching \& LBP }\end{array}$ \\
\hline $\begin{array}{l}\text { O’Kane et al } \\
(2003)\end{array}$ & $\begin{array}{l}\text { Former intercollegiate rowers } \\
\mathrm{n}=1829\end{array}$ & $\begin{array}{l}\text { Retrospective } \\
\text { survey }\end{array}$ & $\begin{array}{l}\text { Self-reported questionnaire to } \\
\text { former rowers who had } \\
\text { graduated 1978-1998 }\end{array}$ & $\begin{array}{l}\text { LBP during college rowing }=38.4 \% \\
\text { Injury severity of those that missed training: } \\
\text { mild }=64 \% \\
\text { moderate }=19 \% \\
\text { major }=17 \%\end{array}$ \\
\hline
\end{tabular}


Smoljanovic et al International Junior rowers

(2009) $\mathrm{n}=596$ (119 males, 98 females)

Stutchfield \& University rowers

Coleman $\quad n=26$ (male)

(2006)

Teitz et al

(2002)

Teitz et al

(2003)
Former intercollegiate rowers $\mathrm{n}=1632$ (936 males, 694 females)

Former intercollegiate rowers $\mathrm{n}=1561$ (897 male, 662

females, 2 unknown)
Retrospective

survey

Cross-sectional

study

Retrospective survey

Retrospective survey
LBP ended career of 105 athletes, $15 \%$ of those with LBP and $6 \%$ of total participants

Self-reported questionnaire to competitors at Junior World Rowing Championships

Self-reported questionnaire +

Lx flexion and hamstring

flexibility testing

LBP during season $=21 \%$

LBP $32 \%$ of all injuries sustained during season

LBP point prevalence $=42 \%$

$>5$ episodes LBP in previous 12 months $=40 \%$

LBP lifetime prevalence $=81 \%$

LBP caused missed training in $30 \%$

No association between LBP and hamstring inflexibility

No association between hamstring inflexibility and Lx flexion

LBP associated with reduced Lx flexion

Self-reported questionnaire to LBP during college rowing $=32 \%$

former rowers who had graduated 1978-1998

Injury severity of those with LBP

mild or $\bmod =72 \%$

major $=8 \%$

missed entire season $=2 \%$

LBP ended careers of 83 athletes, $16 \%$ of those with LBP and $5 \%$ of total participants.

Starting rowing before 16 years old significantly associated with LBP Erg rowing $>30$ mins and use of free weights consistently associated with LBP in all age groups

Self-reported questionnaire to former rowers who had graduated 1978-1998
LBP lifetime prevalence since college $=51 \%$

in subjects with LBP during college $=79 \%$

in subjects without LBP during college $=38 \%$

LBP point prevalence $=32 \%$

in subjects with LBP during college $=58 \%$

in subjects without LBP during college $=20 \%$

Lifetime prevalence of LBP in former rowers no different to the general population

Age a significant predictor of back pain 


\begin{tabular}{|c|c|c|c|c|}
\hline $\begin{array}{l}\text { Wilson et al } \\
(2004)\end{array}$ & $\begin{array}{l}\text { Irish rowers who had been } \\
\text { rowing }>1 \text { year } \\
\text { ( } \mathrm{n}=227 \text { (158 males, } 69 \\
\text { females) }\end{array}$ & $\begin{array}{l}\text { Retrospective } \\
\text { survey }\end{array}$ & $\begin{array}{l}\text { Self-reported questionnaire } \\
\text { investigating all injuries } \\
\text { sustained }\end{array}$ & LBP prevalence $=35 \%$ \\
\hline $\begin{array}{l}\text { Wilson et al } \\
(2010)\end{array}$ & $\begin{array}{l}\text { Senior international rowers } \\
\mathrm{n}=20 \text { ( } 12 \text { males, } 8 \text { females })\end{array}$ & $\begin{array}{l}\text { Prospective } \\
\text { cohort study }\end{array}$ & $\begin{array}{l}\text { Monthly telephone interviews } \\
\text { over a } 12 \text {-month period }\end{array}$ & $\begin{array}{l}\text { LBP }(+ \text { SIJ) incidence rate }=1.31 \text { per } 1000 \text { hours } \\
\text { LBP }(+ \text { SIJ) prevalence over previous } 12 \text { months }=85 \% \\
\text { LBP }(+ \text { SIJ }) 39 \% \text { of all injuries sustained over } 12 \text { months } \\
\text { Ergometer training load significantly associated with injury }\end{array}$ \\
\hline
\end{tabular}




\subsubsection{Possible risk factors associated with low back pain}

The possible cause of low back pain in rowers has been the source of controversy and debate for many years (Stutchfield \& Coleman, 2006). It is likely that its origins are multi-factorial. Research has suggested a number of sports specific risk factors associated with rowing that can potentially increase the risk of low back pain. Stallard (1980) speculated that the increase in lower back pain might have been due to two factors that had developed in the previous ten years. He noted firstly the introduction of higher intensity training techniques and schedules, and secondly, the evolution of rowing techniques that put more strain on the back as the style of rowing had changed from a straight back swing to a flexion rotation movement of the lumbar spine in the catch position. The combination of flexion with compressive loading and rotation of the spine has previously been identified as a mechanism of injury to the lumbar spine (Adams \& Dolan, 1995). Teitz et al. (2002) felt that the increased prevalence of back pain during the 20 years covered by their study may have reflected a complex and interrelated set of changes in the sport. These included changes in the type and intensity of training, changes in equipment, changes in the age at which competitive rowing begins, and changes in rower physique.

Individual risk factors such as limitations in anterior pelvic tilt, a lack of hamstring flexibility, deficits in lumbo-pelvic motor control and deficits in back muscle and lower limb endurance and poor sitting posture have also been suggested as risk factors for low back pain amongst rowers as well as the general population (Adams \& Dolan, 1995; Gajdosik, Albert, \& Mitman, 1994; Perich et al., 2011; Reid \& McNair, 2000; Roy et al., 1990). Two studies were identified in this literature review that have investigated the relationship between hamstring flexibility, lumbar range of movement and low back 
pain; one in lightweight female rowers (Howell, 1984), and the other in male university level rowers (Stutchfield \& Coleman, 2006). Neither of these studies found an association between low back pain and hamstring inflexibility (Howell, 1984; Stutchfield \& Coleman, 2006). Howell (1984) found a high positive correlation between hyperflexion of the lumbar spine and low back pain. Hyperflexion of the lumbar spine was assessed using sit and reach and straight leg raise tests. In contrast, Stutchfield and Coleman (2006) found that low back pain sufferers among their male rowers showed reduced lumbar range of movement and they found no association between hamstring flexibility and lumbar flexion range. In addition Howell (1984) found that a high adherence to a regular stretching programme was highly correlated to low back pain. These findings would suggest that techniques to increase hamstring flexibility may not prevent or be useful in rehabilitation of rowers with low back pain (Stutchfield \& Coleman, 2006).

It is important to define the factors contributing to lower back pain in rowers, and determine whether altering these factors will have an effect on its incidence in order to guide rehabilitation and prevention. Therefore, further intervention studies are needed to investigate relationships between these risk factors and this condition.

\subsubsection{Relationship between training volume and low back pain}

Increases in the length of training times and volumes may also represent potential mechanisms for strain to the lumbar spine structures due to the repetitive cyclic flexion action of the rowing stroke (Reid \& McNair, 2000). Time spent training on ergometers and heavy weight training have been associated with increased rate of back pain (Teitz et al., 2002; Wilson et al., 2010). Studies have shown that rowers consistently report more low back pain during periods of higher training and competition load (Bahr et al., 
2004; Foss et al., 2012; Hickey et al., 1997; Wilson et al., 2010). Smoljanovic et al (2009) found that junior rowers who averaged more than seven training sessions per week had significantly more overuse low back injuries compared with those with fewer training sessions per week. The type of training sessions undertaken was not reported in this study. They also found that an increase in months of on-water training was significantly associated with low back injury. Foss et al. (2012) also found that athletes with a training volume of greater than 550 hours a year were two and a half times more likely to develop low back pain than those athletes who trained less than 200 hours a year. However Wilson et al. (2010) failed to find a significant association between high on-water training volume and high injury rate.

The time spent ergometer training and heavy weight training have been consistently reported as having the most significant impact on low back injury (Teitz et al., 2002; Wilson et al., 2010). Teitz et al (2002) found that ergometer training for more than 30 minutes was the most significant and consistent predictor of back pain for all age groups of rowers. These finding highlight the need for further research into the effects of training type and training volume on low back pain in rowers. Investigation into rowers' land-based training methods is particularly important.

\subsubsection{Effect of low back pain on training}

A number of studies have investigated the effect that low back pain has on training and competition (Budgett \& Fuller, 1989; O'Kane et al., 2003; Smoljanovic et al., 2009; Stutchfield \& Coleman, 2006; Teitz et al., 2002; Teitz et al., 2003). Smoljanovic et al (2009) investigated injury severity using previously reported criteria (Morgan \& Oberlander, 2001) and found that $49 \%$ of the low back injuries reported by junior elite rowers were incidental and therefore did not result in any time lost from training or 
competition. Thirty-one percent interrupted training for less than a week, $16 \%$ interrupted training for more than a week and 5\% of lower back injuries were reported as major and caused an absence from training for more than one month. Wilson et al. (2010) found that of the 14 rowers with a low back injury, eight subjects lost training hours while six actually completed more training hours than the mean of the non-injured group. However, this study reported time lost from training and competition rather than the number of trainings or competitions missed or modified. A more accurate picture of injury severity would be found by determining how injury affects the need for modification from the planned training in terms of intensity, frequency and duration. O'Kane et al. (2003) and Teitz et al. (2002) also reported injury severity based on the amount of training missed and reported similar findings to Smoljanovic et al. (2009)

(Table 2.). The authors of these two studies also reported a high number of athletes ended their rowing career due to low back pain $(6 \%$ and $5 \%$ of the total study cohort respectively) (O'Kane et al., 2003; Teitz et al., 2002).

Interestingly, Smoljanovic et al. (2009) found there was no significant association between the incidence or severity of reported injuries and the final ranking of the injured rowers compared to the uninjured rowers. They did not analyse this data for low back pain specifically, however this information does indicate the need for further investigation into the effect low back pain on both training and competition.

\subsubsection{Intervention studies on low back pain in rowing}

Two studies were identified in this literature review that have investigated specific intervention strategies for the prevention of low back pain among rowers (Perich et al., 2011; Thorpe, O'Sullivan, Burnett, \& Caneiro, 2009) (Table 2.2). 
Both of these non-randomised controlled trials were conducted on Western Australian schoolgirl rowers, and investigated the efficacy of specific multi-dimensional physiotherapy intervention programmes at decreasing the prevalence of low back pain and associated disability. In the study by Perich et al. (2011) subjects from one school were allocated to the intervention group, and subjects from three other similar schools were allocated to the control group. The intervention involved low back pain education sessions, musculoskeletal screening, individualised exercise programmes, and an offwater conditioning programme. The results of this study were promising and the authors concluded that the multi-dimensional approach was effective in reducing the incidence of low back pain in this rowing population at both mid and end-seasons of the study. With incidence rates in the control group of $47 \%$ and $45 \%$ at mid and end season respectively, and incidence rates in the intervention group of $27 \%$ and $25 \%$ at the same time points.

In the study by Thorpe et al. (2009) all subjects were offered the opportunity to partake in the intervention, with the fees associated being standard physiotherapy consultation charges. Those who were unwilling to be part of the intervention were assigned to the control group. The intervention in this study was the same protocol as the study by Perich et al. (2011), however in this instance, both the intervention and control groups underwent the same education sessions and physical conditioning programme; thereby controlling for these components of the programme. The authors of this study also concluded that a specific physiotherapy exercise intervention was effective in reducing the prevalence and pain intensity of low back pain among female rowers over the course of a season. They reported a reduction in the prevalence of low back pain across the rowing season from $48 \%$ to $24 \%$ in the intervention group. Whereas the prevalence of 
low back pain over the season was unchanged from pre-season to end-season in the control group.

Unfortunately, in both of these studies there were a high number of drop outs over the period of investigation, especially in the control groups. In addition, neither of the studies control groups were selected randomly, and in the study by Thorpe et al. (2009) subjects elected to be part of the intervention group leading to more subjects with low back pain in this group and causing self-selection bias. However, despite these methodological limitations the results of both these intervention studies are encouraging, indicating that the prevalence of low back pain can be altered in a rowing population with a specific exercise programme. 
Table 2.2 Rowing low back pain intervention studies

\begin{tabular}{|c|c|c|c|c|c|}
\hline Study & Participants & Study Design & Intervention group & Control Group & Results \\
\hline $\begin{array}{l}\text { Perich et al } \\
(2011)\end{array}$ & $\begin{array}{l}\text { Schoolgirl rowers } \\
\text { int } n=90 \\
\operatorname{ctrl} n=131\end{array}$ & $\begin{array}{l}\text { Non-randomised } \\
\text { controlled trial }\end{array}$ & $\begin{array}{l}\text { Subjects from } 1 \text { school received } \\
\text { physiotherapy screening, } \\
\text { prescription of individualised } \\
\text { exercises based on screening } \\
\text { findings + follow-up sessions, } \\
\text { education session }\end{array}$ & $\begin{array}{l}\text { Subjects from } 3 \text { other schools } \\
\text { received no advice or intervention; } \\
\text { however, co-interventions were not } \\
\text { controlled for }\end{array}$ & $\begin{array}{l}\text { Significant differences in the prevalence of } \\
\text { LBP between int and ctrl groups at mid- and } \\
\text { end-season } \\
\text { Significant difference in mean change in pain } \\
\text { level from start to end season between groups }\end{array}$ \\
\hline $\begin{array}{l}\text { Thorpe et al } \\
(2009)\end{array}$ & $\begin{array}{l}\text { Schoolgirl rowers } \\
\text { int } n=36 \\
\text { ctrl } n=46\end{array}$ & $\begin{array}{l}\text { Non-randomised } \\
\text { controlled trial }\end{array}$ & $\begin{array}{l}\text { Subjects who indicated a } \\
\text { willingness to participate in the } \\
\text { intervention received; } \\
\text { physiotherapy screening, } \\
\text { prescription of individualised } \\
\text { exercises based on screening } \\
\text { findings + follow-up sessions, } \\
\text { education session and a physical } \\
\text { conditioning programme }\end{array}$ & $\begin{array}{l}\text { Subjects unwilling to undergo } \\
\text { intervention received education } \\
\text { session and physical conditioning } \\
\text { programme }\end{array}$ & $\begin{array}{l}\text { Int group demonstrated significant reduction } \\
\text { in LBP prevalence across rowing season } \\
\text { Int group demonstrated reduced pain intensity } \\
\text { over the season compared to ctrl group }\end{array}$ \\
\hline
\end{tabular}




\subsection{Functional movement screening}

Screening of athletes either during the pre-season or mid-season training is now almost mandatory in elite and professional sport and is commonplace in competitive sport even at junior levels (Comerford, 2006; Mottram \& Comerford, 2008). Originally, preseason orthopaedic screening had a number purposes; firstly it fulfilled legal and insurance requirements (in some countries), secondly it assumed all team members would start the season with a common level of health and fitness, thirdly it helped discover pre-existing conditions that might interfere with or worsen with physical activity, and finally it was thought to help prevent or predict future injuries (Garrick, 2004). The screening of athletes is now seen as an important component of the sports medicine team's job (Brukner \& Khan, 2011) and is still promoted as both a strategy to minimise injury risk and to enhance performance (Comerford, 2006; Mottram \& Comerford, 2008). The screening procedure can also be used in order to counsel individuals with sport specific functional deficits, create individual pre-habilitation or rehabilitation programs and to enhance sporting performance (Schneiders, Davidsson, Horman, \& Sullivan, 2011).

Athlete screening has most often been performed by assessing joint range of movement, ligament laxity, muscle strength and muscle extensibility usually in an isolated fashion (Comerford, 2006; Garrick, 2004; Mottram \& Comerford, 2008). More recently, screening has shifted towards a more functional approach. Such screening tools aim to evaluate an individual's dynamic and functional capacity and are based on fundamental proprioceptive and kinaesthetic awareness principles (Cook et al., 2006). The tests aim to place the participant in positions and perform movements where weaknesses and imbalances become noticeable if appropriate stability and mobility is not utilised (Cook et al., 2006). It is assumed that identifiable deficits in fundamental movement patterns may increase the risk of injury and have the potential to limit performance (Chorba, 
Chorba, Bouillon, Overmyer, \& Landis, 2010; Cook et al., 2006). Assessing fundamental movement patterns also provides an opportunity to develop a more individualised training programmes that focus on changing or modifying movement patterns, instead of focusing on the rehabilitation of specific joints and muscles (Schneiders et al., 2011).

\subsubsection{Movement competency screen}

The MCS is a movement-screening tool that was developed to provide strength and conditioning professionals with a straightforward understanding of an individual's movement competency related to fundamental movement patterns performed in activities of daily living, sport and sport specific training (Kritz, 2012). Movement competency has been defined as the cognitive awareness and technical quality of an individual's movement strategies (Kritz, Cronin, \& Hume, 2009a). The MCS is currently used within strength and conditioning and physiotherapy professions in New Zealand, Malaysia, Philippines, Australia and North America and is used by High Performance Sport New Zealand to guide strength training and rehabilitation exercise prescription (Kritz, 2012).

The fundamental movement tasks assessed in the MCS have been validated via a survey of strength and conditioning experts, sports physiotherapists and sport biomechanists. It was found to have excellent percentage agreement among the participants regarding the structure, movement tasks and screening criteria (Kritz, 2012). The tool has been shown to be reliable in uninjured subjects. The inter-rater reliability analysis of 58 raters, rating three athletes was substantial (79\%) and the intra-rater test-retest reliability was almost perfect $($ Kappa $=0.93)($ Kritz, 2012). To the authors knowledge however, the MCS's ability to predict injury has not yet been investigated in a specific sporting 
population. The next section provides a review of literature pertaining to movement competency screening tools.

\subsubsection{Literature review}

\subsubsection{Search strategy}

The papers reviewed in this work were selected from a comprehensive Medline, CINAHL and SPORT Discus database search from the year 1980 to June 2012 using combinations of the following the key words: screen, screening, functional, movement, competency, pre-participation, risk factors, injury, performance and reliability. In addition, a further search was undertaken on the reference lists of the included articles. The titles and abstracts of the articles that were identified were reviewed by the author (CN) for potential relevance. The full text of possibly relevant articles was then analysed for final inclusion based on the criteria that the article was related to a dynamic or functional movement screening tool and investigated the relationship with injury, performance and / or reliability. This left a total of 23 articles for review.

\subsubsection{Results}

Five different screening tools that utilise dynamic, functional or balance tests were identified in the literature review. By far the most widely investigated and reported on tool was the Functional Movement Screen (FMS), developed by Gray Cook to determine if an individual possesses or lacks the ability to perform fundamental movement patterns (Cook et al., 2006). The Landing Error Scoring System (LESS) (Beutler, de la Motte, Marshall, Padua, \& Boden, 2009; Smith et al., 2012), a nine-test screening battery (Frohm, Heijne, Kowalski, Svensson, \& Myklebust, 2012), the Performance Matrix (Comerford, 2006; Mottram \& Comerford, 2008), the MCS (Kritz, 2012) and core stability tests (Leetun, Ireland, Willson, Ballantyne, \& Davis, 2004; 
Okada, Huxel, \& Nesser, 2011) are all screening tools that have also been described in the literature.

\subsubsection{Functional movement screening tools reliability}

Reliability is the degree to which an assessment tool produces stable and consistent results between subjects and across test occasions. In this literature review eleven studies were identified that investigated the reliability of different functional movement screening tools (Table 2.3); nine looked specifically at the inter-rater, intra-rater and/or test-retest reliability (Butler, Plisky, \& Kiesel, 2012; Frohm et al., 2012; Minick et al., 2010; Onate, Cortes, Welch, \& van Lunen, 2010; Onate et al., 2012; Padua et al., 2009; Schneiders et al., 2011; Shultz et al., 2011; Teyhen et al., 2012). One investigated reliability as part of a pilot study imbedded within a correlation study (Smith et al., 2012), and one as part of a thesis into the development, reliability and effectiveness of a screening tool (Kritz, 2012). Six of the studies investigated the reliability of the FMS and the remaining studies investigated other screening tools.

\subsubsection{Functional movement screen (FMS) reliability}

The majority of the studies investigated the reliability of the FMS and found the reliability of the tool to be high or excellent. A recent study by Butler et al. (2012) investigated the inter-rater reliability of the FMS using a new 100-point scoring system. They screened thirty school-aged children from the eighth grade using two experienced raters, and a videotaped analysis. They found that the inter-rater reliability for all the tests was high, with the intra-class correlation coefficient $\left(\operatorname{ICC}_{(2,1)}\right)$ value for the overall score being 0.99 . The $\mathrm{ICC}_{(2,1)}$ value for all the tests in the screen ranged from between 0.91 and 1.00. They concluded that the 100-point FMS is a reliable measurement tool when comparing scores between raters who have undertaken formal training on the 
FMS tool (Butler et al., 2012). This is the only study found that looks at the reliability of a screening tool in young children and further research is required to assess whether or not these results can be repeated in an adult and / or athletic population.

In a study by Minick et al. (2010), researchers videotaped 39 college students performing the FMS. They used four raters; two of which were experts, having over ten years' experience with the tool and were instrumental in the development of it, and two were novices having less than one years' experience using the tool. The authors calculated a Kappa statistic between the two sets of rater for each test. The pair of novice raters displayed excellent agreement on six of the 17 tests (seven tests, five measure both sides of the body), substantial agreement on eight of the 17 tests and moderate agreement on three of the 17 tests. The pair of expert raters showed excellent agreement in four of the tests, substantial agreement in nine tests and moderate agreement in four of the 17 tests, therefore showing more variance than the novice raters. The kappa values for the individual tests ranged from 0.74 to 1.00 when comparing average scores of expert versus novice raters. The authors concluded that the FMS has high inter-rater reliability and can be used confidently when applied by trained individuals and the standard procedure is used. However, the study only assessed the agreement of individual tests of the FMS and not the overall composite score, which is typically used as the primary indicator of injury risk.

In another recent study investigating the real-time intersession and inter-rater reliability of the FMS, Onate et al. (2012) undertook a test-retest design study using two raters of differing experience. The first rater was a certified FMS specialist with four years' experience with the tool; the second rater was a novice who had had no previous experience at scoring the FMS. The subjects of the study were 19 physically active individuals with a mean age of 25 years and were tested on two occasions, one week 
apart. The authors of this study reported that the inter-rater reliability was excellent for the FMS total score with an ICC of 0.98 . However, the inter-rater reliability of each of the individual tests ranged from kappa values of 0.33 to 1.00 . The inter-session reliability was also found to be excellent for the total score with an ICC of 0.92. Again, the kappa values of the individual tests ranged from 0.16 to 0.84 . The kappa value for the test of Rotary Stability was unable to be determined for either intersession- or interrater reliability because of a lack of covariance in scores producing a standard deviation of zero.

As part of their study to establish normative values for the FMS in a population of active healthy individuals Schneiders et al. (2011) undertook a reliability study in a subgroup of their study population. In this study, two raters with similar clinical experience scored ten subjects simultaneously and independently in real-time. The inter-rater reliability of the composite score for both testers was excellent with an ICC of 0.97 . The inter-rater reliability of each of the individual tests was either substantial or excellent, with kappa values ranging from 0.70 to 1.00 . Six of the seven total scores demonstrated excellent agreement and six of the ten right and left side scores also showed excellent agreement.

Shultz et al. (2011) assessed the inter-rater and test-retest reliability of the FMS as well as the use of video scoring versus real-time assessment of the test. They examined 40 university athletes by testing and retesting them one week apart by the same rater, who also scored the first sessions from a video recording. Five other raters then scored these video recordings. They measured reliability using Krippendorff alpha (Kalpha) for the three tests of inter-rater, test-retest and real-time versus video and reported scores of 0.3806, 0.6161 and 0.9096 respectively. They concluded that inter-rater reliability was poor and clinicians should avoid comparison across multiple raters. However, they 
found that test-retest reliability was good and therefore if a single rater is used, clinicians can be confident that a change in score is due to an actual change in the athlete. They also concluded that the use of video analysis to aid scoring of the test is appropriate to improve the reliability of the test.

In a recent high quality study investigating the reliability of the FMS among 64 activeduty military service members, Teyhen et al. (2012) used eight novice raters to assess inter- and intra-rater test-retest reliability. The novice raters in this study consisted of physical therapy students who underwent 20 hours of training on the FMS. Four of the raters were randomly assigned to the participants to assess intra-rater test-retest reliability by assessing the FMS on both day one and day two. Each rater assessed between 14 and 18 subjects each on day one. To determine inter-rater reliability, on the second day, 48 to 72 hours later, the remaining four raters were randomly assigned to assess the movements simultaneously with the first set of raters. In order to minimise bias all the raters were randomly assigned, raters on day two were blinded to the scores on day one, and the pairs of raters were blinded to each other's scores.

The inter-rater reliability of the FMS composite score was good with an $\mathrm{ICC}_{(2,1)}$ of 0.76 . In regards to the individual tests the inter-rater reliability was excellent for one of the tests, substantial for five of the tests and moderate for one. The kappa values ranged from 0.45 to 0.82 . The intra-rater reliability was reported as moderate with an $\operatorname{ICC}_{(3,1)}$ of 0.74 . In regards to the individual tests the intra-rater reliability was substantial for five of the tests, moderate for one and poor for one of the tests. The kappa values ranged from 0.29 to 0.76 . The authors of this study concluded that the FMS has an adequate level of reliability when assessing healthy service members by novice raters. By utilising a large number of raters, having a moderate number of subjects, using adequate blinding and randomisation of subject to rater allocation and assessing the 
FMS in real time, Teyhen et al. (2012) have conducted a high quality study that would challenge the assessment of the FMS. Therefore, the conclusion that the tool has an adequate level of reliability is positive.

When comparing the reliability of the composite or total score of the FMS across the investigations, the inter-rater reliability was found to be excellent in three studies (Butler et al., 2012; Onate et al., 2012; Schneiders et al., 2011) and adequate in one (Teyhen et al., 2012). Only one study found the inter-rater reliability to be poor (Shultz et al., 2011). In those studies that investigated intra-rater / test-retest reliability of the FMS it was found to range from good (Shultz et al., 2011; Teyhen et al., 2012) to excellent (Onate et al., 2012).

When comparing the studies that investigated the inter-rater reliability of the individual tests of the FMS, the inline lunge test has the lowest Kappa value in two of the four studies (Minick et al., 2010; Teyhen et al., 2012) and second to lowest in one study (Schneiders et al., 2011) with a range of 0.45 to 0.86 . The hurdle step test was also consistently a test that had lower inter-rater reliability with the lowest Kappa value in two studies (Onate et al., 2012; Schneiders et al., 2011) and second to lowest in the remaining two studies (Minick et al., 2010; Teyhen et al., 2012) with Kappa values ranging from 0.31 to 0.86 .

From the results of these studies it can be assumed that the FMS is a reliable screening tool and produces stable and consistent results between raters and across test occasions when used to give a subject a total score. However, clinicians should take care when interpreting the individual test scores of their athletes or patients.

The use of video analysis may help to improve the reliability of the FMS as a screening tool (Shultz et al., 2011), as the studies that made use of video (Butler et al., 2012; 
Minick et al., 2010) generally showed higher inter-rater reliability than those that didn't, with the exception of the study by Schneiders et al. (2011). However it has been argued that in a clinical situation the use of video analysis may not be practical and that real-time analysis more accurately mimics a preparticipation screening environment (Teyhen et al., 2012). There are situations where the use of video analysis is entirely appropriate, and if possible should be utilised. This also has the advantage of keeping a record of the screen for future analysis or comparison.

Minick et al. (2010) stated that assessors of the FMS should have undergone a standardised training protocol to use the tool in order for it to be used confidently. Butler et al. (2012) also reported that the FMS is reliable if raters have undergone formal training. However Onate et al. (2012) found that the FMS certification process did not seem to have an impact on the inter-rater reliability scores of a real-time assessment, and the raters in the study by Schneiders et al. (2011) had not undergone any formal training in the FMS. The clinical experience of the raters may be more important in the accuracy of using the tool than the formal training or certification in the use of the tool. Agreement between raters in the visual rating of movement quality during functional tests has found to be improved with increased level of clinical experience (Whatman, Hing, \& Hume, 2012).

\subsubsection{Other screening tools reliability}

The literature review resulted in five studies that investigated the reliability of functional screening tools other than the FMS (Frohm et al., 2012; Kritz, 2012; Onate et al., 2010; Padua et al., 2009; Smith et al., 2012). Frohm et al. (2012) investigated a nine-test battery screen, of which included six FMS tests with modified criteria, a onelegged squat test, the straight leg raise test and the seated rotation test. The subjects of this study were healthy male elite soccer players from two elite Swedish teams. Eight 
experienced physiotherapists conducted the screening tests on two occasions separated by seven days. The authors found no significant difference in the mean total scores of the test battery between test occasions with the ICC 0.80 on the first test and 0.81 on the second. However, they did find significant differences between physiotherapists with regard to the mean total scores on the first test occasion and this was indicated but not significant on the second test occasion. The inter-rater reliability for each exercise ranged from 0.30 to 0.85 on the first test occasion. The intra-rater reliability was found to be good with a mean ICC value of 0.75 .

The authors of this study concluded that this nine-test battery showed good inter- and intra-rater reliability when used on elite male soccer players. They came to this conclusion using the mean total scores of the tests; however, two of their tests, the onelegged squat test and the diagonal lift test had an ICC value of 0.52 and 0.30 respectively for inter-rater reliability. In this study, the authors did not use video for their analysis and this may have had an effect of the scoring of these two particular tests. On the whole, this test battery can be considered a reliable test when assessing the total score, however care should be taken when interpreting the results of these individual tests due to the poor consistency between raters.

As part of his thesis into the development of the MCS, Matthew Kritz (2012) under took a reliability study to determine the test-retest and inter-rater reliability of the screening tool. In this particular study, the participants were the 58 raters, of which there were 41 strength and conditioning specialists and 17 physiotherapists. The participants viewed and rated the video performance of three elite athletes of varying movement abilities. All 58 participants rated the three videos to determine inter-rater reliability; and 12 of the 58 participants rated the videos twice over a 10-day period to determine test-retest reliability. The results of this study showed that the test-retest reliability of the MCS 
was almost perfect with an overall average Kappa value of 0.93 . The inter-rater reliability for each of the movement tasks of the MCS ranged from Kappa values of 0.70 to 0.85 , with an average for all movements of 0.79 indicating substantial agreement. Kritz (2012) did not report on either the inter-rater or test-retest reliability of a composite score for all the tests. This is a shame, as the MCS is also scored out of 21, it may have allowed some comparison to the more frequently investigated FMS. The participants of this study were not given any training or detailed instruction into the scoring of the MCS. It is therefore possible that further training and/or instruction into the scoring criteria of the tool would have increased the reliability.

The landing error scoring system (LESS) is a clinical screening tool that is used to identify individuals at risk of suffering non-contact anterior cruciate ligament (ACL) injury (Onate et al., 2010; Padua et al., 2009; Smith et al., 2012). It evaluates participants landing biomechanics during a drop vertical jump and is a valid tool for identifying potentially high-risk movement patterns during a movement task (Padua et al., 2009). Three studies were identified in this literature review that investigated the reliability of the LESS. Padua et al. (2009) rescored the videos of a randomly selected subset of 50 subjects out of the 2691 subjects of their cohort study into the LESS. The inter-rater reliability was assessed by having two raters assess the same videos. The intra-rater reliability was determined by having a single rater assess the videos on two occasions separated by a minimum of one week. The raters were blinded to the original scores on all follow up occasions and had both undergone a comprehensive training programme into the scoring of the LESS. The inter-rater reliability was found to be good, with an $\mathrm{ICC}_{(2,1)}$ of 0.84 . The intra-rater reliability was found to be excellent with and $\operatorname{ICC}_{(2,1)}$ of 0.91 . 
Onate et al. (2010) examined the inter-rater reliability of the LESS between an expert and a novice rater. The expert rater had over 15 years' experience using the LESS and was one of the original developers of the tool. The novice rater had no experience with the tool and had only undergone a one-hour training session with the expert rater. Both raters analysed the videos of 19 female college soccer athletes doing a drop-jump task and the inter-rater agreement was found to be excellent with a $\operatorname{ICC}_{(2,1)}$ of 0.84 for the overall score.

As part of their prospective cohort study of the LESS as a screening tool for ACL injuries among high school and college athletes, Smith et al. (2012) conducted a reliability study of a subgroup of 10 participants. Two raters, who had the same amount of experience with the LESS, independently scored the videos of the participants at two time points separated by a week to determine the inter- and intra-rater reliability of the tool. They reported excellent agreement in LESS score between raters and between repeated assessments by the same rater. The inter-rater reliability was ICC of 0.92 and intra-rater reliability was ICC of 0.97 . It would appear, looking at the results of these three studies, that the LESS is a reliable screening tool. 
Table 2.3 Screening tools reliability studies

\begin{tabular}{|c|c|c|c|c|c|}
\hline Study & Participants & Study design & $\begin{array}{l}\text { Screening } \\
\text { tool }\end{array}$ & Methods & Results \\
\hline $\begin{array}{l}\text { Butler et al } \\
(2012)\end{array}$ & $\begin{array}{l}\text { Middle school-aged } \\
\text { students } \\
\mathrm{n}=30 \text { ( } 11 \text { males, } 19 \\
\text { females) }\end{array}$ & $\begin{array}{l}\text { Inter-rater } \\
\text { Reliability study }\end{array}$ & $\begin{array}{l}\text { FMS 100- } \\
\text { point scoring } \\
\text { scale. }\end{array}$ & $\begin{array}{l}2 \text { experienced raters. } \\
\text { Videotaped analysis }\end{array}$ & $\begin{array}{l}\text { Interrater reliability high for all tests. } \\
\text { Overall score } \mathrm{ICC}_{(2,1)}=0.99\end{array}$ \\
\hline $\begin{array}{l}\text { Frohm et al } \\
(2012)\end{array}$ & $\begin{array}{l}\text { Healthy elite soccer } \\
\text { players } \\
\mathrm{n}=26 \text { (male) }\end{array}$ & $\begin{array}{l}\text { Inter- and intra- } \\
\text { rater reliability }\end{array}$ & $\begin{array}{l}\text { Nine-test } \\
\text { screening } \\
\text { battery, } \\
\text { including } \\
\text { FMS }\end{array}$ & $\begin{array}{l}8 \text { raters (physiotherapists). } \\
\text { Subjects tested on two occasions } \\
\text { seven days apart. }\end{array}$ & $\begin{array}{l}\text { Inter-rater reliability good } \mathrm{ICC}_{(2,1)}=0.80 \\
\text { Intra-rater reliability good mean } \mathrm{ICC}_{(2,1)}=0.75\end{array}$ \\
\hline $\begin{array}{l}\text { Kritz } \\
(2012)\end{array}$ & $\begin{array}{l}\text { Healthy elite level athletes } \\
\text { Various sports } \\
\mathrm{n}=3 \text { ( } 1 \text { male, } 2 \text { females })\end{array}$ & $\begin{array}{l}\text { Inter-rater and } \\
\text { test-retest } \\
\text { reliability }\end{array}$ & MCS & $\begin{array}{l}58 \text { raters ( } 41 \mathrm{~S} \& \mathrm{C} \text { and } 17 \\
\text { physiotherapists) analysed the } \\
\text { video of the } 3 \text { participants online. } \\
12 \text { raters reviewed the videos twice } \\
\text { over } 10 \text { day period }\end{array}$ & $\begin{array}{l}\text { Inter-rater reliability substantial agreement, } \\
\text { Kappa }=0.79 \text { (range } 0.70-0.85) \\
\text { test-retest reliability almost perfect, Kappa }=0.93\end{array}$ \\
\hline $\begin{array}{l}\text { Minick et al } \\
(2010)\end{array}$ & $\begin{array}{l}\text { Healthy college students } \\
\mathrm{n}=40 \text { ( } 17 \text { males, } 23 \\
\text { females })\end{array}$ & $\begin{array}{l}\text { Inter- rater } \\
\text { reliability }\end{array}$ & FMS & $\begin{array}{l}4 \text { raters ( } 2 \text { expert, } 2 \text { novice) } \\
\text { Videotaped analysis }\end{array}$ & $\begin{array}{l}\text { Novice raters agreement moderate } 3 / 17 \text { tests, } \\
\text { substantial } 8 / 17 \text { tests, } 6 / 17 \text { tests. } \\
\text { Expert raters agreement: moderate } 4 / 17 \text { tests, } \\
\text { substantial } 9 / 17 \text { tests, } 4 / 17 \text { tests. }\end{array}$ \\
\hline $\begin{array}{l}\text { Onate et al } \\
(2010)\end{array}$ & $\begin{array}{l}\text { College soccer athletes } \\
n=19 \text { (females) }\end{array}$ & $\begin{array}{l}\text { Inter-rater } \\
\text { reliability }\end{array}$ & LESS & $\begin{array}{l}2 \text { raters ( } 1 \text { expert, } 1 \text { novice) } \\
\text { Videotaped analysis }\end{array}$ & Inter-rater reliability high, total score $\operatorname{ICC}_{(2,1)}=0.84$ \\
\hline $\begin{array}{l}\text { Onate et al } \\
(2012)\end{array}$ & $\begin{array}{l}\text { Physically active subjects } \\
\mathrm{n}=19 \text { ( } 12 \text { males, } 7 \text { females }\end{array}$ & $\begin{array}{l}\text { Inter-session } \\
\text { and inter-rater } \\
\text { reliability }\end{array}$ & FMS & $\begin{array}{l}\text { test-retest design } \\
2 \text { raters ( } 1 \text { expert, } 1 \text { novice })\end{array}$ & $\begin{array}{l}\text { Inter-session reliability high, } \operatorname{ICC}\left(_{3,1}=0.92\right. \\
\text { Inter-rater reliability high, total score } \operatorname{ICC}_{(3,1)}=0.98\end{array}$ \\
\hline $\begin{array}{l}\text { Pauda et al } \\
\text { (2009) }\end{array}$ & $\begin{array}{l}\text { Freshmen at US military } \\
\text { academies } \\
\mathrm{n}=50 \text { ( } 25 \text { males, } 25 \\
\text { females }\end{array}$ & $\begin{array}{l}\text { Inter-rater and } \\
\text { intra-rater } \\
\text { reliability }\end{array}$ & LESS & $\begin{array}{l}2 \text { raters } \\
\text { Videotaped analysis }\end{array}$ & $\begin{array}{l}\text { Inter-rater reliability good, total score } \mathrm{ICC}_{(2,1)}=0.84 \\
\text { Intra-rater reliability excellent, total score } \\
\operatorname{ICC}_{(2,1)}=0.91\end{array}$ \\
\hline
\end{tabular}




\begin{tabular}{|c|c|c|c|c|c|}
\hline $\begin{array}{l}\text { Schneiders et al } \\
\text { (2011) }\end{array}$ & $\begin{array}{l}\text { Healthy tertiary students } \\
\mathrm{n}=10\end{array}$ & Inter-reliability & FMS & $\begin{array}{l}2 \text { raters of similar clinical } \\
\text { experience. Subjects scored } \\
\text { simultaneously and independently }\end{array}$ & Inter-rater reliability excellent, $\mathrm{ICC}_{(3,1)}=0.971$ \\
\hline $\begin{array}{l}\text { Shultz et al } \\
(2011)\end{array}$ & $\begin{array}{l}\text { Varsity athletes, multiple } \\
\text { sports } \\
\mathrm{n}=40 \text { (19 males, } 21 \\
\text { females }\end{array}$ & $\begin{array}{l}\text { Inter-rater \& } \\
\text { test-retest } \\
\text { reliability } \\
\text { +video versus } \\
\text { live scoring. }\end{array}$ & FMS & $\begin{array}{l}6 \text { raters. Subjects tested and re- } \\
\text { tested } 1 \text { week apart by one rater. } \\
\text { Video recordings then scored by all } \\
6 \text { raters. }\end{array}$ & $\begin{array}{l}\text { Inter-rater reliability Kalpha }=0.3806 \\
\text { Test-retest Kalpha }=0.6161 \\
\text { Live/video Kalpha }=0.9096\end{array}$ \\
\hline $\begin{array}{l}\text { Smith et al } \\
(2011)\end{array}$ & $\begin{array}{l}\text { High school and college } \\
\text { athletes, variety of sports } \\
n=10\end{array}$ & $\begin{array}{l}\text { Intra \& inter- } \\
\text { rater reliability }\end{array}$ & LESS & $\begin{array}{l}2 \text { raters scored video analysis at } 2 \\
\text { time points } 1 \text { week apart }\end{array}$ & $\begin{array}{l}\text { Intra-rater reliability excellent, } \mathrm{ICC}_{(3,1)}=0.97 \\
\text { Inter-rater reliability excellent, } \mathrm{ICC}_{(3,1)}=0.92\end{array}$ \\
\hline $\begin{array}{l}\text { Teyhen et al } \\
(2012)\end{array}$ & $\begin{array}{l}\text { Active-duty service } \\
\text { members } \\
n=64\end{array}$ & $\begin{array}{l}\text { Intra-rater test- } \\
\text { retest }+ \text { inter- } \\
\text { rater reliability }\end{array}$ & FMS & $\begin{array}{l}8 \text { novice raters. Subjects tested and } \\
\text { retested } 48-72 \text { hours apart. } \\
2 \text { raters assessed same tests } \\
\text { simultaneously on retest. }\end{array}$ & $\begin{array}{l}\text { Intra-rater test-retest reliability } \mathrm{ICC}_{(3,1)}=0.76 \\
\text { Inter-rater reliability } \operatorname{ICC}_{(2,1)}=0.74\end{array}$ \\
\hline
\end{tabular}




\subsubsection{The relationship between functional screening tools and injury}

There were ten observational studies identified in this review that have been conducted in order to determine whether screening tools are able to predict injury, and identify those athletes who are susceptible to injuries (Table 2.4). Research has investigated a number of different populations, across multiple sports and professions, including professional athletes (Kiesel, Plisky, \& Voight, 2007; Parchmann \& McBride, 2011), collegiate and university athletes (Chorba et al., 2010; Leetun et al., 2004), high school athletes (Smith et al., 2012; Sorenson, 2009; Wieczorkowski, 2010), recreational athletes (Hoover et al., 2008; Okada et al., 2011; Schneiders et al., 2011), firemen (Peate, Bates, Lunda, Francis, \& Bellamy, 2007), and military personnel (O'Connor, Deuster, Davis, Pappas, \& Knapik, 2011).

\subsubsection{Prospective cohort studies}

The literature review in the current study revealed six prospective cohort studies that investigated the relationship between screening tool scores and the likelihood of sustaining an injury (table 2.4). In a cohort study, an outcome or injury free population is first identified by the exposure and is then followed in time until the outcome of interest occurs (Song \& Chung, 2010). Because the exposure is identified before the outcome, cohort studies have the potential to assess causality and thus provide strong scientific evidence (Song \& Chung, 2010). The results of the identified studies are conflicting as to the relationship between screening tools and injury and therefore their ability to predict susceptible individuals.

Chorba et al. (2010) investigated whether the FMS tool could be used to predict injuries in 38 female collegiate athletes competing in soccer, volleyball and basketball. In their study, the participants were screened prior to their respective seasons and injury data 
were then collected over the course of the season. The injury definition in this study included any injury that was sustained as a result of participation in an organised intercollegiate practice or competition setting and required medical attention or advice. A distinction was made between all athletes, and those whom had previously undergone ACL reconstruction surgery. During the period of the study 18 injuries were recorded and the investigators concluded that a score of 14 or less was a positive predictor of injury $(\mathrm{OR}=3.85)$ for all athletes. When those athletes who had a previous history of ACL injury were removed from the analysis the likelihood of sustaining an injury increased $(\mathrm{OR}=4.58)$. They found that there was a significant correlation between lowscoring athletes and injury $(\mathrm{r}=0.76, \mathrm{p}=0.0214)$. The small number of participants limits this study as only 38 athletes participated from three different sports. In addition, it has only investigated injury among female athletes and therefore its findings should not be generalised to a male population.

A second prospective study that found a positive correlation between a screening tool and injury investigated the predicative value of the FMS by comparing entry scores with subsequent injury among Marine Corps Officer candidates during Officer Candidate School training (O'Connor et al., 2011). This large-scale study included 847 males aged between 18 and 30 years old who were enrolled in either 6-week short-cycle or 10-week long-cycle programmes. The participants underwent both a FMS and a physical fitness test during the first week of the training programme. Injury data were collected daily during the training cycle and injury was defined as physical damage to the body secondary to physical training. Injuries were further grouped into overuse, traumatic, any and serious injuries. Serious injuries were those that were severe enough to remove the subject from the training programme. The authors of this study reported that the risk was two times greater for sustaining any injury in those participants who scored 14 
or less on the FMS $(\mathrm{OR}=2.0, \mathrm{p}=0.002)$. Interestingly, in contrast to all injuries and serious injuries, the authors found no significant correlation between FMS score and overuse injuries. The other interesting finding in this study was that not only were those participants who scored 14 or less at greater risk of injury, but so were those who scored 18 or greater, thereby indicating a bimodal distribution (O'Connor et al., 2011). When they compared the FMS scores by any injury versus no injury, the scores were the same between the groups. O'Conner et al. (2011) also compared the physical fitness scores, FMS scores and injury. They dichotomised the physical fitness scores as either high or moderate fitness levels. Those participants who had moderate fitness were 2.2 times more likely to have FMS scores of 14 or less and were also significantly more likely to sustain an injury across all types of injury, including overuse injuries $(\mathrm{OR}=2.1$, $\mathrm{p}<0.0001)$. The authors concluded that physical fitness scores were just as predictive of future injury as FMS scores and had a higher sensitivity. One factor that needs to be taken into account when interpreting the results of this study is the population under investigation were highly fit men who had previously been challenged and screened in the Marine Corps and therefore represent a relatively homogeneous group (O'Connor et al., 2011).

The third prospective cohort study that found FMS scores to be predictive of injury, Wieczorkowski (2010) is his unpublished Master's thesis, investigated the relationship between the screening tool and lower limb injuries in a group of 82 male and female high school basketball players. Injury was defined as that which resulted in time lost from participation, it was not clear as to whether participation included training or was only competition. The data collected were further separated into three groups; all subjects, subjects with previous history of low extremity injury and subjects without a previous history of lower extremity injury. Those who had a history of lower extremity 
surgery were excluded from the study. This study demonstrated that high school basketball athletes who scored 14 or less on the FMS and who did not have a previous history of injury had 5.6 times greater risk of injury than those with a score above 14 . However, the FMS did not have the ability to predict injury in those athletes who had a previous history of lower extremity injury or the all subject groups.

A second study that investigated the relationship between FMS score and non-contact injury among 112 male and female high school basketball athletes was the unpublished doctoral thesis of Sorenson (2009). In this study, injury was defined as neuromusculoskeletal impairments that were reported to the school staff or certified athletic trainers. Injuries were excluded if they did not occur during or were unrelated to a school-sanctioned practice or game. Contact injuries that were caused by contact with a ball, another player or the floor were also excluded from this study. Sorenson (2009) reported that the FMS was unable to predict at-risk athletes at either the commonly reported cut-off point of 14 or less, or at any other cut-off point. He found that $24 \%$ of those that scored above 14 sustained an injury, whereas only $22 \%$ of those that scored 14 or less suffered an injury. In order to determine if a subset of demographic variables and FMS movements could more accurately predict injury risk a logistic regression analysis was also undertaken. This also revealed that none of the predictors were significant, either in isolation or in combination. In comparison with the study by Wieczorkowski (2010), this study did not group the participants into those who had, and those that had no previous history of injury. Wieczorkowski (2010) found that the FMS was unable to predict injury among high school basketball athletes who had a previous history of injury and all athletes. It is possible that by not analysing these groups separately the study by Sorenson (2009) is limited. It is also possible that by including only non-contact injuries a sub-group of injuries would have been missed 
and therefore affected the results, making comparisons between these two studies difficult. Sorenson (2009) did report the number of chronic or overuse injuries compared to the number of acute injuries that were sustained during the period of the study. Interestingly the majority $(69 \%)$ of the injuries sustained, between both the males and females, were chronic. It may be that the high percentage of overuse injuries had an effect on the ability of the FMS to predict injuries in this study. However, Sorenson (2009) did not find a significant difference in FMS scores between these two groups.

Another prospective cohort study that was unable to establish any predictive validity of the FMS to injury in an athletic population was that of Hoover et al. (2008). In this study, the investigators screened 60 recreational athletes training for a half marathon with the FMS. The participants then completed a weekly online survey as means of tracking training and injury status. Data were collected over a four-month period in the lead up to the half marathon event. The definition of injury was not clear in this study, apart from stating that they were overuse injuries. The results of this study found that neither linear nor logistic regression analyses identified FMS scores as a predictor of musculoskeletal injury. The authors were also unable to identify a cut-off score that was able to predict future injury risk. This study adds to the body of evidence suggesting that functional screening tools are ineffective at predicting overuse injuries over a variety of populations (Hoover et al., 2008; O'Connor et al., 2011; Sorenson, 2009).

A prospective cohort study identified in this literature review investigated the predictive relationship between core stability tests and back and lower extremity injuries (Leetun et al., 2004). Although it could be argued that core stability tests are not strictly functional or movement tests, it was decided to include this study for review due to the 
current study including some of these tests in the analysis. Leetun et al. (2004) assessed the core stability of 140 male and female university athletes from the sports of basketball and cross-country running. Their core stability testing consisted of hip abduction and external rotation isometric strength, back extensor strength as assessed with a modified Biering-Sorensen test (Biering-Sorensen, 1984), abdominal muscle strength as assessed with both a flexor endurance test as described by (McGill, Childs, \& Liebenson, 1999) and a straight leg lowering test, and quadratus lumborum strength as assessed by a side bridge test (McGill et al., 1999). Injury was defined as an event that occurred during athletic participation, required treatment or attention, and resulted in at least one full missed day of practice or competition. The authors of this study found that athletes who experienced an injury over the course of the season generally demonstrated lower core stability measures than those who did not; however, these differences were only significant for hip abduction and lateral rotation strength. A logistic regression analysis showed that poor hip external rotation strength was the only useful predictor of future injury $(\mathrm{OR}=0.86)$.

The final prospective cohort study identified was a large scale study that involved 3876 athletes and 5047 screenings that took place and were followed over a three-year period (Smith et al., 2012). The participants were athletes from 18 high schools and 8 colleges that participated in a variety of sports associated with sustaining non-contact ACL injuries. Thirty-two athletes sustained an ACL injury over the three-year period, of these, 28 agreed to participate in the study. The analysis of this study involved a nested case-control analysis with injured participants matched to three controls from the same team who were the same sex and the same age. The participants and their matched controls had also been screened on the same day. Smith et al. (2012) found that there was no significant relationship between LESS score and the risk of suffering an ACL 
injury when the LESS score was analysed as either a continuous or categorical variable. This was the finding for all participants as a combined group and for subgroup analyses of female, male, high school and college athletes. Although this was a large prospective cohort, because the analysis was a nested case-control, the authors did a post hoc power analysis and found that in order to have $80 \%$ power of detecting an odds ratio of three or larger, approximately 148 cases of ACL injury would have been needed. The level of evidence of a case-control study is not as high as that of a prospective cohort (Song \& Chung, 2010), however the authors addressed the methodological issues through the selection of cases through a large prospective cohort, the use of multiple controls and by controlling for potential confounders in the matching of the controls. The findings of this study suggest that the screening tool is not able to predict a specific injury, that being ACL injuries, in a population of high school and college athletes. It would have been of interest to analyse all lower limb injuries in this cohort, however case-control study designs are selected for reasons of practicality and feasibility (Song \& Chung, 2010), and following this sized cohort for this was unlikely to be either.

\subsubsection{Retrospective cohort and cross-sectional studies}

One of the first studies to investigate the relationship between FMS score and the risk of injury was a retrospective descriptive study which looked at serious injuries among professional football players (Kiesel et al., 2007). In this study, 46 athletes from one professional American football team were assessed with the FMS prior to the football season, and at the end of the season the composite FMS scores were analysed and compared with the injury data. The definition of injury in this study was that which resulted in an athlete being on the injured reserve list and unable to compete for three weeks. Kiesel et al. (2007) found that an American football player has an eleven-fold increased chance of sustaining a serious injury when their FMS score is 14 or less. The 
authors of this study also established that a cut off score of 14 or less was specific and sensitive enough to predict serious injury; this cut-off score has also been used investigated in subsequent studies (Chorba et al., 2010; Hoover et al., 2008; O'Connor et al., 2011; Sorenson, 2009; Wieczorkowski, 2010). Due to the small sample size and the fact that the population of professional football players didn't represent a general athletic population this cut-off value should be used with caution (Schneiders et al., 2011). With an odds ratio of 11.67 this study found the highest predictive validity of the FMS of any of the studies reviewed in the current study, however this study had a small sample size and this was selected from one sports team, therefore selection bias could be an issue. A disadvantage of retrospective studies is the limited control the investigator has over data collection, and the recall of injuries may be incomplete which leads to bias (Song \& Chung, 2010), however in this instance, due to the definition of injury in this study it is unlikely that any of these injuries would have been missed over the period of one season. The limited injury definition is also a limitation of this study as it is likely that this would have missed a number of injuries that were meaningful, but of shorter duration than three weeks (Kiesel et al., 2007). This makes these findings difficult to compare to other studies.

Two studies have investigated the relationship between FMS scores and history of previous musculoskeletal injury (Peate et al., 2007; Schneiders et al., 2011). As part of their intervention study Peate et al. (2007) used the FMS to screen 433 fire-fighters, and analysed the relationship between these scores and previous work-related injuries. They also investigated the relationship between FMS scores and the participants' age, rank, tenure and gender. The authors found that after adjusting for age in a multiple linear regression analysis, fire-fighters with a history of injury scored 0.24 points lower than those without. However, this was not found to be statistically significant, and with a 
difference of less than a quarter of a point, it is unlikely to be clinically relevant. Peate et al. (2007) also investigated a pass/fail score, with a cut-off of 16 points, and found that after adjusting for age in a multiple logistic regression analysis participants were 1.68 times more likely to fail the FMS if they had a history of injury. This was a statistically significant finding. The main methodological flaw in this study is that the injury data were collected retrospectively from the fire department database and only included work related musculoskeletal injuries. The collection method is likely to have missed non-work related injuries that could potentially have affected the FMS scores. In addition, it is not clear how long prior to completing the screening did the injuries recorded occurred.

Schneiders et al. (2011) undertook a cross-sectional study to establish normative values for the FMS in a population of active, healthy individuals. They screened 209 females and males recruited from a tertiary student population, sport clubs and the general public, and reported that 50 participants had sustained an injury in the previous six months. An independent sample t-test found no significant difference, on the composite FMS score, between participants who had a previous history of injury and those who did not.

At present, there is inconsistency among the research as to functional screening tools' ability to predict injury in sporting and occupational populations, with four of the studies reviewed reporting a positive correlation between scores and injury (Chorba et al., 2010; Kiesel et al., 2007; O'Connor et al., 2011; Wieczorkowski, 2010), and four reporting no correlation (Hoover et al., 2008; Leetun et al., 2004; Smith et al., 2012; Sorenson, 2009). A lack of consistency in the definition of injury between studies makes it difficult to compare their results. It would seem from the studies reviewed that screening tools are not able to detect those athletes with previous injury and are also less 
able to predict injury risk among those with a previous history of injury (Chorba et al., 2010; Peate et al., 2007; Schneiders et al., 2011; Wieczorkowski, 2010). Studies have also found that screening tools are less able to predict the risk of overuse or gradual onset injuries among different populations (Hoover et al., 2008; O'Connor et al., 2011) than acute injuries. A possible explanation for this may be that the body contains reserve capacity to accommodate for imperfections without failure or symptoms, and body structures are capable of self-repair and are able to adapt according to demands (Lederman, 2011). Therefore, the functional movement impairments assessed by screening tools are less relevant in injuries that happen over time. In contrast, in a situation that occurs acutely such as contact with another individual, or a sudden change in direction, the body is unable to accommodate and adapt to the stress and therefore an acute injury can occur. In these situations an athlete's dynamic and functional capacity is more likely to have an impact on the risk of injury. 
Table 2.4 Studies investigating the relationship between screening tools and injury

\begin{tabular}{|c|c|c|c|c|c|}
\hline Study & Participants & Study Design & $\begin{array}{l}\text { Screening } \\
\text { Tool }\end{array}$ & Outcome Measure & Results \\
\hline $\begin{array}{l}\text { Chorba et al } \\
(2010)\end{array}$ & $\begin{array}{l}\text { Collegiate athletes, } \\
\text { multiple winter and fall } \\
\text { sports } \\
\mathrm{n}=38 \text { (female) }\end{array}$ & $\begin{array}{l}\text { Prospective } \\
\text { cohort }\end{array}$ & FMS & Musculoskeletal injury & $\begin{array}{l}\text { FMS score of } \leq 14 \text { positive predictor of injury } \\
(\mathrm{OR}=3.85) \text {. } \\
\text { Significant correlation between low scoring athletes } \\
\text { and injury }(\mathrm{r}=0.76, \mathrm{p}=0.02)\end{array}$ \\
\hline $\begin{array}{l}\text { Hoover et al } \\
(2008)\end{array}$ & 60 recreational runners & $\begin{array}{l}\text { Prospective } \\
\text { cohort }\end{array}$ & FMS & Injury & $\begin{array}{l}\text { No correlation found between FMS and } \\
\text { musculoskeletal injury. }\end{array}$ \\
\hline $\begin{array}{l}\text { Kiesel et al } \\
(2007)\end{array}$ & $\begin{array}{l}\text { Professional American } \\
\text { Football athletes } \\
\mathrm{n}=46 \text { (male) }\end{array}$ & $\begin{array}{l}\text { Retrospective } \\
\text { descriptive }\end{array}$ & FMS & $\begin{array}{l}\text { Serious injury (on injured reserve } \\
\text { list for at least } 3 \text { weeks) }\end{array}$ & $\begin{array}{l}\text { FMS score of } \leq 14 \text { positive predictor of serious injury } \\
(\mathrm{OR}=11.67)\end{array}$ \\
\hline $\begin{array}{l}\text { Leetun et al } \\
(2004)\end{array}$ & $\begin{array}{l}\text { Varsity intercollegiate } \\
\text { basketball and cross- } \\
\text { country athletes } \\
\mathrm{n}=140 \text { ( } 44 \text { males, } 60 \\
\text { females) }\end{array}$ & $\begin{array}{l}\text { Prospective } \\
\text { cohort }\end{array}$ & Core stability* & Back and lower extremity injuries & $\begin{array}{l}\text { Hip external rotation strength the only significant risk } \\
\text { factor }(\mathrm{OR}=0.86, \mathrm{CI}=0.77,0.097)\end{array}$ \\
\hline $\begin{array}{l}\text { O'Conner et al } \\
\text { (2011) }\end{array}$ & $\begin{array}{l}\text { Military personal } \\
\mathrm{n}=847 \text { (male) } \\
\text { Both SC ( } 38 \text { days) and LC } \\
\text { ( } 68 \text { days) trainees }\end{array}$ & $\begin{array}{l}\text { Prospective } \\
\text { cohort }\end{array}$ & FMS & $\begin{array}{l}\text { Musculoskeletal injury. } \\
\text { Grouped: 1) overuse 2) traumatic } \\
\text { 3) any 4) serious }\end{array}$ & $\begin{array}{l}\text { FMS score of } \leq 14 \text { positive predictor of injury }(\mathrm{RR}=1.5 \text {, } \\
\mathrm{p}=0.003) . \\
\text { Any injury: } \mathrm{OR}=2.0(\mathrm{CI} 1.3-3.1, \mathrm{p}=0.002) \\
\text { Serious injury: } \mathrm{OR}=2.0(\mathrm{CI} 1.0-4.1, \mathrm{p}=0.05) \\
\text { No correlation between FMS score and overuse injuries }\end{array}$ \\
\hline $\begin{array}{l}\text { Peate et al } \\
(2007)\end{array}$ & $\begin{array}{l}\text { Fire-fighters } \\
\mathrm{n}=433 \text { : } 408 \text { males, } 25 \\
\text { females. }\end{array}$ & $\begin{array}{l}\text { Retrospective }+ \\
\text { intervention } \\
\text { programme }\end{array}$ & FMS & Previous injury history & $\begin{array}{l}\text { No significant correlation between previous injury and } \\
\text { FMS score }\end{array}$ \\
\hline $\begin{array}{l}\text { Schneiders et al } \\
(2011)\end{array}$ & $\begin{array}{l}\text { Physically active } \\
\text { individuals } \\
\mathrm{n}=209 \text { ( } 101 \text { males, } 108\end{array}$ & Cross-sectional & FMS & Previous injury history & $\begin{array}{l}\text { No significant correlation found between FMS and } \\
\text { previous injury }\end{array}$ \\
\hline
\end{tabular}




\section{females)}

Smith et al High school and college

athletes, variety of sports

Prospective

LESS

ACL injury

No correlation found between LESS score and ACL

$\mathrm{n}=3876$ (2021 male, 1855

cohort with a

injury

female).

nested case-

Cases n=28 (9 male, 19

female)

Controls $n=64$ (20 male,

44 female)

\begin{tabular}{|c|c|c|c|c|c|}
\hline $\begin{array}{l}\text { Sorenson } \\
(2009)\end{array}$ & $\begin{array}{l}\text { High school basketball } \\
\text { athletes } \\
n=112 \text { ( } 52 \text { male, } 60 \\
\text { female) }\end{array}$ & $\begin{array}{l}\text { Prospective } \\
\text { cohort } \\
\text { Thesis }\end{array}$ & FMS & $\begin{array}{l}\text { Non-contact } \\
\text { neuromusculoskeletal injuires. } \\
\text { Excluded contact injuries }\end{array}$ & $\begin{array}{l}\text { No correlation found between FMS and } \\
\text { musculoskeletal injury }\end{array}$ \\
\hline $\begin{array}{l}\text { Wieczorkowski } \\
(2010)\end{array}$ & $\begin{array}{l}\text { High school basketball } \\
\text { athletes } \\
n=82 \text { ( } 50 \text { male, } 32 \text { female) }\end{array}$ & $\begin{array}{l}\text { Prospective } \\
\text { cohort } \\
\text { Thesis }\end{array}$ & FMS & $\begin{array}{l}\text { Lower extremity injury that } \\
\text { resulted in any time lost from } \\
\text { practise or competition. } 3 \text { groups: } \\
\text { all subjects, no PHx LL injury, } \\
\text { PHx LL injury. }\end{array}$ & $\begin{array}{l}\text { FMS score of } \leq 14 \text { positive predictor of LL injury in the } \\
\text { no PHx group }(\mathrm{OR}=5.6) \\
\text { FMS score of } \leq 14 \text { positive predictor of LL injury in the } \\
\text { all subjects group (OR=2.3) } \\
\text { No correlation found between FMS and LL injury in } \\
\text { the PHx group }\end{array}$ \\
\hline
\end{tabular}

* Hip abduction and external rotation isometric strength, Modified Biering-Sorensen test, Lateral side bridge, V-sit and straight leg lowering test.

$F M S=$ functional movement screen; OR= odds ratio; $C I=95 \%$ confidence interval; $S C=$ short course; $L$, long course $;$ RR= relative risk; LESS= landing error scoring system ;

$A C L=$ anterior cruciate ligament; $P H x=$ previous injury history; $L L=$ lower limb; $r=$ correlation value; $p=p$-value. 


\subsubsection{The relationship between functional screening tools and performance}

Functional screening tools are often touted as being predictors of sporting performance and able to identify athletes with deficits in fundamental movement patterns that have the potential to limit performance (Chorba et al., 2010; Comerford, 2006; Cook et al., 2006). This literature review found two studies that have investigated the relationship between functional movement, core stability and performance (Table 2.5) (Okada et al., 2011; Parchmann \& McBride, 2011). These two studies reported conflicting results in the relationship between functional movement and performance. Okada et al. (2011) looked at the relationship between functional movement, as assessed by the FMS, core stability as assessed by McGill's trunk muscle endurance tests (McGill et al., 1999), and performance. The performance tests they performed consisted of a backward overhead medicine ball throw, a T-run agility test and single leg squat endurance test. The authors found that there were no significant correlations found between any of the core stability tests and FMS variables. They did report weak to moderate correlations between some of the performance tests and some of the FMS variables. However, these correlations were random in nature and contradictory to each other. For example, the medicine ball throw was positively correlated to the hurdle step and rotational stability on the right and push ups, but negatively correlated with shoulder mobility on the right but not the left, which would indicate that the greater the shoulder mobility, the worse the throwing performance. The single leg squat test was only correlated with shoulder mobility, which is not clinically relevant. The agility test was negatively correlated with the in-line lunge test on the left side, and the hurdle-step test on the right side, indicating the better the FMS score the faster the time. Okada et al. (2011) did not report on the relationship between composite FMS scores and the performance tests, which is unfortunate as the composite score would be more clinically relevant. 
Parchmann and McBride (2011) investigated the relationship between the FMS and athletic performance using the sport specific performance test of golf club head swing velocity, as well as a one-repetition $\max (1 \mathrm{RM})$ squat, 10-metre and 20-metre sprint time, vertical jump height, t-test completion time. The study found no correlation between the FMS and club head swing velocity or any of the other performance variables. This was in contrast to the $1 \mathrm{RM}$ squat test which had strong significant relationships to all variables measured.

It would seem from the results of these two studies that composite or individual FMS task scores do not relate to athletic performance variables in a positive sense (Parchmann \& McBride, 2011). In fact, the results of the Okada study showed that for some of the FMS tasks, higher scores actually related to poorer performances in the tests undertaken. 
Table 2.5 Studies investigating the relationship between screening tools and performance

\begin{tabular}{|c|c|c|c|c|c|}
\hline Study & Participants & Study Design & $\begin{array}{l}\text { Screening } \\
\text { Tool }\end{array}$ & Outcome Measure & Results \\
\hline $\begin{array}{l}\text { Okada et al. } \\
(2011)\end{array}$ & $\begin{array}{l}\text { Recreational athletes } \\
\mathrm{n}=28 \text { (male and female, } \\
\text { numbers not stated) }\end{array}$ & $\begin{array}{l}\text { Multivariate } \\
\text { correlational }\end{array}$ & $\begin{array}{l}\text { FMS + core } \\
\text { stability }\end{array}$ & $\begin{array}{l}\text { Performance variables: } \\
\text { BOMB, TR and SLS }\end{array}$ & $\begin{array}{l}\text { No correlation between core stability and FMS score. } \\
\text { Moderate to weak correlations between FMS score, } \\
\text { core stability and performance }\end{array}$ \\
\hline $\begin{array}{l}\text { Parchmann and } \\
\text { McBride (2011) }\end{array}$ & $\begin{array}{l}\text { National collegiate } \\
\text { division I golfers } \\
\mathrm{n}=25 \text { ( } 15 \text { male, } 10 \text { female })\end{array}$ & $\begin{array}{l}\text { Multivariate } \\
\text { correlation }\end{array}$ & $\begin{array}{l}\text { FMS and 1RM } \\
\text { squat }\end{array}$ & $\begin{array}{l}\text { Performance variables: } \\
10 \mathrm{mSP}, 20 \mathrm{mSP} \text {, VJ, TT and } \\
\text { CHSV }\end{array}$ & $\begin{array}{l}\text { No significant correlations found between FMS score } \\
\text { and any of the performance variables. } \\
\text { No significant correlations found between any of the } \\
\text { FMS individual tests and the performance variables. } \\
1 \text { RM squat significantly correlated to: } \\
\text { CHSV }(r=0.805, p=0.0001), \mathrm{VJ}(\mathrm{r}=0.869, \mathrm{p}=0.0001) \text {, } \\
10 \mathrm{mSP}(\mathrm{r}=-0.812, \mathrm{p}=0.0001), 20 \mathrm{mSP}(\mathrm{r}=0.872,0.0001) \\
\text { and TR }(\mathrm{r}=-0.758, \mathrm{p}=0.0001)\end{array}$ \\
\hline
\end{tabular}

FMS = functional movement screen; BOMB=backward overhead medicine ball throw; TR=T-run agility test; SLS= single leg squat $; 1 R M=1$ repetition max; $10 m S P=10$ metre sprint time; $20 \mathrm{mSP}=20$ metre sprint time; VJ=vertical jump; $C H S V=c l u b$ head swing velocity; 


\subsubsection{Screening tools intervention studies}

Three intervention studies were identified in this literature review (Table 2.6). Two studies investigated whether FMS scores could be improved following intervention training programmes (Goss, Christopher, Faulk, \& Moore, 2009; Kiesel, Plisky, \& Butler, 2011) and the third study investigated the change in injury rates among firemen who had undergone FMS screening and a subsequent intervention programme (Peate et al., 2007). In a descriptive intervention study, Goss et al. (2009) describe a functional training programme that is offered to both patients recovering from injury and healthy individuals, at a Special Operations military training facility in the US. As part of an on-going evaluation of their training programme the authors collected data over first two-year period of the programme. Of the 155 participants who attempted the programme, 90 were able to complete it and the data from these individuals were analysed in the study. The functional training programmes were six weeks in duration and consisted of three exercise classes per week. Participants underwent a FMS in the first week of the programme and again on completion as just one of a number of investigations and tests. The training programmes included agility, core strength and balance, and power and explosiveness training. Participants were given an individualised strength and conditioning programme based on their personal strengths and weaknesses. Goss et al. (2009) found that FMS scores improved an average of 2.5 points on post-intervention testing.

Kiesel et al. (2011) undertook an intervention study to determine if an off-season intervention programme was effective in improving FMS scores in 62 professional American football players from one team. Participants underwent a structured sevenweek off-season strength and conditioning programme that included a component of individualised exercises prescribed based on the individuals score on the FMS. Screens 
were completed pre- and post-intervention and the participants were grouped by position into lineman and non-lineman. The study found that the mean FMS scores improved three points following the intervention for both groups. The authors reported that after the intervention a greater number of player had a score above the injury risk cut-off point of 14 or less (Kiesel et al., 2007) compared with before the intervention.

Although the results of these two studies are encouraging and would indicate that FMS scores can improve with intervention programmes, both have some significant methodological flaws. Neither study had a control group, therefore it cannot be established if the improvements in FMS seen were in fact related to the intervention at all. Both programmes included general strength and conditioning exercises in the programmes as well as the individual exercises prescribed following the screening (Goss et al., 2009; Kiesel et al., 2011) and it is possible that FMS scores would improve without the individualised component of the programme. This could be a result of either the general exercises or a repeated measure effect. Secondly, there was no blinding of the examiners of the screens mentioned in regards to the participant's pretest scores. In the study by Goss et al. (2009) the same examiners did pre- and postintervention testing as well as being involved as the trainers of the programmes. Kiesel et al. (2011) do not state who tested their participants or the relationship between the assessors and participants. This may have introduced bias into the post intervention scores. Keisel et al. (2011) stated that a greater number of players had a score above an injury risk cut-off point of 14 or less following intervention than before, however in the study by Goss et al. (2009) the mean FMS score post pre and post intervention was above this 14 point cut-off. Neither of these studies has investigated the effect of improving the FMS score has on injury rate among their participants. Future research 
should look at the injury rate of a group of participants before and after an intervention aimed at improving functional movement patterns.

One study investigated the effect that a functional core strengthening programme had on injury rate among firefighters (Peate et al., 2007). This study has been described previously in this review in regards to the relationship between FMS scores and previous history of injury. The second objective of this study was to implement an intervention, consisting of a training programme designed by a multi-disciplinary team and delivered to the participants via a three-hour seminar. Each session emphasised functional movement and prevention of injuries, however it is not clear if there was any individualisation of the programmes depending on the findings of the functional screen. A number of exercises were taught to the participants as home exercises. Injury data were then collected prospectively over the following twelve months from the fire department database. This was compared to an historical control from the twelve months prior to the intervention. The authors of this study reported that compared to the historical control group, the total number of injuries decreased $42 \%$ and the time lost due to injury reduced $62 \%$ following the intervention. This study has a number of limitations. Unfortunately, the FMS scores of the participants were not re-tested following the intervention therefore it is not known whether the intervention actually changed the functional movement patterns of the participants. Although the intervention programme in this study was well described there was no mention of compliance to the programme of the participants. It is possible that following the seminars, no further functional training was performed by the participants. Participants may have undertaken co-interventions over the following twelve-month period and this was not controlled for in the study. This study did have a control, however this was an 
historical control and there is no indication of this being matched to the study population. 
Table 2.6 Screening tools intervention studies

\begin{tabular}{|c|c|c|c|c|c|c|}
\hline Study & Participants & Study Type & Screening tool & Methods & $\begin{array}{l}\text { Control } \\
\text { group }\end{array}$ & Results \\
\hline $\begin{array}{l}\text { Goss et al. } \\
(2009)\end{array}$ & $\begin{array}{l}\text { Military personnel } \\
\mathrm{n}=90 \text { ( } 80 \text { males, } 10 \\
\text { females) over a two year } \\
\text { period. } \\
155 \text { started programme but } \\
65 \text { lost to follow-up }\end{array}$ & $\begin{array}{l}\text { Descriptive } \\
\text { study }\end{array}$ & $\begin{array}{l}\text { FMS + } \\
\text { functional } \\
\text { tests*. Pre and } \\
\text { post programme }\end{array}$ & $\begin{array}{l}\text { 6-week functional } \\
\text { training programmes. } \\
\text { Dynamic stretching, } \\
\text { agility exercises, core } \\
\text { strengthening and power } \\
\text { exercises }\end{array}$ & No & $\begin{array}{l}\text { FMS scores improved on average } 2.5 \text { points } \\
\text { (reported as statistically significant, however no } \\
\text { p-value given) } \\
\text { All functional test results also reported as } \\
\text { finding significant improvements }\end{array}$ \\
\hline $\begin{array}{l}\text { Kiesel et al. } \\
\text { (2011) }\end{array}$ & $\begin{array}{l}\text { Professional American } \\
\text { football players } \\
n=62 \text { (male) }\end{array}$ & $\begin{array}{l}\text { Intervention } \\
\text { study }\end{array}$ & FMS & $\begin{array}{l}\text { 7-week off-season } \\
\text { training programme } \\
\text { based on FMS score }+ \\
\text { traditional strength and } \\
\text { conditioning programme }\end{array}$ & No & $\begin{array}{l}\text { Greater number of individuals with a score }>14 \\
\text { following intervention }\left(x^{2}=164.9, p<0.01\right) \\
20 \text { subjects failed to improve their score above } \\
14\end{array}$ \\
\hline $\begin{array}{l}\text { Peate et al. } \\
(2007)\end{array}$ & $\begin{array}{l}\text { Fire-fighters } \\
\mathrm{n}=433: 408 \text { males, } 25 \\
\text { females }\end{array}$ & $\begin{array}{l}\text { Retrospective } \\
+ \text { intervention } \\
\text { programme }\end{array}$ & $\begin{array}{l}\text { FMS pre- } \\
\text { intervention \& } \\
\text { musculoskeletal } \\
\text { injury }\end{array}$ & $\begin{array}{l}\text { 2-month training } \\
\text { programme consisting of } \\
\text { functional exercises } \\
\text { aimed at improving core } \\
\text { stability, flexibility and } \\
\text { improper body } \\
\text { mechanics }\end{array}$ & $\begin{array}{l}\text { Historical } \\
\text { control } \\
\text { group }\end{array}$ & $\begin{array}{l}\text { Compared to historical control group lost time } \\
\text { due to injuries went down } 62 \% \text { and the total } \\
\text { amount of injuries decreased } 42 \% \text { following } \\
\text { intervention consisting of exercises to } \\
\text { strengthen core muscles } \\
\text { FMS score not reassessed post intervention }\end{array}$ \\
\hline
\end{tabular}




\subsection{Conclusion}

Low back pain is the most frequent complaint amongst rowers, with prevalence rates reported as between $24 \%$ and $81 \%$. A lack of consistency in the definition of low back pain amongst the literature may account for some of this reported variation. Differences in the competitive level of the rowers studied, may also account for some of this disparity. A number of possible risk factors for the development of low back pain in rowing have been suggested. It is important to define these factors and determine whether altering them will have an effect on its incidence in order to guide rehabilitation and prevention. In order to implement any intervention studies high quality incidence data is important. To date incidence data is lacking in New Zealand.

Functional screening of athletes is seen as an important part of a sports medicine team's job, and has been promoted as a strategy to minimise an athlete's injury risk, and enhance performance through the detection and subsequent correction of an individual's sports specific functional deficits. A number of screening tools have been developed that aim to achieve these goals. These screens have been investigated and found to be reliable tools in the measurement of athlete's functional movement patterns and or competency. However, these tools need to consistently show predictive validity at identifying athletes or individuals at increased risk of injury across different sports, levels of play, ages and genders before they are widely adopted (Smith et al., 2012). At present, there is inconsistency among the research as to the ability of functional screening tools to predict injury in sporting and occupational populations. There is no conclusive evidence that functional screening tool scores are related to sport specific performance (Okada et al., 2011; Parchmann \& McBride, 2011). However there is some encouraging research indicating that functional competency can be improved with 
an individualised training programme (Goss et al., 2009; Kiesel et al., 2011) and that injury prevalence can be reduced with functional core training and education (Peate et al., 2007). 


\section{Chapter Three}

\section{Methods}

\section{Introduction}

In the current study, the sample of interest was New Zealand national representative rowers from the 2011 rowing season. The type and amount of rowing training and competition as well as the extent of low back pain and its effect on training were collected. Furthermore, the movement competency of the participants was assessed and compared with the injury data. The following chapter describes how this was achieved.

\subsection{Study Design}

This study design was a longitudinal prospective cohort study.

\subsection{Participants}

In accordance with Auckland University of Technology (AUT) Ethics Committee requirements (see Appendix 1), 76 (46 males aged between 17 and 32 years (mean 22.72, SD: 4.15), 30 females aged between 18 and 29 years (mean 20.90, SD 3.52)) participants were recruited from 2011 New Zealand Rowing squads; elite, under 23 and junior (under 19).

All potential participants were informed of the study and asked to participate by a New Zealand Rowing staff member in accordance with ethical requirements. New Zealand Rowing was supportive of the study and happy to help facilitate recruitment. Once the participants had indicated an interest in the study they were then contacted by the principle researcher $(\mathrm{CN})$ and an information sheet (Appendix 2) along with consent 
forms (Appendix 3) were distributed. Once written consent had been received, ID numbers were issued to protect the participants' identity.

To be eligible for inclusion in this study, participants had to be selected to represent New Zealand at either an age group or elite level in rowing during the 2011 season.

Any participants who had been diagnosed with specific lumbar spine disorders such as, inflammatory disorders or neurologic conditions that would affect their participation were excluded from the study.

\subsection{Measurements}

\subsubsection{Questionnaire}

This study consisted of a self-reported survey using an on-line survey tool that was repeated monthly over a twelve-month period. The questionnaire was distributed to each participant via email by the online survey tool, Survey Monkey (www.surveymonkey.com). (For a copy of the questions please see Appendix 4). For those participants who did not have access to the internet or email (two participants), a hard copy of the questionnaire was available to be completed. Participants were asked to complete the questionnaire within one week of receiving it and reminders were sent via the website if this timeframe was exceeded. Follow-up questionnaires were sent out via the above methods monthly for a period of twelve months from the date of the initial questionnaire.

The variables of interest in the questionnaire were developed following the review of literature covered in the previous chapter. These were the rowing specific variables of rowing discipline, which are sweep oar rowing and sculling (see Chapter 2 for definition) and the amount and type of training load performed by the participants. The 
exposure of training load was determined by asking questions on the number and type of training sessions per week as well as the time spent (hours) training over the previous month and the number of kilometers rowed over the previous month. Training load was further divided into 'on water' sessions, rowing ergometer sessions and cross-training sessions. The amount of time spent training on-water over the previous month was determined by asking the average amount of time spent on the water per training session and multiplying this by the total number of on-water training sessions. The amount of training time spent on rowing ergometers was determined by asking the average amount of time spent per ergometer training session and multiplying this by the total number of training sessions.

The presence or absence of low back pain; for the purposes of this study low back pain was defined as: pain, ache, or discomfort in the low back with or without referral to the buttocks or legs (Bahr et al., 2004; Kuorinka et al., 1987) that has been present for greater than one week (O'Kane et al., 2003; Teitz et al., 2002; Teitz et al., 2003) and/or interrupted at least one training session. The period of one week was selected to define low back pain in order to differentiate a low back injury from that of short-term post exercise soreness that is common among elite athletes.

Severity of pain was measured by the Numeric Pain Rating Scale (NPRS) (Childs, Piva, \& Fritz, 2005). Participants who responded positively to the question "over the previous month have you experienced any new pain, ache or discomfort in the low back that has lasted for longer than one week (seven days) and or caused you to miss or modify at least one training session?" were asked to rate the severity of their pain "at its worst over this time" on the NPRS.

The effect on training was obtained by asking questions regarding the number of training sessions that were modified from the planned training session in regards to 
type, intensity or duration; or training sessions missed due to lower back pain over the period of time the athlete had back pain. Previously published injury severity criteria (Morgan \& Oberlander, 2001; Smoljanovic et al., 2009) was altered to include training modification. An incidental injury was defined as one that resulted in no time lost or modified from competition or training; minor injury, interrupted participation in any training sessions for a period of less than one week. Moderate injury necessitated absence from or modification of any training sessions for more than one week but less than one month, and major injury, causing absences or modification of greater than one month.

The categorical variables age, gender, age at commencement of competitive rowing and current level of competition were also collected. These categorical variables were only collected during the initial questionnaire.

Participants were also asked to keep a training diary for the duration of their involvement in the study to aid accurate recall of their training programme.

\subsubsection{Musculo-skeletal screening}

At the beginning of the study, participants underwent a series of screening tests which comprised of the Movement Competence Screen (MCS), an active straight leg raise test for hamstring extensibility, and trunk strength endurance testing. Hamstring extensibility and trunk strength endurance were assessed in addition to the MCS in order to test the hypotheses from previous studies that these factors increase the potential risk of low back pain in rowers (Reid \& McNair, 2000) and/or have been targeted clinically in the treatment of the condition (Perich et al., 2011). The primary investigator $(\mathrm{CN})$ assessed all of the subjects within the first three months of the start of the study. 
The MCS is a tool that consists of five tasks that challenge the fundamental movement patterns identified to exist in activities of daily living, sport and sport specific training (Kritz, 2012). These are the squat, lunge-and-twist, bend-and-pull, push-up, and a single leg squat.

\subsubsection{Procedure}

The MCS tasks were recorded from the frontal and sagittal planes using an iPhone video camera (Apple Inc, USA, Model A1332). The iPhone was positioned on a tripod in front of the athletes, perpendicular to the frontal plane to allow the frame of view to capture the individual from hands stretched overhead to below the feet. Tape was placed on the floor to guide the athlete's transition from sagittal to frontal viewpoints for each movement task. The MCS videos were analysed and scored by the investigator using QuickTime ${ }^{\mathrm{TM}}$ video software (Apple Inc. USA, Version 7.7.3) on completion of the testing.

Each athlete was asked to perform each movement task three times front on to the camera and three times to each side, that is, a total of nine repetitions per test. The athletes were all given the same simple verbal instructions on how to perform each test. If they were unsure of the instructions, the investigator would demonstrate the task.

\subsubsection{Body weight squat}

This task is a bilateral bodyweight squat and can be described as flexing at the hip and knee joints and descending until the top part of the thigh at the hip joint is lower than the knee joint, then ascending by extending the knee and hip joints to return to the start position. Subjects were asked to perform a double leg squat with their fingertips at the side of their head and to squat down as far as they could comfortably. 


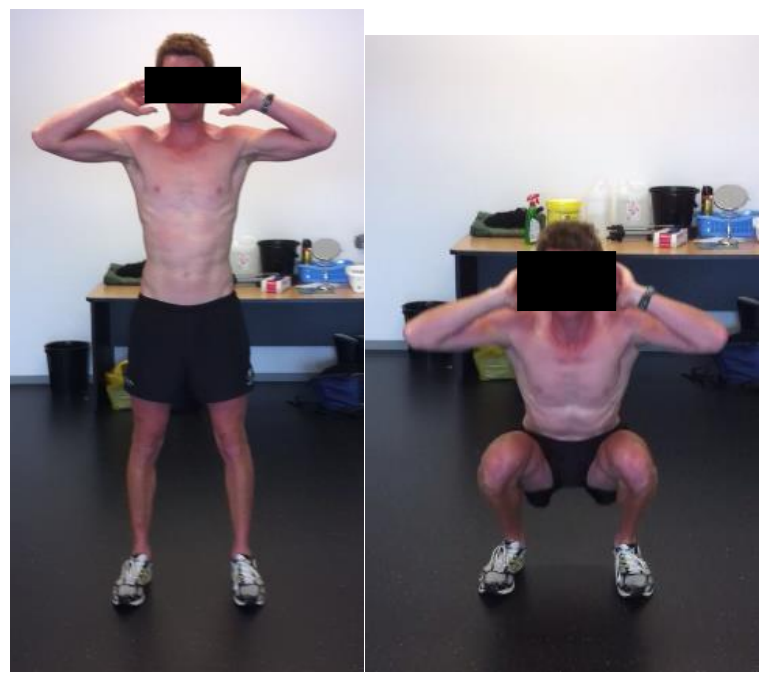

Figure 3.1 Body weight squat

\subsubsection{Lunge and Twist}

This task consists of a forward lunge with an upper body rotation. A forward lunge can be described as an elongated forward step, flexing the lead hip and knee and dorsiflexing the lead ankle while lowering the body toward the floor. At the bottom of the lunge, the subject rotated the upper body ipsilateral to the front leg, and then returned to the midline before returning to standing. Subjects were instructed to cross their arms and place their hands on their shoulders with elbows facing forwards. Perform a forward lunge and then rotate toward the front knee. Return to centre and then push back to return to the starting position.

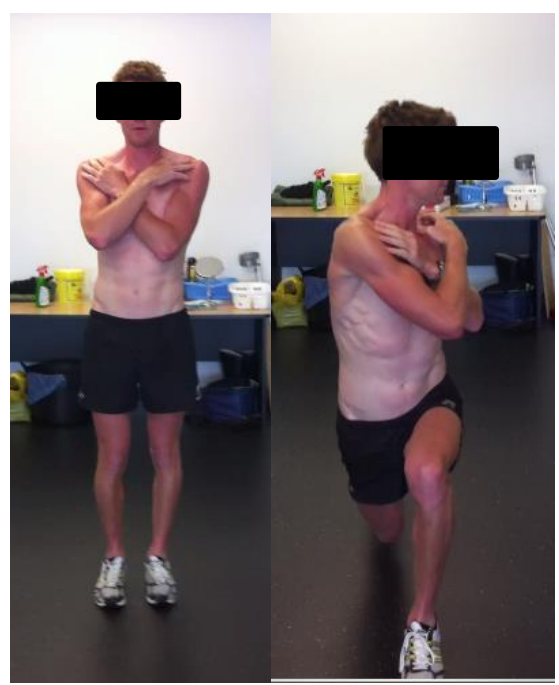

Figure 3.2 Lunge and twist 


\subsubsection{Bend and pull}

The body weight bend-and-pull is a hybrid exercise that involves two movement patterns, the bend pattern and the pull pattern. The task can be described as starting in a standing position with arms in full shoulder flexion and elbow extension. Initiating the movement with forward flexion of the trunk and hips keeping the knees extended, while at the same time extending the shoulders to a hanging position. The pull component consisted of bilateral shoulder extension to end range with elbow flexion. The subjects were instructed to start with their arms stretched overhead; bend forward allowing their arms to drop under their trunk. Pull hands into their body as if holding onto a bar and performing a barbell rowing exercise before returning to the start position with their arms stretched overhead.

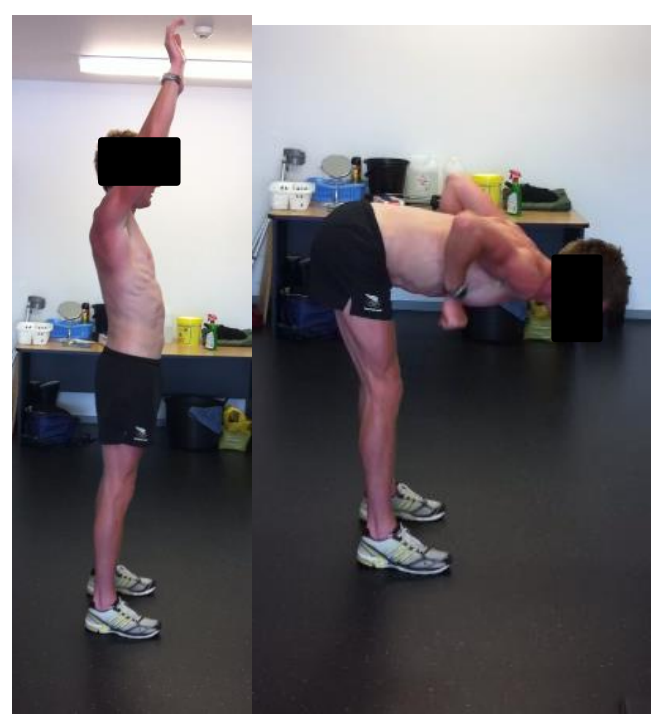

Figure 3.3 Bend and pull

\subsubsection{Push-up}

The push-up task involved subjects starting in prone in a full standard press-up position of weight bearing through their hands and toes with elbows fully extended and toes and ankles in dorsiflexion. The movement involved flexion of the elbows and extension of the shoulders, descending as low as possible, and then returning to the start position by 
extending the elbows and flexing the shoulders. Subjects were instructed to perform a standard push-up.

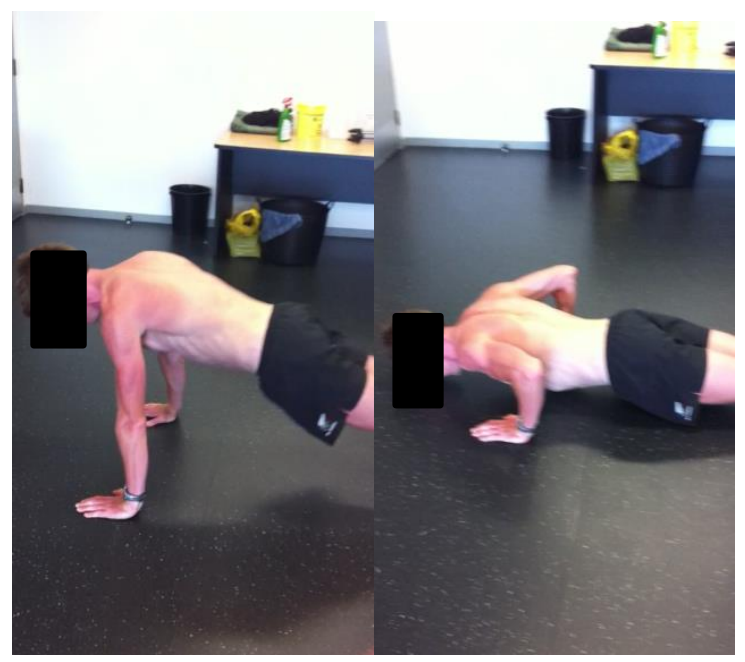

Figure 3.4 Push-up

\subsubsection{Single leg squat}

This task was a unilateral bodyweight squat and can be described as standing on one leg while flexing at the hip and knee joint and descending until the top part of the thigh at the hip joint is lower than the knee joint; then ascending by extending the knee and hip joint to return to the start position. Subjects were instructed to perform a single leg squat with their fingertips at the side of their head and their non-stance leg behind the body, and squat as low as they could comfortably.

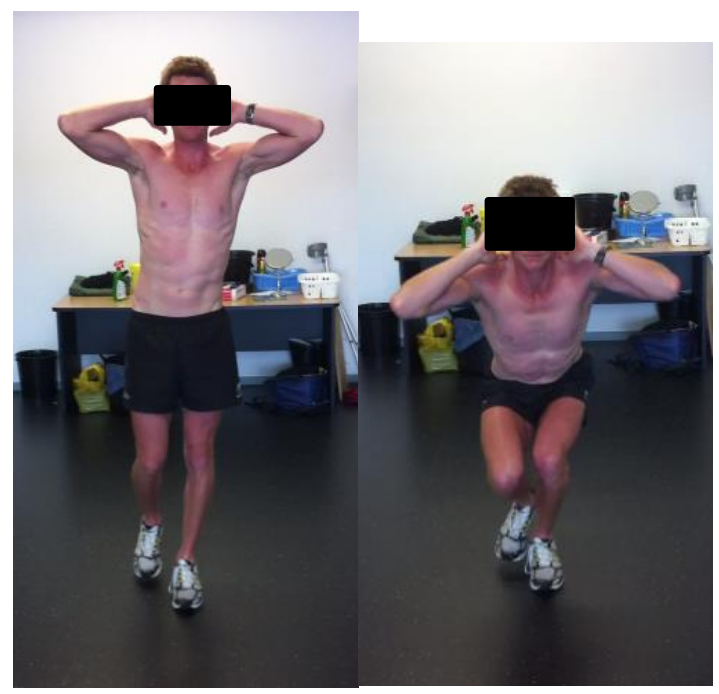

Figure 3.5 Single leg squat 


\subsubsection{Movement Competency Screen scoring}

The MCS is comprised of five separate fundamental movement patterns. For scoring purposes the lunge and twist, and bend and pull movements are divided into the lunge and the twist, and the bend and the pull respectively, giving seven scoring tests. Each test is scored from one to three depending on the competency of the movement, with one indicating poor movement and three indicating competent movement. This gives a total score out of 21. The competency of the participant's movement is graded based on the MCS scoring criteria (Appendix 5). For the purposes of this study, the MCS score was analysed as both a continuous variable and as a pass or fail, with a cut-off score of 16 or more being a pass.

\subsubsection{Active Straight Leg Raise}

This test was modified from previously published research (Cook et al., 2006) and was used to measure hamstring extensibility. Prior to testing the body landmarks of the greater trochanter of the knee and the midline of the lateral joint line of the knee were located and marked. A line was then drawn between these two points on the lateral thigh. Subjects adopted a supine position on a physiotherapy treatment table with the lumbar spine in a neutral position. They were then instructed to actively lift their leg off the bed as far as they could by flexing the hip and keeping the knee extended. The principle researcher placed a hand under the subject's lumbar spine to palpate when the spine started to flex, at which point the subject was instructed to stop flexing their hip. This position was held for approximately five seconds (including measurement time). If pain was experienced during the procedure, testing was stopped immediately. The aim of maintained a neutral lumbar spine was to minimise the effect of spinal movement on the measurement of hip range of motion. A goniometer (Smith \& Nephew Rolyan Inc, 
Germantown) with a spirit level fitted to the fixed arm was used to measure the straight leg raise angle to the nearest five degrees. The centre of the goniometer was positioned over the greater trochanter by the examiner. The fixed goniometer arm was levelled to the horizontal using the spirit level and the adjustable arm positioned on the previously marked landmark on the thigh. The examiner recorded the angle of hip flexion.

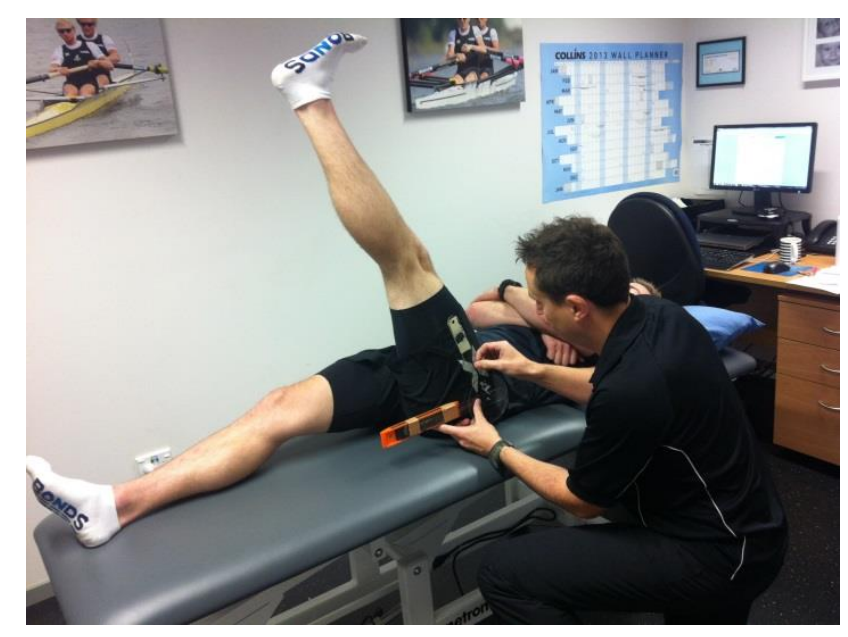

Figure 3.6 Active straight leg raise test used to assess hamstring flexibility

\subsubsection{Trunk extensor endurance test}

This test was modified from previously published research (Biering-Sorensen, 1984) and was used to measure isometric trunk musculature strength endurance. Subjects lay prone on a Roman chair back extension machine (Figure 3.6), an exercise tool commonly found in a gym, with the lower leg fixed under the upper calf and the pelvis resting on the front cushion with the subjects anterior superior iliac crests in line with the front of the cushion. The upper body was extended in a cantilevered fashion over the edge of the machine (Figure 3.6). At the beginning of the test, the upper limbs were held across the chest with the hands resting on the opposite shoulders, and the upper body was lifted until the upper torso was horizontal to the floor. Subjects were instructed to maintain the horizontal position as long as possible. If pain was experienced during the procedure, testing was stopped immediately. The endurance 
time was manually recorded in seconds with a stopwatch from the point at which the subject assumed the horizontal position until they could now longer maintain this position and dropped below the horizontal. One verbal warning was given if the subject dropped below the horizontal.

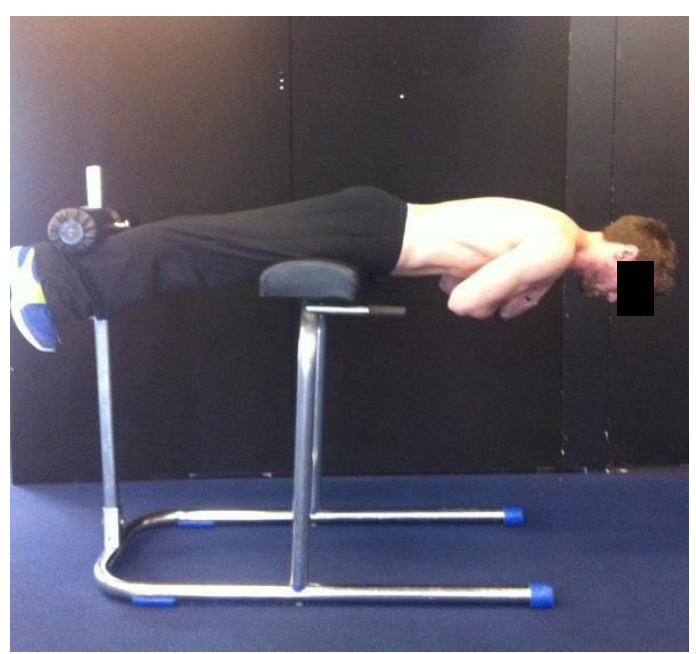

Figure 3.7 Modified Biering-Sorensen test over a roman chair used to assess trunk extensor strength endurance.

\subsubsection{Trunk flexor endurance test}

This test was modified from the previously reported research (McGill et al., 1999). Subjects sat on the floor leaning against a wooden box with a $55^{\circ}$ angled face (Figure 3.7). Both the knees and hips were flexed to $90^{\circ}$ and the arms were folded across the chest with the hands placed on the opposite shoulder. Both feet were anchored to the floor under two 30-kilogram dumbbells. When subjects were ready, the box was slid backwards away from the subject a distance of 10 centimetres. Subjects were instructed to hold their position and kept their trunk parallel to the box (as monitored by the examiner). Subjects were instructed to maintain the body position as long as possible. The endurance time was manually recorded in seconds with a stopwatch from the point at which the support was removed until the subject could no longer able to hold the position and came in contact with the box. 


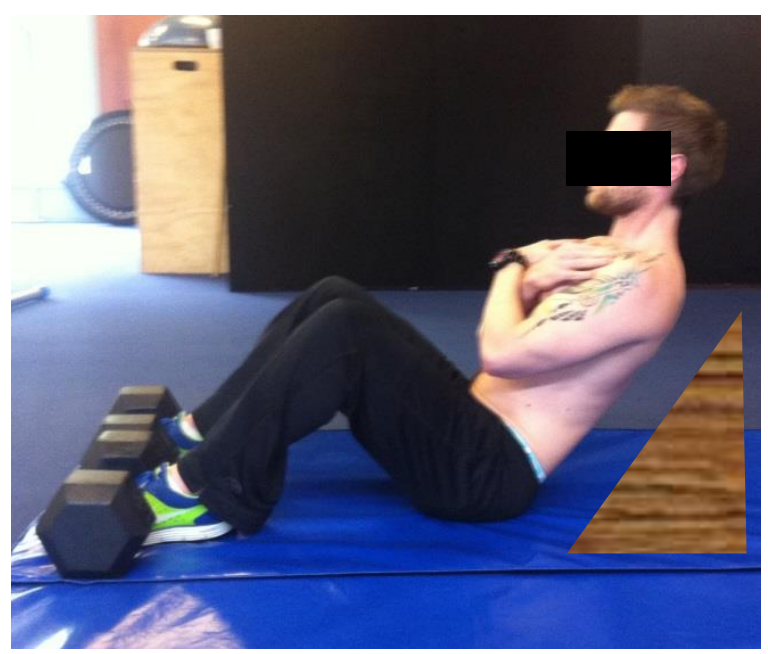

Figure 3.8 Modified flexor endurance test used to assess trunk flexor strength endurance

\subsection{Movement Competency Screen reliability study}

The principle researcher $(\mathrm{CN})$ of this study assessed all MCS screening tests, therefore it was important to establish the intra-rater reliability of the test. To determine this, a reliability study was performed within the main study. Ten of the recorded MCS videos were randomly selected by a third person to be recoded by $\mathrm{CN}$ using the MCS dichotomous screening criteria. The degree of intra-rater reliability was determined using the average measures intraclass correlation coefficient as was found to be high 0.82 (CI 0.58, 0.97, $\mathrm{p}=0.002)$.

\subsection{Data Analysis}

All data were initially analysed descriptively to ensure there were no extreme outliers and that the data were distributed normally. For the continuous variables the means and standard deviations were calculated, and for categorical variables frequencies were recorded. A descriptive analysis was performed to determine the incidence and prevalence rates of lower back pain and incidence was expressed as the number of positive responses per 1000 hours of exposure or training hours (Parkkari et al., 2004; 
Wilson et al., 2010). The incidence rates were calculated separately for each competition level (elite, non-elite).

Pearson correlations were used to determine any correlations between the amount of training and the incidence of back pain and a logistic regression model was constructed to determine the relationship between low back pain and possible risk factors.

The statistical analysis was undertaken using the Statistical Program for Social Science (SPSS) (IBM SPSS Inc, Chicago) Version 19 Alpha levels were set at 0.05. (95\% confidence level). 


\section{Chapter Four}

\section{Results}

\section{Introduction}

This chapter is divided into four sections that represent the main areas of the investigation. The first section provides a description of the subjects that participated in the study. The second section presents the results of the incidence and prevalence of low back pain found in the study. The third section of this chapter presents the results of the correlation analysis between low back pain and training load and the fourth section presents the correlation analysis between low back pain and possible risk factors for low back injury.

\subsection{Subjects}

One hundred and two athletes met the inclusion criteria of having represented New Zealand at rowing during the 2011 season. Of these 42 of them were senior elite athletes and the remainder were age group representatives. Of these 102 athletes contacted by Rowing New Zealand, 76 consented to take part in the study. With respect to the compliance rate, 59 subjects completed all twelve questionnaires (78\%) and of the total 912 questionnaires sent out over the year, $817(90 \%)$ were completed. Of those subjects that did not complete all the questionnaires, six stopped rowing during the season due to non-selection in teams (1), injury (3) and other reasons (2). The remaining eleven subjects whom did not complete all twelve questionnaires continued rowing during the season and either withdrew from the study (4) or missed one or more questionnaires (7). 
Data from seventy-six subjects were collected. There were forty-six males aged between 17 and 32 years (mean 22.72, SD: 4.15) and thirty females aged between 18 and 29 years (mean 20.90, SD 3.52). A descriptive analysis of all variables collected revealed no significant outliers and all continuous data were distributed normally. There was homogeneity of variance as assessed by Levene's Test for Equality of Variances. Therefore, an independent t-test was run on the data. No significant difference was found between males and females for the variables of age, the age the participant began rowing and number of years rowing $(\mathrm{p}>0.05)$. However there was a significant difference between these two groups for the variables of height, weight and BMI $(\mathrm{p}<0.05)$. Descriptive characteristics of the subjects are presented in Table 4.1.

Table 4.1 Subjects demographic data

\begin{tabular}{llllll}
\hline & \multicolumn{2}{l}{$\begin{array}{l}\text { Males } \\
\text { Mean (SD) }\end{array}$} & \multicolumn{2}{l}{$\begin{array}{l}\text { Females } \\
\text { Mean (SD) }\end{array}$} & p-value \\
\hline $\mathrm{N}$ & 46 & & 30 & & \\
\hline Age $($ years) & 22.7 & $(4.1)$ & 21.0 & $(3.5)$ & 0.05 \\
\hline Height $(\mathrm{cm})$ & 190 & $(5.2)$ & 176 & $(5.7)$ & $<0.0001^{* *}$ \\
\hline Weight $(\mathrm{kg})$ & 87.3 & $(8.6)$ & 71.8 & $(6.8)$ & $<0.0001^{* *}$ \\
\hline BMI & 24.1 & $(1.8)$ & 23.1 & $(1.6)$ & $0.02^{*}$ \\
\hline Age when began competitive rowing & 14 & $(2.0)$ & 14 & $(2.1)$ & 0.83 \\
\hline Years rowing & 8 & $(4.3)$ & 6 & $(3.3)$ & 0.07 \\
\hline *. Statistically significant at $\mathrm{p}<0.05$ & & & & & \\
**.Statistically significant at $\mathrm{p}<0.01$ & & & & &
\end{tabular}

Two of the subjects in the study (one male and one female) did not partake in the musculoskeletal screening component. No significant difference was found between males and females for the variables of MCS score and core strength endurance ratio ( $>0.05)$. Active SLR, for both left and right, was significantly higher in females than males $(\mathrm{p}=0.01)$. There was no significant difference found in active SLR between the left and right sides (right, mean 74.8 (10.6); left, mean 72.8 (16) $\mathrm{P}=0.01$ ). Subjects' musculoskeletal characteristics are presented in table 4.2 
Table 4.2 Subjects musculoskeletal screening scores

\begin{tabular}{llllll}
\hline & \multicolumn{2}{l}{$\begin{array}{l}\text { Males } \\
\text { Mean (SD) }\end{array}$} & \multicolumn{2}{l}{$\begin{array}{l}\text { Females } \\
\text { Mean (SD) }\end{array}$} & p-value \\
\hline $\mathrm{N}$ & 45 & & 29 & & \\
\hline MCS score & 15.6 & $(2.4)$ & 15.0 & $(2.1)$ & 0.31 \\
\hline Active SLR Left & 72.9 & $(9.5)$ & 80.3 & $(8.8)$ & $0.01^{*}$ \\
\hline Active SLR Right & 71.7 & $(9.9)$ & 79.7 & $(9.9)$ & $0.01^{*}$ \\
\hline Core Ratio ext/flex & 0.73 & $(0.19)$ & 0.68 & $(0.19)$ & 0.81 \\
\hline
\end{tabular}

*. Statistically significant at $\mathrm{p}<0.05$

Of the seventy-six subjects, forty-one were elite and thirty-five were non-elite athletes.

Elite rowers were on average five years older than non-elite rowers were $(p<0.0001)$ and this was reflected with the elite rowers having five more years' experience than the non-elite rowers $(\mathrm{p}<0.0001)$. Elite rowers were slightly taller than those in the non-elite group ( $\mathrm{p}=0.01$ ). No statistically significant differences were found between the groups for weight, BMI, age began rowing, MCS score, active SLR and core strength endurance ratio $(\mathrm{p}>0.05)$. The descriptive characteristics of these groups are shown in tables 4.3 and 4.4 .

Table 4.3 Descriptive characteristics of elite and non-elite athletes

\begin{tabular}{llllll}
\hline & $\begin{array}{l}\text { Elite } \\
\text { Mean }(\mathrm{SD})\end{array}$ & \multicolumn{3}{l}{$\begin{array}{l}\text { Non-elite } \\
\text { Mean }(\mathrm{SD})\end{array}$} & p-value \\
\hline $\mathrm{N}$ & 41 & \multicolumn{3}{l}{35} \\
\hline Age (years) & 24.4 & $(3.9)$ & 19.1 & $(1.3)$ & $<0.0001^{* *}$ \\
\hline Height $(\mathrm{cm})$ & 187 & $(8.3)$ & 182 & $(8.5)$ & $0.01^{*}$ \\
\hline Weight $(\mathrm{kg})$ & 83.5 & $(11.8)$ & 78.6 & $(9.5)$ & 0.05 \\
\hline BMI & 23.8 & $(1.9)$ & 23.7 & $(1.7)$ & 0.82 \\
\hline Age when began competitive rowing & 15 & $(2.1)$ & 14 & $(1.9)$ & 0.22 \\
\hline Years rowing & 10 & $(3.8)$ & 5 & $(2.4)$ & $<0.0001^{* *}$ \\
\hline
\end{tabular}

*. Statistically significant at $\mathrm{p}<0.05$

**.Statistically significant at $\mathrm{p}<0.01$

Table 4.4 Musculoskeletal screening scores of elite and non-elite athletes

\begin{tabular}{llllll}
\hline & \multicolumn{2}{l}{$\begin{array}{l}\text { Elite } \\
\text { Mean (SD) }\end{array}$} & \multicolumn{2}{l}{$\begin{array}{l}\text { Non-elite } \\
\text { Mean (SD) }\end{array}$} & p-value \\
\hline $\mathrm{N}$ & 41 & & 33 & \\
\hline MCS score & 15.3 & $(2.0)$ & 15.5 & $(2.7)$ & 0.65 \\
\hline Active SLR Left & 76.1 & $(8.9)$ & 75.5 & $(11.1)$ & 0.78 \\
\hline Active SLR Right & 74.1 & $(10.1)$ & 75.2 & $(4.8)$ & 0.56 \\
\hline Core Ratio ext/flex & 0.74 & $(0.21)$ & 0.68 & $(0.16)$ & 0.18 \\
\hline
\end{tabular}


Of the subjects $39(51 \%)$ were scullers and 37 (49\%) were sweep oar rowers. Chisquare tests revealed no statistically significant difference between disciplines in either male and female $\left(X^{2}=2.87, p=0.09\right)$ or elite and non-elite $\left(X^{2}=0.23, p=0.63\right)$ subjects. Table 4.5 shows the rowing specific characteristics of the subjects.

Table 4.5 Rowing specific characteristic of athletes

\begin{tabular}{lllll}
\hline & & \multicolumn{2}{l}{ Rowing Discipline } & \\
& & Sculling & Sweep Oar & p-value \\
\hline Gender & Male & 20 & 26 & 0.09 \\
& Female & 19 & 11 & \\
\hline Competition & Elite & 20 & 21 & 0.63 \\
level & Non-elite & 19 & 16 & \\
\hline
\end{tabular}

Of the seventy-six subjects, forty experienced at least one episode of new low back pain during the twelve-month period. No statistically significant differences were found between the low back pain and the no low back pain groups for age, height, weight, BMI, the age they began rowing, or the number of years they had been rowing. Chisquare tests also revealed no statistically significant difference between these groups for either gender $\left(X^{2}=0.10, p=0.92\right)$, rowing discipline $\left(X^{2}=0.46, p=0.50\right)$ or competition level $\left(\mathrm{X}^{2}=0.43, \mathrm{p}=0.51\right)$. The descriptive characteristics of these groups are shown in tables 4.6 and 4.7 .

Table 4.6 Descriptive characteristics of low back pain and no low back pain groups

\begin{tabular}{llllll}
\hline & \multicolumn{3}{l}{$\begin{array}{l}\text { Experienced any low back pain } \\
\text { No } \\
\text { Mean (SD) }\end{array}$} & \multicolumn{3}{l}{$\begin{array}{l}\text { Yes } \\
\text { Mean (SD) }\end{array}$} & p-value \\
& 36 & & 40 & & \\
\hline $\mathrm{N}$ & 21.3 & $(3.2)$ & 22.6 & $(4.5)$ & 0.15 \\
\hline Age (years) & 185 & $(8.8)$ & 184 & $(8.8)$ & 0.75 \\
\hline Height $(\mathrm{cm})$ & 81.3 & $(10.3)$ & 81.1 & $(11.7)$ & 0.92 \\
\hline Weight $(\mathrm{kg})$ & 23.7 & $(1.7)$ & 23.8 & $(1.9)$ & 0.88 \\
\hline BMI & 14.3 & $(2.1)$ & 14.5 & $(2.1)$ & 0.78 \\
\hline Age when began competitive rowing & 7 & $(3.7)$ & 8 & $(4.2)$ & 0.21 \\
\hline Years rowing & & & & & \\
\hline
\end{tabular}


Table 4.7 Rowing specific characteristics of the low back pain and no low back pain groups

\begin{tabular}{|c|c|c|c|c|c|}
\hline & & \multicolumn{3}{|c|}{ Experienced any low back pain } & \multirow[b]{2}{*}{ p-value } \\
\hline & & No & Yes & $X^{2}$ & \\
\hline \multirow[t]{2}{*}{ Gender } & Male & 22 & 24 & 0.10 & 0.92 \\
\hline & Female & 14 & 16 & & \\
\hline Rowing & Sweep oar & 19 & 18 & 0.46 & 0.50 \\
\hline Discipline & Sculling & 17 & 22 & & \\
\hline Competition & Elite & 18 & 23 & 0.43 & 0.51 \\
\hline Level & Non-elite & 18 & 17 & & \\
\hline
\end{tabular}

\subsection{Injury Incidence, Prevalence and Severity}

\subsubsection{Injury Incidence}

A total injury incidence rate of 1.667 (CI 1.666-1.667) per 1000 (total on water and ergometer training) hours was reported for all subjects with 72 new low back injuries reported over the twelve-month data collection period. A total of 43196 hours (average of 568.37 (29.15) hours per subject) was spent training and competing on water and on rowing ergometers. The cumulative incidence or incidence proportion over the twelvemonth period was $95 \%$. The elite athlete group of subjects reported a total injury incidence rate of 1.783 (CI 1.782-1.784) per 1000 hours with 43 new low back injuries in the twelve-month period. The cumulative incidence over the twelve-month period was $105 \%$. The non-elite athlete group of subjects total injury incidence rate reported was 1.520 (CI 1.519-1.521) per 1000 hours. The cumulative incidence over the twelvemonth period was $83 \%$.

Table 4.8 Low back pain incidence

\begin{tabular}{|c|c|c|c|c|c|c|c|c|c|}
\hline \multirow{2}{*}{ Level } & & & \multirow{2}{*}{$\begin{array}{c}\text { New } \\
\text { LBP } \\
\mathrm{N}\end{array}$} & \multirow[t]{2}{*}{$\begin{array}{l}\text { Total } \\
\text { Training } \\
\text { Hours }\end{array}$} & \multirow[t]{2}{*}{$\begin{array}{l}\text { Mean } \\
\text { Training } \\
\text { Hours }\end{array}$} & \multirow{2}{*}{$\begin{array}{l}\text { Std } \\
\text { Dev }\end{array}$} & \multirow{2}{*}{$\begin{array}{l}95 \% \\
\text { CI }\end{array}$} & \multirow{2}{*}{\multicolumn{2}{|c|}{$\begin{array}{c}\text { Injuries per } 1000 \\
\text { Training Hours } \\
95 \% \text { CI }\end{array}$}} \\
\hline & & $\begin{array}{c}\text { ipants } \\
\%\end{array}$ & & & & & & & \\
\hline Elite & 41 & 54 & 43 & 24120 & 588 & 30 & 0.297 & 1.78 & $(1.782-1.784)$ \\
\hline Non-Elite & 35 & 46 & 29 & 19077 & 545 & 27 & 0.288 & 1.52 & $(1.519-1.521)$ \\
\hline Total & 76 & 100 & 72 & 43196 & 568 & 29 & 0.210 & 1.67 & (1.666-1.667) \\
\hline
\end{tabular}


There was no statistically significant difference between the numbers of new low back injuries reported over the twelve-month period between the elite and non-elite subject groups $\left(\mathrm{X}^{2}=1.59, \mathrm{p}=0.21\right)$.

\subsubsection{Injury Prevalence and Severity}

Forty $(52.6 \%)$ of the subjects experienced at least one new episode of low back pain over the twelve-month period. Of these $21(52.5 \%)$ reported more than one new episode, that is, recurrent episodes of back pain throughout the year. Thirty subjects (75\%) experienced back pain lasting for more than one month, or responded positively to having back pain in two or more consecutive questionnaires. The prevalence of subjects experiencing low back pain at any point in time during the twelve-month period was $13.7 \%$.

Of these injuries, $45 \%$ were incidental, $29 \%$ were minor, $18 \%$ were moderate and $9 \%$ were severe. The mean severity of pain, as assessed by intensity rating on the NPRS scale, was 3.5 out of 10 (SD 1.9).

\subsubsection{Life-time Prevalence}

Forty $(52.6 \%)$ of the subjects reported having had experienced at least one episode of back pain previously. Of these $12(30 \%)$ were incidental, $11(28 \%)$ were minor, $7(18 \%)$ moderate and $10(25 \%)$ were major in severity. 


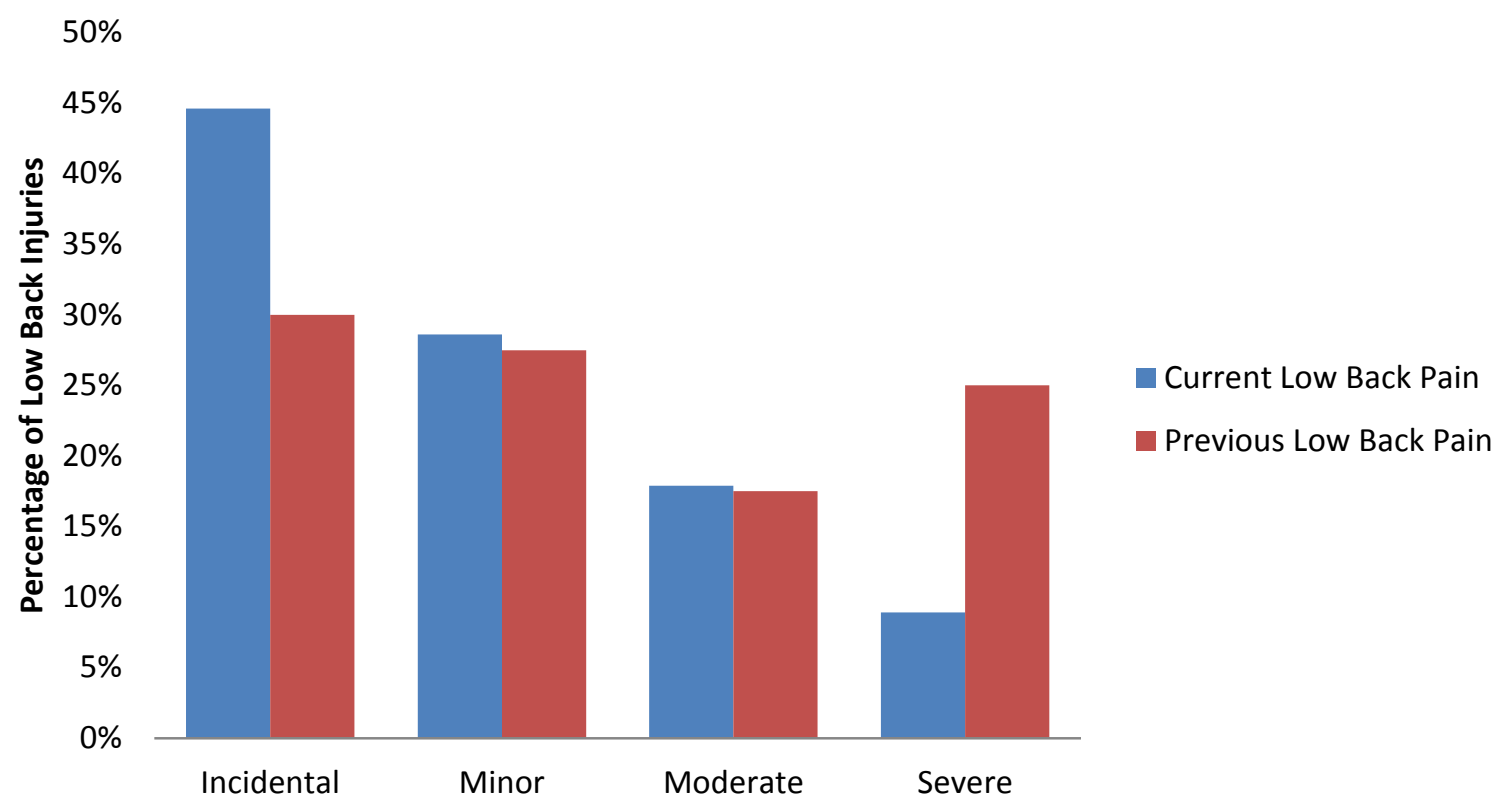

Figure 4.1 Severity of current and previous low back injuries as determined by number of trainings missed or modified

\subsection{Relationship between training load and low back pain}

\subsubsection{Relationship between training hours and distance rowed.}

There was a significantly positive correlation (see table 4.9) between the total training hours per month and the number of kilometres rowed per month $(0.98, \mathrm{p}<0.0001)$. There were significantly positive correlations between the total training hours per month and the average training hours per athlete per month $(0.98, \mathrm{p}<0.0001)$ and the average number of kilometres rowed per athlete per month $(0.95, \mathrm{p}<0.0001)$.

Table 4.9 Correlation between training hours and distance rowed

\begin{tabular}{|c|c|c|}
\hline \multicolumn{3}{|l|}{ Correlations } \\
\hline & \multicolumn{2}{|c|}{ Total Training Hours per Month } \\
\hline & Rho & p-value \\
\hline Total KM rowed per month & $0.981^{* *}$ & $<0.0001$ \\
\hline Ave training hours per athlete & $0.979^{* *}$ & $<0.0001$ \\
\hline Ave KM rowed per athlete & $0.949^{* *}$ & $<0.0001$ \\
\hline
\end{tabular}




\subsubsection{Relationship between new low back injuries and subjects currently experiencing low back injuries.}

There was a significantly positive correlation between the number of new low back injuries and those subjects currently experiencing low back pain per month $(0.94$, $\mathrm{p}=<0.0001)$.

\subsubsection{Relationship between training hours and low back injury}

There was a significantly positive high correlation between new low back injuries and total training hours per month $(\mathrm{r}=0.83, \mathrm{p}=0.001)$. There was a significantly positive high correlation between new low back injuries and per 1000 kilometres rowed per month $(\mathrm{r}=0.81, \mathrm{p}=0.001)$. There was also a significantly positive correlation between new low back injuries and total ergometer training hours per month $(\mathrm{r}=0.80, \mathrm{p}=0.002)$.

In order to control for those subjects who had left the study, training load was also averaged per subject per month. This revealed a significantly positive high correlation between new low back injuries and the average training hours per subject per month $(\mathrm{r}=$ $0.73, \mathrm{p}=0.007)$. There was a significantly positive high correlation between new low back injuries and the average number of kilometres rowed per subject per month $(\mathrm{r}=0.71, \mathrm{p}=0.01)$. 


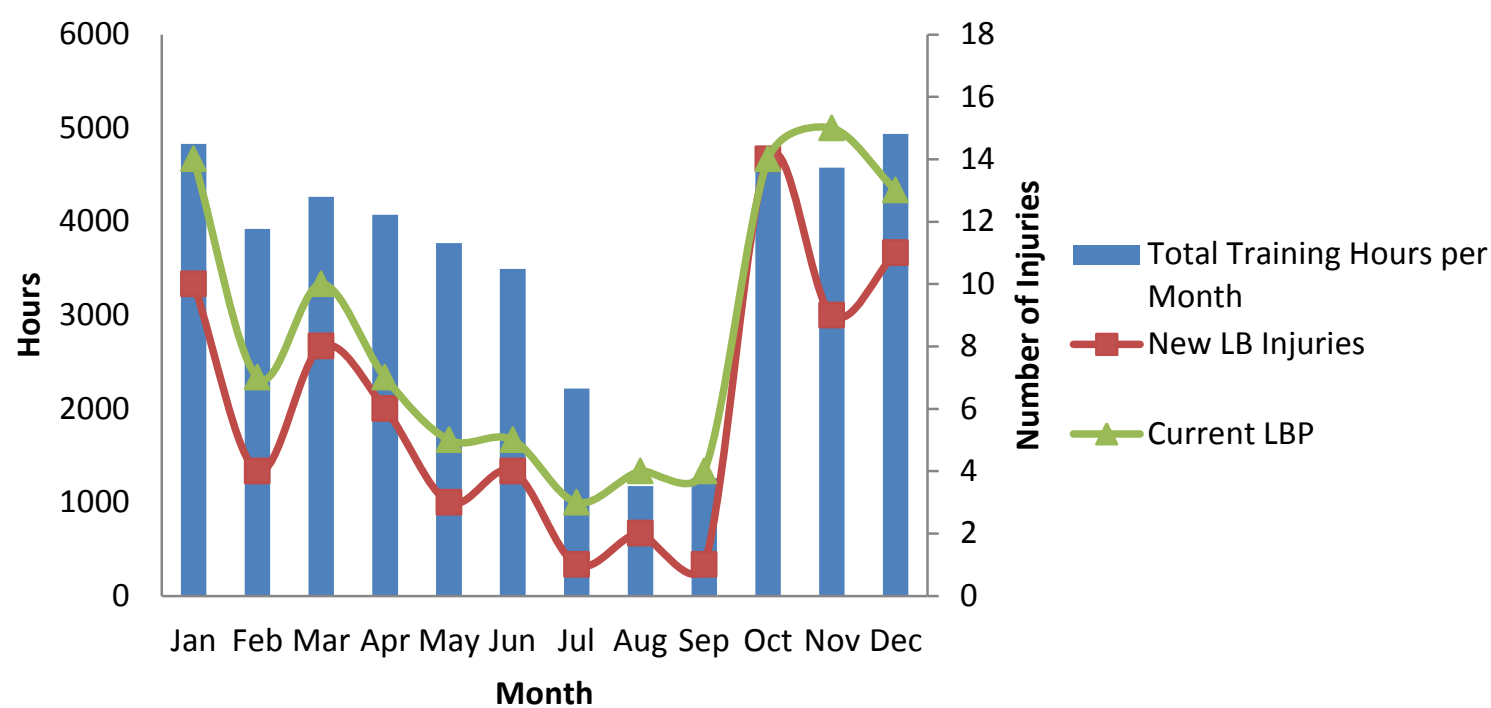

Figure 4.2 Relationship between total monthly training hours and number of low back pain cases per month over the twelve-month period.

\subsection{Association between possible risk factors, movement competency and low back pain.}

\subsubsection{Association between new low back injuries and possible risk factors.}

To determine the relationship between possible risk factors and experiencing a new episode of back pain during the twelve-month period a full logistic regression model was constructed using the longitudinal data set. New episode of low back pain was the dependent variable and this was compared with age, gender, BMI, MCS score, ASLR, trunk strength-endurance ratio, the age subjects began rowing, the number of years rowing and competition level. The estimated risk of developing a new low back injury increased by 2.06 times if a subject had had a previous episode of back pain $(\mathrm{p}=0.01$, table 4.10); and risk increased by 1.08 times for every increase in year of age of the subjects ( $\mathrm{p}=0.02$, table 4.10). Subjects who had an MCS score of 16 or more out of 21 were 1.58 times more likely to develop low back pain than those with a score of 15 or less out of 21 ; however this was not a statistically significant finding $(\mathrm{p}=0.08$, table 
4.10). None of the other variables reached a significance threshold of $p<0.10$, indicating no association with new low back pain. Gender, BMI and rowing discipline were retained in the final model as they were considered important factors. See appendix 6 for the regression analysis output for these variables.

Table 4.10 Relationship between new low back pain and risk factors

\begin{tabular}{lllll}
\hline Variable & OR & p-value & $\begin{array}{l}95 \% \\
\text { Interval }\end{array}$ & Confidence \\
\hline Age & 1.08 & $0.02^{*}$ & 1.01 & 1.15 \\
Gender & 1.07 & 0.81 & 0.62 & 1.86 \\
BMI & 1.02 & 0.84 & 0.87 & 1.18 \\
Rowing Discipline & 0.79 & 0.37 & 0.48 & 1.31 \\
History of previous LBP & 2.06 & $0.01^{* *}$ & 1.22 & 3.48 \\
MCS score & 1.58 & 0.08 & 0.95 & 2.65 \\
\hline
\end{tabular}

*. Significant at the 0.05 level

**. Significant at the 0.01 level

\subsubsection{Association between any low back injury and possible risk factors.}

To determine the relationship between possible risk factors and subjects having had experienced at least one episode of back pain over the twelve-month collection period, a cross-sectional logistic regression model was constructed. Subjects who had experienced any low back pain over the twelve-month period was the dependent variable and this was compared with age, gender, BMI, MCS score, ASLR, trunk strength-endurance ratio, the age subjects began rowing and the number of years rowing.

The estimated risk of developing an episode of low back pain was 3.40 times greater if a subject had had a previous episode of back pain $(\mathrm{p}=0.02$, table 4.11). Subjects who had an MCS score of 16 or more out of 21 were 2.57 times more likely to develop low back pain than those with a score of 15 or less out of 21 ; however this did not reach statistical significance $(\mathrm{p}=0.07$, table 4.11$)$. None of the other variables reached a significance threshold of $\mathrm{p}<0.10$ indicating no association with low back pain cases. Gender, BMI 
and rowing discipline were retained in the final model as they were considered important factors. See appendix 6 for the regression analysis output for these variables.

Table 4.11 Relationship between any low back pain and risk factors

\begin{tabular}{lllll}
\hline Variable & OR & p-value & $\begin{array}{l}95 \% \\
\text { Interval }\end{array}$ & Confidence \\
\hline Age & 1.11 & 0.12 & 0.97 & 1.27 \\
Gender & 0.72 & 0.56 & 0.24 & 2.19 \\
BMI & 1.02 & 0.91 & 0.76 & 1.37 \\
Rowing discipline & 0.79 & 0.65 & 0.28 & 2.22 \\
History of previous LBP & 3.40 & $0.02 *$ & 1.23 & 9.38 \\
MSC score & 2.57 & 0.07 & 0.90 & 7.33 \\
\hline
\end{tabular}

*. Significant at the 0.05 level

\subsubsection{Association between previous history of low back pain and possible risk}

\section{factors}

To determine the relationship between a having a previous history of low back pain and possible risk factors, a cross-sectional logistic regression model was constructed. History of low back pain was the dependent variable and was compared with age, gender, BMI, MCS score, active SLR, trunk strength-endurance ratio, the age subjects began rowing, the number of years rowing and competition level.

The analysis found there was no statistically significant association between having a history of low back pain and the variables in this model as none of the variables reached a significance threshold of $\mathrm{p}<0.10$. See appendix 7 for output analysis.

Table 4.12 Relationship between previous low back pain and risk factors

\begin{tabular}{lllll}
\hline Variable & OR & p-value & $\begin{array}{l}95 \% \\
\text { Interval }\end{array}$ & Confidence \\
\hline Age & 1.01 & 0.20 & 0.96 & 1.23 \\
Gender & 1.24 & 0.69 & 0.43 & 3.57 \\
BMI & 1.01 & 0.96 & 0.75 & 1.34 \\
Rowing discipline & 0.55 & 0.23 & 0.21 & 1.46 \\
MCS score & 0.88 & 0.79 & 0.34 & 2.29 \\
\hline
\end{tabular}




\section{Chapter Five}

\section{Discussion}

\subsection{Subjects}

All the subjects in this study had been New Zealand National representative rowers during the 2011 season, at either a senior or age group level. One of the strengths of this study is the high compliance rate achieved. Seventy-five percent of the rowers who were eligible for the study agreed to participate, therefore this study is representative of the full international rowing population of the country. In addition to this, $90 \%$ of the possible 912 questionnaires were completed by $78 \%$ of the subjects.

The average age of the subjects in this study was 22.72 years for the males and 20.96 years for the females, with a range of between 17 and 32 years. This is a similar age demographic to previous research into rowing injuries among elite level athletes (Bahr et al., 2004; Hickey et al., 1997). Bahr et al. (2004) investigated low back pain among national representative Norwegian rowers who had an average age of 21 years for the males and 22 years for the females. Hickey et al. (1997) retrospective study of rowing injuries among Australian Institute of Sport scholarship holders had an average age at the start of scholarship of 21.3 years for the males and 20.3 years for the females. In their study of senior Irish national rowers (Wilson et al., 2010) the average age of 26.25 years is somewhat higher than overall average age of the current study subjects; however it is similar to the mean age of the elite level subjects of 24.4 years. Consideration of the subjects' age and competition level needs to be taken when comparing the results of the current study with other previous research (Perich et al., 2011; Smoljanovic et al., 2009). Perich et al (2011) investigated low back pain among 
school level female rowers with an average age of 14.7 years, ranging from 14 to 17 years and Smoljanovic et al. (2009) investigated junior elite rowers with an average age of 18 years.

Not surprisingly, there was a significant difference between the males and females in this study with respect to their height and weight, with the males on average being 14 centimetres taller and 15.5 kilograms heavier than their female counterparts were. However, there was no difference in overall BMI. These BMI scores are considered within the "normal" range for this age group (Kuczmarski, Carroll, Flegal, \& Troiano, 1997).

No significant difference was found between males and females for the variables of MCS score and core strength endurance ratio. There was a significant difference found in the variables of active SLR between males and female groups with the females having, on average, hamstring flexibility of eight degrees SLR more than the males. This is similar to previous research that has found that on average females have more flexible hamstrings than males (Minkler \& Patterson, 1994).

Of the seventy-six subjects, forty-one were elite and thirty-five were non-elite or age group athletes. Elite rowers were on average five years older than non-elite rowers and this was reflected with the elite rowers having five more years' experience than the nonelite rowers. Therefore, the incidence data for both groups was calculated individually as well in combination. The elite group of rowers were on average five centimetres taller than those in the non-elite group. No statistically significant differences were found between the groups for weight, BMI, age began rowing, MCS score, active SLR and core strength endurance ratio. 
Of the seventy-six subjects, forty experienced at least one episode of new low back pain during the twelve-month period. When the group of low back pain cases was compared to those subjects who had not experienced any low back pain there was no statistically significant differences found between them for any of the variables of gender, age, height, weight, BMI, the age they began rowing, the number of years they had been rowing, rowing discipline or competition level.

\subsection{Incidence, Prevalence and Severity of Low Back Pain}

\subsubsection{Incidence rate}

One of the primary objectives of this study was to determine the incidence rate of low back pain among New Zealand rowers and compare this across different competitive levels. The incidence rate in the current study was found to be 1.68 injuries per 1000 rowing specific (that is, on water and rowing ergometer training combined) training hours. The incidence rate of low back pain amongst the elite group of athletes was slightly higher than that of the non-elite group with injury rates reported as 1.78 for the elite group and 1.52 for the non-elite group per 1000 rowing specific training hours. This difference might be explained by the difference in age between the two groups, with the elite athletes being a mean of five years older than the non-elite athletes, rather than differences in the amount or type of training completed.

Comparison of the incidence rate of low back pain in this study with previous research is difficult due to the low number of prospective cohort studies in the sport of rowing. The one previously published study that looked at injury incidence rate among rowers (Wilson et al., 2010) reported an incidence rate of 1.31 lumbar spine and sacroiliac joint injuries per 1000 hours of combined training and competing. This is similar to the rate found in the current study. It is worth noting that Wilson et al. (2010) included cross 
training, weight training and core stability training hours in the exposure time when calculating their incidence rate. It is likely that if these training hours were included in the current study, the incidence rate found would be very similar between the two studies.

\subsubsection{Prevalence rate}

Over the twelve-month collection period, there were 72 new low back injuries reported and therefore the cumulative incidence over the twelve-month period was $95 \%$. The prevalence of subjects experiencing low back pain at any point in time during the twelve-month period was $13.7 \%$. This prevalence rate is low in comparison with Bahr et al. (2004) who reported a point prevalence of $25.3 \%$ among the rowers in their study, and with Stutchfield \& Coleman (2006) who reported a point prevalence of $42 \%$ among their study group of University level rowers. It is also low in comparison with Perich et al. (2006) who reported a point prevalence of $47.5 \%$ among adolescent female rowers (Perich et al., 2006).

Forty $(52.6 \%)$ of the subjects experienced at least one new episode of low back pain over the twelve-month period. This is very similar to the prevalence of low back pain of $55.3 \%$ over a twelve-month period among Norwegian national elite level rowers (Bahr et al., 2004). It is somewhat higher than the $32 \%$ prevalence of low back pain among American rowers reported over their intercollegiate rowing careers (Teitz et al., 2002) and that of $21.3 \%$ among elite junior rowers during a season (Smoljanovic et al., 2009). When comparing these results, consideration needs to be made to the fact that these last two studies were retrospective in nature and therefore more susceptible to recall bias. The study by Teitz et al. (2002) covered a 20 -year period and only $46 \%$ of the surveys were returned. 
Of the subjects who experienced low back pain over the twelve-month period, 21 $(52.5 \%)$ reported more than one new episode, that is, recurrent episodes of back pain throughout the year. This recurrence rate is somewhat higher than the $24 \%$ to $33 \%$ incidence of recurrence reported in a cohort study investigating the prognosis and diagnosis of low back pain in primary care in Sydney, Australia (Stanton et al., 2008). However, again there is a wide range of between $24 \%$ to $80 \%$ recurrence rates at one year reported in other studies (Hoy, Brooks, Blyth, \& Buchbinder, 2010). In the current study, an attempt was made to determine if subjects were experiencing a new episode or a recurrent episode of low back pain, or the back pain they were currently experiencing was unresolved pain from the previous questionnaire. Subjects were asked if they were currently experiencing low back pain. If they responded positively to this the follow-up question was "is this back pain NEW, i.e. wasn't present in the previous months questionnaire". Therefore, this provides the rate of true recurrences rather than flareups of low back pain. It would seem therefore that after the resolution of an acute episode of low back pain, one in two New Zealand rowers have recurrence within twelve months. This is higher than that of one in four in the general population of Australians (Stanton et al., 2008).

\subsubsection{Lifetime Prevalence}

Lifetime prevalence of low back pain was determined by asking the subjects in this study if they had ever experienced low back pain that had lasted longer than one week or caused them to miss or modify any planned training session or competition. Forty $(52.6 \%)$ of the subjects reported having had experienced at least one episode of back pain previously. When making comparisons to previous studies there is a large variation in the reported lifetime prevalence of low back pain among rowers (Bahr et al., 2004; Stutchfield \& Coleman, 2006; Teitz et al., 2002; Wilson et al., 2004). This is between 
$32 \%$ among intercollegiate rowers (Teitz et al., 2002) to $81 \%$ among English club rowers (Stutchfield \& Coleman, 2006). The only study that reports lifetime prevalence among elite level rowers, (Bahr et al., 2004) and is therefore most relevant to compare to the current study, found this to be $63.3 \%$. However the definition of back pain in the Bahr et al. (2004) study was "pain, ache or discomfort in the low back with or without radiation to one or both legs (sciatica)' and is therefore slightly different to the current study as there is no specification on how long the pain needed to last to be classed as an injury. Hoy et al. (2010) in their review of the epidemiology of low back pain found that those studies that included a minimum episode duration of pain, where one day was the most common. These studies had a slightly lower prevalence reported than those that did not have a minimum duration in their definition (Hoy et al., 2010). Therefore, it is possible that by having minimum episode duration of one week, the current study would have a lower prevalence reported.

It is interesting to note that prevalence rate of low back pain in the general population in similar age ranges is also comparable to that found in the current study (Hill \& Keating, 2009; Hoy et al., 2010; Leboeuf-Yde \& Kyvik, 1998; McMeeken et al., 2001). For example the high prevalence rate of low back pain by the mid-teens is similar to the rates found in adults (Hill \& Keating, 2009). Life time prevalence rates have been reported as between 11 and 84\% (Hill \& Keating, 2009), one year prevalence rates from $0.8 \%$ to $82.5 \%$ with a mean of $38.1 \%$, and point prevalence between $1 \%$ and $58.1 \%$ with a mean of $18.1 \%$ (Hill \& Keating, 2009; Hoy et al., 2010).

Low back pain prevalence rate has been found to gradually increase with age in the general population (Hill \& Keating, 2009; Leboeuf-Yde \& Kyvik, 1998; McMeeken et al., 2001) and this finding is consistent with the finding of the current study. LeboeufYde and Kyvik (1998) in their study of 29424 twins found that lifetime prevalence 
surpassed $50 \%$ at 18 years of age for girls, and 20 years of age for boys, after which it stayed relatively stable until middle age.

It would seem therefore that the New Zealand rowers in the current study are at no greater risk of having at episode of low back pain at either a point in time, over a twelve-month period or life-time than that of the general population of a similar age group. This correlates with the findings of previously reported studies (Foss et al., 2012; Teitz et al., 2003). In addition, as it is well known among the rowing population that low back pain is a common problem, and also the injury that causes the most interruption to training, it is likely that these athletes may have a lower threshold for reporting and remembering episodes of low back pain than the general population. A strength of the current study is also the fact that subjects were followed up monthly over a twelve-month period and therefore recall bias will be less than that of some other studies, further increasing the reported prevalence of low back pain compared to other studies.

\subsubsection{Severity}

An objective of this study was to determine the severity of low back pain among New Zealand rowers as it relates to the effect on training and competition. It was found that approximately three out of four of the reported episodes of pain were either incidental $(45 \%)$ or minor $(29 \%)$, meaning that subject's did not miss or modify any of their training sessions and/or competitions; or missed or modified training or competition for under a week. Of the remaining quarter of the injuries, $18 \%$ were moderate and caused the subjects to miss or modify training and or competition for between one week and one month; and 9\% were major, resulting in greater than one month of training modification. Of the major injuries, three of the subjects retired from rowing because of on-going back pain. This equated to $4 \%$ of the cohort, which is lower than that reported 
in a college rowing population (O'Kane et al., 2003; Teitz et al., 2003). Interestingly, of those subjects who reported having experienced a previous history of low back pain, $30 \%$ of the episodes were incidental, $28 \%$ minor, $18 \%$ moderate and $25 \%$ were major. The lower percentage of incidental and minor low back pain episodes and the relatively high percentage of major episodes reported, in comparison to that of current episodes, might indicate an under reporting of previous low back pain. It is likely that athletes do not recall as readily the less severe previous injuries, especially those that have not affected their training.

Thirty subjects $(75 \%)$ of the 40 who experienced low back pain over the twelve-month period, experienced low back pain that lasted for more than one month, or responded positively to having back pain in two or more consecutive questionnaires. This indicates that in most of the cases the subjects were experiencing low back pain for a longer period than the length of time their training was affected. Therefore, in this population, the effect on training is a more relevant indicator of injury severity than the duration of symptoms.

This distribution of injury severity is very similar to that reported among elite junior rowers (Smoljanovic et al., 2009) of 49\% incidental, 31\% minor, 16\% moderate and 5\% major; and that of intercollegiate rowers who had experienced low back pain prior to starting rowing (O'Kane et al., 2003) of 79\% incidental and minor, $15 \%$ moderate and $6 \%$ major injuries. O'Kane et al. (2003) found that those subjects with back pain who had not experienced low back pain before starting rowing were more likely to miss practice with $62 \%$ of these injuries incidental or minor, $20 \%$ moderate and $18 \%$ major.

Wilson et al. (2010) established the severity of injury by the number of training and racing hours lost due to injury. They found that when the number of hours completed by the injured subjects was compared to the non-injured cohort, a number of the injured 
subjects completed more training hours than their non-injured counterparts (Wilson et al., 2010). Therefore time lost is a very poor indicator of injury severity (Wilson et al., 2010). When an athlete suffers an injury, it is likely that they will substitute their planned training session for a cross-training session that they are able to complete without aggravating their symptoms. It is unusual for them to stop training completely. By including sessions modified from that planned in terms of type, time and intensity, the current study's findings reflect a more accurate picture of injury severity.

With over $50 \%$ of subjects in the current study suffering low back pain over a twelvemonth period, and a quarter of these causing subjects to miss or modify more than weeks training, low back pain causes a significant interruption to rowers' preparation for competition. Of particular concern are those $9 \%$ that modify their training for over one month and for some, low back pain is a significant factor in their retirement from the sport. It is interesting to note that the twelve-month period that this study took place was during the 2012 Olympic Games season. This was New Zealand Rowing's most successful year ever with respect to podium finishers at the Olympic Games and the respective age group World Championships. Therefore, although it is clear that low back pain has a significant effect on rowing training, it is less clear to what extent this affects performance or rowing success. Another factor to be considered in the current study is that a number of the participants have been in the rowing New Zealand system for a number of years and have undergone previous screenings and proactive training so the low prevalence and severity results may relate to the system that they are in. Therefore, it is important to continue monitoring this area. 


\subsection{Relationship between training load and low back pain.}

\subsubsection{Training load and low back pain}

A significant finding in this study was the high correlation between rowing specific training load and both new low back pain and current back pain among the subjects. Low back pain was highly correlated with both the total number of training hours and the number of kilometres rowed per month. This clearly shows that as training load increases so does the incidence of low back pain among the subjects. This supports the findings of Smoljanovic et al. (2009) who found that junior rowers, who averaged more than seven training sessions per week, had more overuse low back pain than those with fewer training sessions per week. Bahr et al. (2004) and Wilson et al. (2010) found more low back pain during periods of higher competition and training load. It also supports the findings from the study by Wilson et al. (2010) who found an association between high on-water training volume and injury rate; however, in their study this association was not found to be statistically significant. Kinematic studies of spinal motion have found that spinal motion markedly increases with prolonged rowing (Holt, Bull, Cashman, \& McGregor, 2003) and there are important changes to lumbo-pelvic and spinal kinematics with increasing work intensity levels (Caldwell et al., 2003; McGregor, Bull, \& Byng-Maddick, 2004; McGregor, Patankar, \& Bull, 2005). Although these studies have investigated these changes during ergometer rowing, it is possible that these changes are important in explaining the relationship between high training load and the new low back pain found in the current study.

The current study also found a significant relationship between ergometer training and low back pain. The time spent ergometer training has previously been reported as having a significant impact on low back pain (Smoljanovic et al., 2009; Teitz et al., 
2002; Wilson et al., 2010) with ergometer training for more than 30 minutes being the most significant predictor of back pain for all age groups of rowers (Teitz et al., 2002). Interestingly, in the current study, no subject, in any of the questionnaires who reported doing ergometer training during the previous month averaged less than 30 minutes per training.

Another factor to consider when comparing the current study to other research that investigated the relationship between training load and low back pain, is that those studies were either undertaken or included athletes from parts of the Northern Hemisphere where on-water training is difficult over the winter months due to the weather conditions (Bahr et al., 2004; Smoljanovic et al., 2009; Wilson et al., 2010). It is likely that cross-training in these populations is a bigger part of the yearly training regime than that of New Zealand rowers.

\subsubsection{Time of year injuries occur}

When the timing of low back pain occurrences was analysed, there appeared to be a peak over the summer months from October to January (Figure 4.2). From February to September, there was a general trend of the rate of low back pain decreasing. The months with the lowest rate of low back pain being July, August and September which corresponds with the seasons pinnacle competition events and the off-season. There are a number of possible reasons for this monthly pattern in low back pain occurrence. As mentioned in the previous section, there is a strong correlation between training load and low back pain, and the peak in injury occurrence corresponds with the months of highest volume of training. Conversely, the time of year of the lowest rate of injury corresponds with the lowest training volume, and the off-season, for the majority of the studies subjects. It is also possible that the type of training varies depending to the time of the season. For example, over the summer months from October to January, training 
consists of long kilometre, aerobic based training rows and often increased, unaccustomed cross training; whereas leading into the international competition period in June, July and August the training rows become shorter and more intense, speed based training. A third possible factor is that the majority of the subjects in this study were elite athletes who spend a significant portion of the year training and competing in the Northern Hemisphere. The rate of occurrence of low back pain is lower over this period than during the summer months when they are training at home.

This monthly pattern of injury is very similar to previous findings (Hickey et al., 1997; Wilson et al., 2010) both of whom were investigating elite level athletes, both in the Northern and Southern Hemispheres, therefore supporting the argument that injury rate follows the type and amount of training occurring depending on the time of the rowing season.

Another relevant observation from the time of year analysis is the sudden increase in new low back pain episodes in the month of October. It would appear that this is related to the rapid increase in training load as the athletes come out of their off-season. Previous research has noted that sudden changes in training load, in terms of intensity, duration and frequency, in adolescent athletes increases the risk of low back pain (Duggleby \& Kumar, 1997). It is possible that education of coaches regarding this risk factor and safe increases in training load at this particular time of the year would be beneficial in reducing this sudden increase in incidence of low back pain. 


\subsection{Risk factors}

\subsubsection{Correlation between movement competency and the development of low}

\section{back pain}

The secondary objective of this study was to investigate the relationship between functional movement patterns as assessed by the Movement Competency Screen (MCS), and the development of low back pain. The MCS scores were analysed as both a continuous variable and categorical variable using a cut-off score of 16 as an acceptable level of movement competence. This was done in order to help compare these results with research previously performed on movement screening tools that have used a dichotomised pass/fail score. The score of 16 was chosen, as this was both the mean and median score of the cohort. The longitudinal analysis of MCS score and the development of new back pain throughout the twelve-month period found that those subjects who had an MCS score of 16 or more out of 21 were 1.6 times more at risk of developing a new episode of low back pain than those with a score below 16. On crosssectional analysis, those subjects who had a MCS score of 16 or more were 2.6 times more likely to have had at least one episode of low back pain during the year. Although neither of these findings reached statistical significance, they are somewhat surprising as it implies that those subjects who had a better MCS score, and therefore moved better, were more at risk of injuring their low back throughout the year. It is generally believed and promoted among the sports medicine community that screening functional movement patterns is important as an injury prevention strategy and performance strategy (Batt, Jaques, \& Stone, 2004; Chorba et al., 2010; Comerford, 2006; Cook et al., 2006; Frohm et al., 2012; Kiesel et al., 2007; Minick et al., 2010) as it is thought that inefficient movement strategies may reinforce poor biomechanical movement patterns and lead to injury (Chorba et al., 2010). The findings of the current study 
would tend to question these assumptions when it comes to low back injuries in the sport of rowing. These results are in contrast to previous studies that have investigated the relationship between functional movement screening test scores and injury, in both sporting (Chorba et al., 2010; Kiesel et al., 2007; Wieczorkowski, 2010) and military (O'Connor et al., 2011) populations. Investigating the relationship between FMS score and injury, Kiesel et al (2007), Chorba et al (2010), and O'Conner et al (2011) all found that a score of 14 or less was a positive predictor of injury. Interestingly O'Conner et al. (2011) found that those subjects with a score of 18 or more were also more at risk of suffering any injuries. The findings of the current study however do support the findings of a number of studies that have found no predictive value in functional movement screening (Hoover et al., 2008; Smith et al., 2012; Sorenson, 2009) or relationship between movement screening and previous injury (Peate et al., 2007; Schneiders et al., 2011).

A possible reason for these current findings is that the movement tasks performed in the MCS were not specific or sensitive enough to assess the risk of one particular injury, that is, low back pain in one sporting population. Another possible reason is that the majority of low back injuries that occur in rowing a gradual onset injuries. It seems from the research that screening tools are less able to predict the risk of overuse or gradual onset injuries among different populations (Hoover et al., 2008; O'Connor et al., 2011) than acute injuries. Further research is warranted to assess the ability of the MCS test to determine risk of any injury in rowing and other sports. Given that low back pain is the most prevalent injury in the sport of rowing, the findings of this study highlight the need for on-going investigation into the importance of using the MCS test to screen elite rowers as part of a minimising injury risk strategy. 


\subsubsection{Correlation between previous history of low back pain and age on the development of low back pain}

A previous history of low back pain was the most relevant risk factor of developing low back pain in the future. Subjects who had a previous history of low back pain were significantly more at risk of developing low back pain during this study. Preventing the first episode of low back pain among rowers is therefore the most significant factor is reducing the incidence of these injuries in the rowing population. As a large number of athletes are entering a New Zealand rowing programme having already experienced their first episode of low back pain, it could be argued that injury prevention strategies are best targeted at the younger, school aged, rowing population. Research has already shown that a multidimensional approach consisting of physiotherapy screening, prescription of individualised "specific exercise", education, and strength and conditioning sessions can be successful in reducing the incidence of low back pain in schoolgirl rowers (Perich et al., 2011; Thorpe et al., 2009).

The age of the subjects was also a risk factor in developing low back pain with the older subjects more at risk than those younger subjects. This supports the findings of previous epidemiology studies (Hill \& Keating, 2009; Leboeuf-Yde \& Kyvik, 1998; McMeeken et al., 2001) that have found low back pain gradually increases with age in the general population.

\subsubsection{Other risk factors}

In the current study, scullers were more likely to experience low back pain than sweep oar rowers however the difference between the two disciplines was not significant. These findings support those of previous research (Wilson et al., 2010) that reports a similar number of both scullers and sweep oar rowers sustaining low back injuries. It is 
often hypothesised that sweep rowing would place more load on the lumbar spine due to the rotational component of the rowing stroke; and thereby increasing the risk of low back injury. Recent research may help to explain these findings. A study investigating the spinopelvic kinematics of both sweep oar and sculling on rowing ergometers found no difference in the lateral bend or axial rotation in the lower lumbar spine between the two disciplines (Strahan et al., 2011); and despite the asymmetrical demands of sweep oar rowers the thickness of the lateral abdominal musculature has been found to be symmetric (Gill, Mason, \& Gerber, 2012).

There was also no significant correlation found between the factors of gender, BMI, the age the subjects began rowing, and core strength endurance, and low back pain. The current study also found no significant correlation between hamstring flexibility, as assessed by an active straight leg raise (SLR) test, and low back pain. This was true when analysing SLR scores as both continuous data and categorical, using a cut-off point of 75 degrees. This supports the findings of previous research investigating the relationship between hamstring length and low back pain in rowers (Howell, 1984; Stutchfield \& Coleman, 2006) that found low back pain was not associated with hamstring inflexibility.

\subsection{Limitations of the Study}

When gathering the exposure data in the current study the amount of cross training hours that subjects completed was not included. Although data was collected on the type and number of cross training sessions completed, the time exposure was not, and therefore it could not be included in the calculation of injury incidence. This would cause the incidence rate to be overestimated in comparison to other studies that have collected this information. 
There were 72 cases of low back pain in this study. Sample size mainly depends on the expected effect of the risk factor on injury risk, and to detect moderate to strong associations 20-50 injury cases are needed, whereas small to moderate associations would need about 200 injured subjects (Bahr \& Holme, 2003). Therefore, the current study had enough power to detect moderate to strong associations with injury, but not to detect small to moderate associations. The sample size and power can be addressed by continuing to collect such data in future research.

Another limitation was that although the current study was prospective, having the questionnaires completed on a monthly basis might have introduced an element of recall bias. Although all the subjects were asked to complete training diaries, this was not compulsory or monitored and therefore the compliance rate is unknown. Further to this, the exposure data was rounded to the nearest 50 kilometres per week. Although this would not affect the incidence data, it may have affected the correlation with the number of kilometres rowed and low back pain.

\subsection{Conclusion}

The purpose of this study was to provide good quality incidence and prevalence data on low back pain amongst New Zealand rowers, as well as establish whether a relationship between type of training, high level of training times and volumes and the development of lower back pain exists. This study also established to what extent lower back pain affects an athlete's training. The secondary objective of this study was to determine the correlation between the development of low back pain and possible risk factors, including functional movement patterns, hamstring flexibility, core strength endurance and demographic risk factors. 
Over a twelve-month period, the incidence rate was found to be 1.68 injuries per 1000 rowing specific training hours. This is similar to previously reported injury incidence among elite rowers. The cumulative incidence was $95 \%$ with 72 new LBP episodes reported. $52.6 \%$ of subjects experienced at least one new episode of low back pain. The point prevalence of low back pain was $13.7 \%$. Of these injuries, $45 \%$ were incidental, $29 \%$ were minor, $18 \%$ were moderate and $9 \%$ were severe.

A significant finding in this study was the high correlation between rowing specific training load and the development of low back pain among the subjects. Low back pain was highly correlated with the total number of training hours, the number of kilometres rowed per month and the amount of ergometer training completed per month. Indicating that as training load increases so does the incidence of low back injuries. These findings are consistent with previous research investigating the relationship between rowing training and injury. The correlation between training load and low back pain was also related to the time of the year that the injuries occurred and this was consistent with previous research. Another relevant observation was the sudden increase in new low back pain episodes at the start of the rowing season as the athletes come out of their off-season. Previous history of low back pain was found to be the most significant risk factor in developing new low back pain. The age of the subjects was also a risk factor with the likelihood of developing a new low back injury increasing for every year in age. None of the other risk factors investigated, including MCS score, were found to have a significant correlation to the development of back pain. Further research is warranted to assess the ability of the MCS test to determine risk of any injury in rowing and other sports. 


\subsection{Future research}

This study has established a link between training load and low back pain among rowers. Future research should look into the relationship between the type of training and low back pain. For example, establishing a link between the different types of training sessions, cross training sessions and weight training. It is possible that education of coaches regarding the increased risk of low back injury in the early stages of the season, and safe increases in training load at this particular time of the year would be beneficial in reducing this sudden increase in incidence of low back pain.

Because of this study, a screening tool more specific to rowing training may need to be developed as a tool to minimise the injury risk of the sport. As an accurate representation of the extent of the problem of low back pain among New Zealand rowers is now known, an intervention study could now be implemented to assess the effectiveness of such a tool.

This study has developed a web-based questionnaire to collect data regarding injury and training exposure in rowers. Future studies could utilise a modified version of this tool to collect information of all rowing injuries. 


\section{Appendices}

\section{Appendix 1}

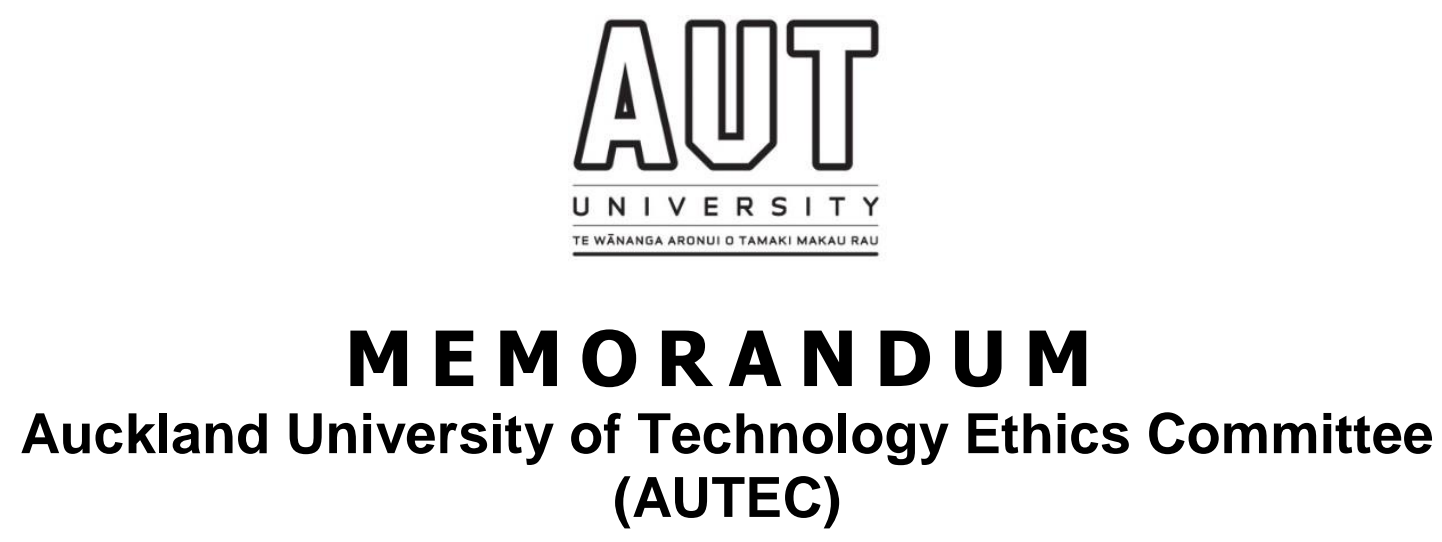

To:

Duncan Reid

From:

Date:

Dr Rosemary Godbold Executive Secretary, AUTEC

Subject:

26 August 2011

Ethics Application Number 11/186 The incidence of low back pain in New Zealand rowers and the relationship with functional movement patterns.

\section{Dear Duncan}

Thank you for providing written evidence as requested. I am pleased to advise that it satisfies the points raised by the Auckland University of Technology Ethics Committee (AUTEC) at their meeting on 25 July 2011 and I have approved your ethics application. This delegated approval is made in accordance with section 5.3.2.3 of AUTEC's Applying for Ethics Approval: Guidelines and Procedures and is subject to endorsement at AUTEC's meeting on 12 September 2011.

Your ethics application is approved for a period of three years until 24 August 2014.

I advise that as part of the ethics approval process, you are required to submit the following to AUTEC:

- A brief annual progress report using form EA2, which is available online through http://www.aut.ac.nz/research/research-ethics/ethics. When necessary this form may also be used to request an extension of the approval at least one month prior to its expiry on 24 August 2014;

- A brief report on the status of the project using form EA3, which is available online through http://www.aut.ac.nz/research/research-ethics/ethics. This report is to be submitted either when the approval expires on 24 August 2014 or on completion of the project, whichever comes sooner;

It is a condition of approval that AUTEC is notified of any adverse events or if the research does not commence. AUTEC approval needs to be sought for any alteration to the research, including any alteration of or addition to any documents that are provided to participants. You are reminded that, as applicant, you are responsible for ensuring that research undertaken under this approval occurs within the parameters outlined in the approved application.

Please note that AUTEC grants ethical approval only. If you require management approval from an institution or organisation for your research, then you will need to make the arrangements necessary to obtain this.

When communicating with us about this application, we ask that you use the application number and study title to enable us to provide you with prompt service. Should you have any further 
enquiries regarding this matter, you are welcome to contact Charles Grinter, Ethics Coordinator, by email at ethics@aut.ac.nz or by telephone on 9219999 at extension 8860.

On behalf of AUTEC and myself, I wish you success with your research and look forward to reading about it in your reports.

Yours sincerely

Dr Rosemary Godbold

Executive Secretary 


\section{Appendix 2}

\section{Participant Information Sheet

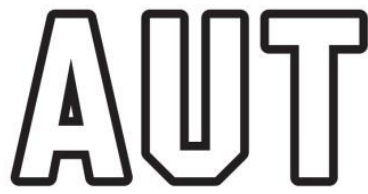

\section{Date Information Sheet Produced:}

26.5.2011

\section{Project Title}

The incidence of low back pain in New Zealand rowers and the relationship with functional movement patterns.

\section{An Invitation}

My name is Craig Newlands. I am undertaking a Masters degree at AUT University under the supervision of Assoc Professor Duncan Reid. You are invited to take part in a study being completed at the Rowing New Zealand High Performance Centre Karapiro, in conjunction with Auckland University of Technology. This study is investigating the incidence of low back pain in New Zealand rowers and its relationship to specific functional movement patterns. This information sheet provides information about the study which will enable you to decide if you wish to participate. As many of you are known to me as the Physiotherapist to NZ Rowing it is important for you to understand that your participation is entirely voluntary and if you agree to participate, you are free to withdraw at any stage prior to its completion without needing to give a reason. There will be no disadvantages if you decide to withdraw from the research and in the event that you do, the information about you will be destroyed. You are welcome to ask questions and seek clarification about any part of the research at any time that you do not understand.

\section{What is the purpose of this research?}

Low back pain is the most common injury affecting rowers; however at present it is not known how common it is among New Zealand rowers or how injury rates compare across different competitive levels. Previous research has suggested a number of sports specific risk factors associated with rowing that can potentially increase the risk of low back pain High levels of training times and volumes may also represent potential mechanisms for strain to the lumbar spine structures.

This study aims to provide good quality incidence data on lower back pain amongst New Zealand rowing as well as establishing whether a relationship between type of training, high level of training times and volumes and the development of lower back pain exists. This will potentially give coaches guidelines on what is a safe training load. This study will also establish to what extent lower back pain affects an athlete's training and therefore whether further research is warranted. A secondary aspect of this study is to look at the relationship between specific risk factors and specific functional movement patterns and the development of low back pain. At the completion of the study I will have completed the requirements for a Masters of Heath Science Degree from AUT. There will likely be some conference presentations and journal publications that will result from this research. It will not be possible to identify you as an individual in these presentations. 


\section{How was I identified and why am I being invited to participate in this research?}

You have been invited to participate in this research because you were selected to row for New Zealand in either the elite, under 23, under 21 or junior team in 2011. Rowing New Zealand has been contacted regarding this study, and following the initial recruitment via Lisa Holton they have provided me with your contact details following you responding to the advertisements placed around the High Performance Centre. If you have been diagnosed with an inflammatory or neurological condition that effects the nerves in the back or legs you will be unable to be part of this study.

\section{What will happen in this research?}

This study will involve a survey using an online questionnaire that you will be asked to complete every month over one year. The questionnaire will include rowing specific questions as well as questions regarding the amount and type of training you have done over the last month and whether or not you have experienced any low back pain. If you have experienced any back pain over the last month there will be further questions regarding this and the affect it has had on your training. This questionnaire will be distributed to you via email by an online survey tool. If you don't have access to the internet or email, a hard copy of the questionnaire will be posted to your residential address and a prepaid self addressed envelope will be included. You will be asked to complete the questionnaire within one week of receiving it. Automatic reminders will be sent via the website if this timeframe is exceeded. To help you remember the amount of training you have done over the month a simple training diary can be filled in weekly.

Around the time of the initial questionnaire you will also complete a series of simple screening movements, flexibility tests and endurance tests. Pictures of these tests are shown below. You will be videoed doing these tests and assessed and given a score by the researchers.
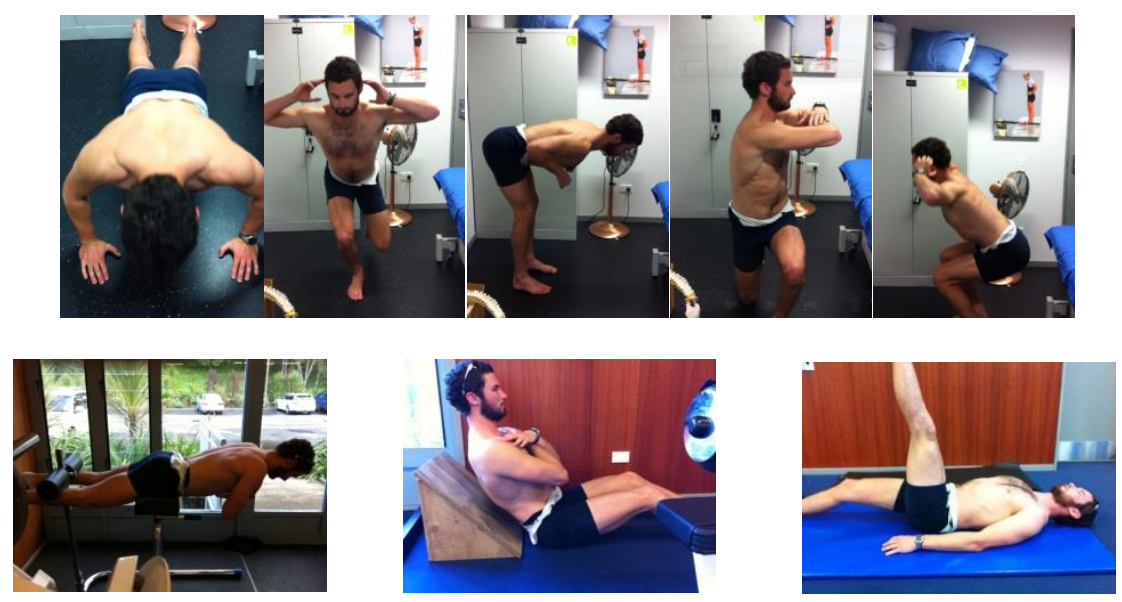

\section{What are the discomforts and risks?}

There is a very small risk that you could sustain an injury or discomfort during the initial screening tests. It is important that you stop any of the tests if you feel any pain during testing and that you notify the researcher as soon as this occurs.

\section{How will these discomforts and risks be alleviated?}

To minimise the risk of injury you will be asked to do a light warm up before participating in the screening tests. The testing area will be clean and clear of clutter to minimise the risk of slipping, tripping or falling. 
In the unlikely event that you injure yourself, ice and a first aid kit will be on hand and the researcher is a qualified physiotherapist who will be able to administer care.

Your coach will also be informed that you are undergoing testing and what the testing involves so that they can modify any subsequent training if they deem it necessary.

\section{What are the benefits?}

While there are no immediate benefits to you personally, this research may serve to inform the rowing community as to the extent of the problem of low back amongst New Zealand rowing as well as establishing whether a relationship between type of training, high level of training times and volumes and the development of lower back pain exists. This will potentially give coaches guidelines on what is a safe training load.

If there is a relationship established between faulty movement patterns, flexibility and/or strength endurance and the development of low back pain it may be possible to be more proactive in minimizing the risk of these injuries in the future.

\section{What compensation is available for injury or negligence?}

In the unlikely event of a physical injury as a result of your participation in this study, rehabilitation and compensation for injury by accident may be available from the Accident Compensation Corporation, providing the incident details satisfy the requirements of the law and the Corporation's regulations.

\section{How will my privacy be protected?}

Your privacy and confidentiality will be ensured at all times. The online survey website employs multiple layers of security to make sure that the collected data remains private and secure. In addition to this each participant will be assigned a participant ID number and the data collected during the initial screening and the questionnaires will be linked to this number so that it remains anonymous in any publication of the research. In addition no information that could identify you as an individual participant will be used in any reports of the research or be given to rowing New Zealand. The video analysis will be stored in a secure and locked cabinet and erased once the study is complete. The coaching staff will also not be able to access the data but once the study is complete the summary data of the injury incidence will be available to help plan improvements in injury prevention strategies.

\section{What are the costs of participating in this research?}

It is anticipated that the initial testing will take approximately 30 minutes per participant and the initial questionnaire will take 20 minutes to complete. Follow-up questionnaires will take approximately 10 minutes to complete each month. In addition the basic training diary is also expected to take 5 minutes to complete each week. There are no other monetary or time costs involved in this research.

You will be reimbursed a $\$ 20$ food or petrol voucher three times during the year; one initially, one midyear and one on completion, in lieu of the time that you give towards the project.

\section{What opportunity do I have to consider this invitation?}

From the time you receive this information sheet, you will be given two weeks to consider if you would like to participate in the study. 


\section{How do I agree to participate in this research?}

If you wish to participate in the research, please complete the consent form attached and return it to Craig Newlands within two weeks of receiving the forms. Following this you will be contacted by Craig to arrange a time to complete the initial screening session.

\section{Will I receive feedback on the results of this research?}

Please indicate on your consent form if you wish to receive information regarding the results of the research.

\section{What do I do if I have concerns about this research?}

Any concerns regarding the nature of this project should be notified in the first instance to the Project Supervisor, Assoc Professor Duncan Reid, duncan.reid@aut.ac.nz, 649921 9999 ext 7806

Concerns regarding the conduct of the research should be notified to the Executive Secretary, AUTEC, Madeline Banda, madeline.banda@aut.ac.nz, 9219999 ext 8044.

\section{Whom do I contact for further information about this research?}

Researcher Contact Details:

\section{Craig Newlands}

Email: craign@nzasni.org.nz or phone: 0272707309

\section{Project Supervisor Contact Details:}

\section{Duncan Reid}

Email: duncan.reid@aut.ac.na or phone: 6499219999 ext 7806

Approved by the Auckland University of Technology Ethics Committee on 26 August 2011, AUTEC Reference number 11/186. 


\section{Appendix 3}

\section{Consent Form}

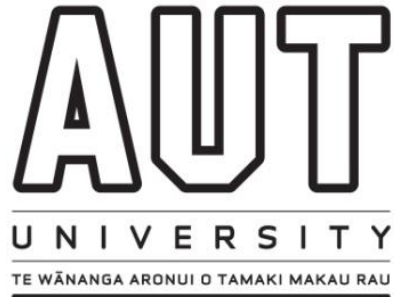

Project title:

The incidence of low back pain in New Zealand rowers and the relationship with functional movement patterns.

\section{Project Supervisor: Duncan Reid}

Researcher:

\section{Craig Newlands}

0 I have read and understood the information provided about this research project in the Information Sheet dated 26 May 2011.

O I have had an opportunity to ask questions and to have them answered.

$0 \quad$ I understand that I may withdraw myself or any information that I have provided for this project at any time prior to completion of data collection, without being disadvantaged in any way.

O I am not suffering from a diagnosed inflammatory disorder or neurologic condition.

O I agree to take part in this research.

O I wish to receive a copy of the report from the research (please tick one): YesO NoO

Participant's Contact Details (if appropriate):

Date:

Approved by the Auckland University of Technology Ethics Committee on 26 August 2011

\section{AUTEC Reference number 11186}

Note: The Participant should retain a copy of this form. 
Appendix 4

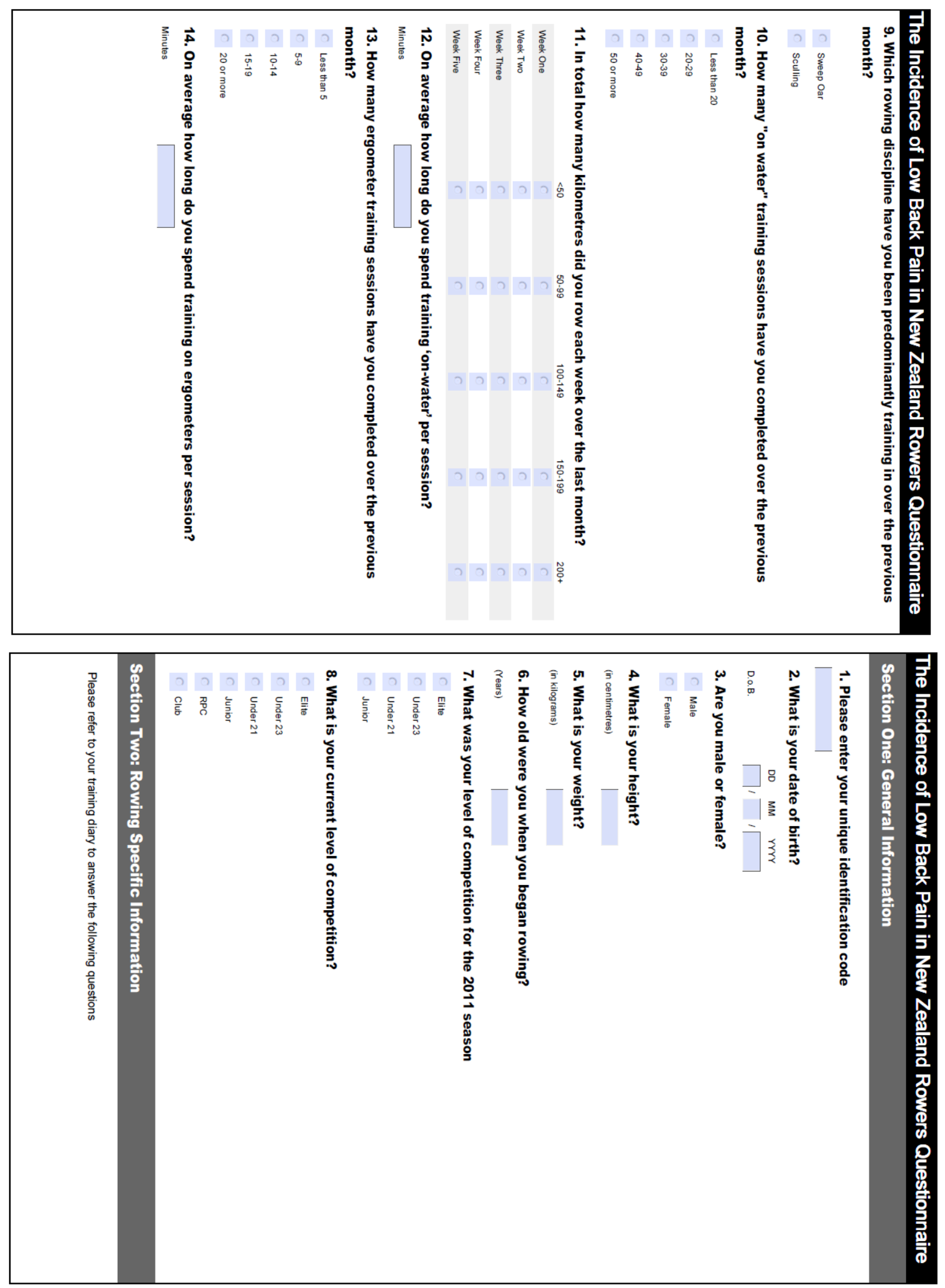



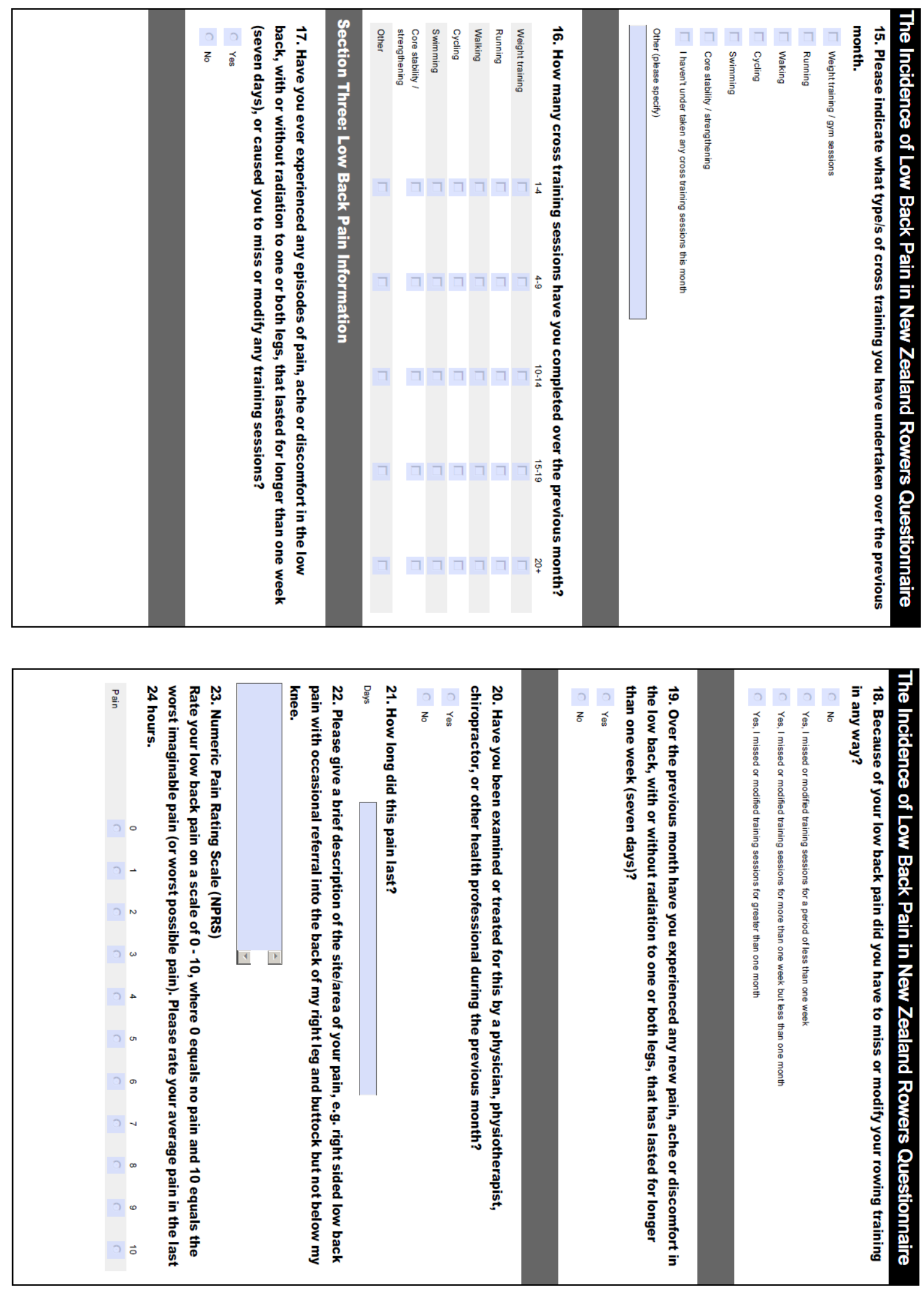


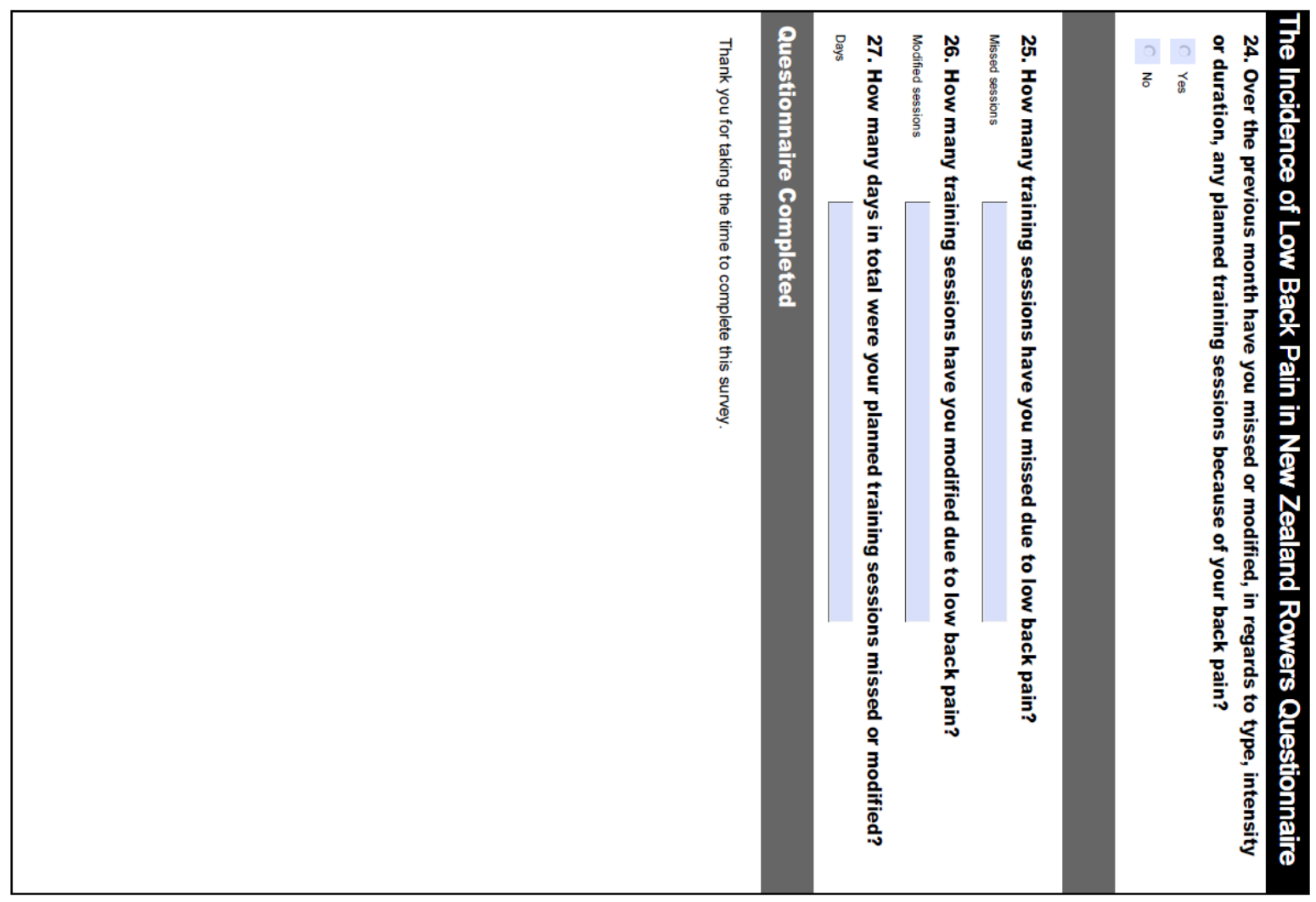




\section{Appendix 5}

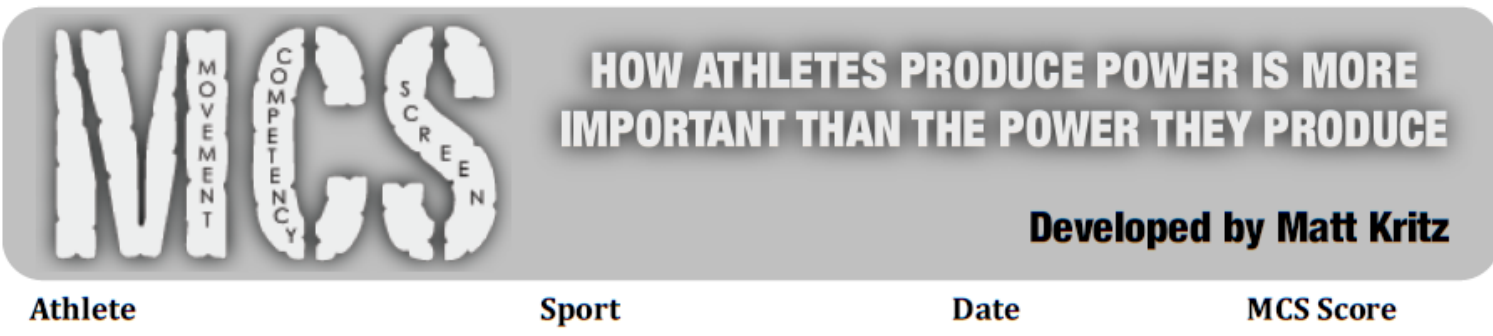

SCREENING INSTRUCTIONS: Based on the MCS criteria mark the PRIMARY or SECONDARY area that is of concern when observing the athlete perform the MCS movement patterns.

\begin{tabular}{|c|c|c|c|c|}
\hline PATTERN & PRIMARY & SECONDARY & $\begin{array}{l}\text { LOAD } \\
\text { LEVEL }\end{array}$ & COMMENTS \\
\hline SQUAT & \begin{tabular}{|ll}
0 & SHOULDERS \\
0 & LUMBAR \\
0 & HIPS \\
0 & ANKLES/FEET \\
\end{tabular} & $\begin{array}{ll}\circ & \text { HEAD } \\
\circ & \text { KNEES } \\
\circ & \text { DEPTH } \\
\circ & \text { BALANCE } \\
\end{array}$ & $\begin{array}{l}1 \\
2 \\
3\end{array}$ & \\
\hline $\begin{array}{c}\text { LUNGE \& } \\
\text { TWIST } \\
\text { (The Lunge) } \\
\end{array}$ & \begin{tabular}{|ll}
0 & BALANCE \\
0 & LUMBAR \\
0 & HIPS \\
0 & ANKLES/FEET \\
\end{tabular} & $\begin{array}{ll}\circ & \text { HEAD } \\
\circ & \text { KNEES } \\
\circ & \text { DEPTH }\end{array}$ & $\begin{array}{l}1 \\
2 \\
3\end{array}$ & \\
\hline $\begin{array}{c}\text { LUNGE \& } \\
\text { TWIST } \\
\text { (The Twist) }\end{array}$ & \begin{tabular}{|ll} 
& SHOULDERS \\
0 & LUMBAR \\
0 & HIPS \\
0 & ANKLES/FEET \\
\end{tabular} & $\begin{array}{ll}\circ & \text { HEAD } \\
\circ & \text { KNEES } \\
\circ & \text { DEPTH } \\
\circ & \text { BALANCE } \\
\end{array}$ & $\begin{array}{l}1 \\
2 \\
3\end{array}$ & \\
\hline $\begin{array}{l}\text { BEND \& PULL } \\
\text { (The Bend) }\end{array}$ & \begin{tabular}{|ll}
0 & SHOULDERS \\
0 & LUMBAR \\
0 & HIPS \\
0 & DEPTH \\
\end{tabular} & $\begin{array}{ll}\circ & \text { HEAD } \\
\circ & \text { KNEES } \\
\circ & \text { ANKLES/FEET } \\
\circ & \text { BALANCE } \\
\end{array}$ & $\begin{array}{l}1 \\
2 \\
3 \\
\end{array}$ & \\
\hline $\begin{array}{l}\text { BEND \& PULL } \\
\text { (The Pull) }\end{array}$ & \begin{tabular}{|ll}
0 & SHOULDERS \\
0 & LUMBAR \\
0 & HIPS \\
0 & DEPTH \\
\end{tabular} & $\begin{array}{ll}\circ & \text { HEAD } \\
\circ & \text { KNEES } \\
\circ & \text { ANKLES/FEET } \\
\circ & \text { BALANCE } \\
\end{array}$ & $\begin{array}{l}1 \\
2 \\
3\end{array}$ & \\
\hline PUSH UP & \begin{tabular}{|ll} 
& HEAD \\
0 & SHOULDERS \\
0 & LUMBAR \\
0 & DEPTH \\
\end{tabular} & $\begin{array}{ll}\circ & \text { HIPS } \\
\circ & \text { KNEES } \\
\circ & \text { ANKLES / FEET } \\
\circ & \text { BALANCE } \\
\end{array}$ & $\begin{array}{l}1 \\
2 \\
3 \\
\end{array}$ & \\
\hline $\begin{array}{l}\text { SINGLE LEG } \\
\text { SQUAT }\end{array}$ & \begin{tabular}{|ll} 
& DEPTH \\
0 & LUMBAR \\
0 & HIPS \\
0 & ANKLES / FEET \\
\end{tabular} & $\begin{array}{ll}\circ & \text { HEAD } \\
\circ & \text { SHOULDERS } \\
\circ & \text { KNEES } \\
\circ & \text { BALANCE } \\
\end{array}$ & $\begin{array}{l}1 \\
2 \\
3 \\
\end{array}$ & \\
\hline \multicolumn{5}{|c|}{ SCORING INSTRUCTIONS } \\
\hline \multicolumn{2}{|c|}{ Load Level } & \multicolumn{2}{|c|}{ Scoring rationale } & \multirow{4}{*}{$\begin{array}{l}\text { Considerations } \\
\text { To score the MCS simply mark what is not happening } \\
\text { as it is detailed in the MCS screening criteria table. } \\
\text { Pay close attention to the primary regions for each } \\
\text { movement task. The primary regions will have the } \\
\text { most meaningful impact on movement competency. } \\
\text { To score unilateral patterns the load level should } \\
\text { reflect the poorest side. For example: If an athlete } \\
\text { scores a } 3 \text { on their right leg and a } 2 \text { on their left leg, } \\
\text { that athlete would score a } 2 \text { for their single leg squat } \\
\text { pattern. Athletes' unilateral movement competency } \\
\text { should be a reflection of their weakest side. }\end{array}$} \\
\hline \multicolumn{2}{|c|}{1 (Assisted) } & $\begin{array}{l}2 \text { or more primary } \\
\text { checked and any sec } \\
\text { region checke }\end{array}$ & & \\
\hline \multicolumn{2}{|c|}{2 (Bodyweight) } & \multicolumn{2}{|c|}{$\begin{array}{l}1 \text { primary region and any } \\
\text { secondary region checked }\end{array}$} & \\
\hline 3 (Exte & ernal Load) & $\begin{array}{l}\text { No primary or seco } \\
\text { regions checke }\end{array}$ & & \\
\hline
\end{tabular}

THE MOVEMENT COMPETENCY SCREEN (MCS) 


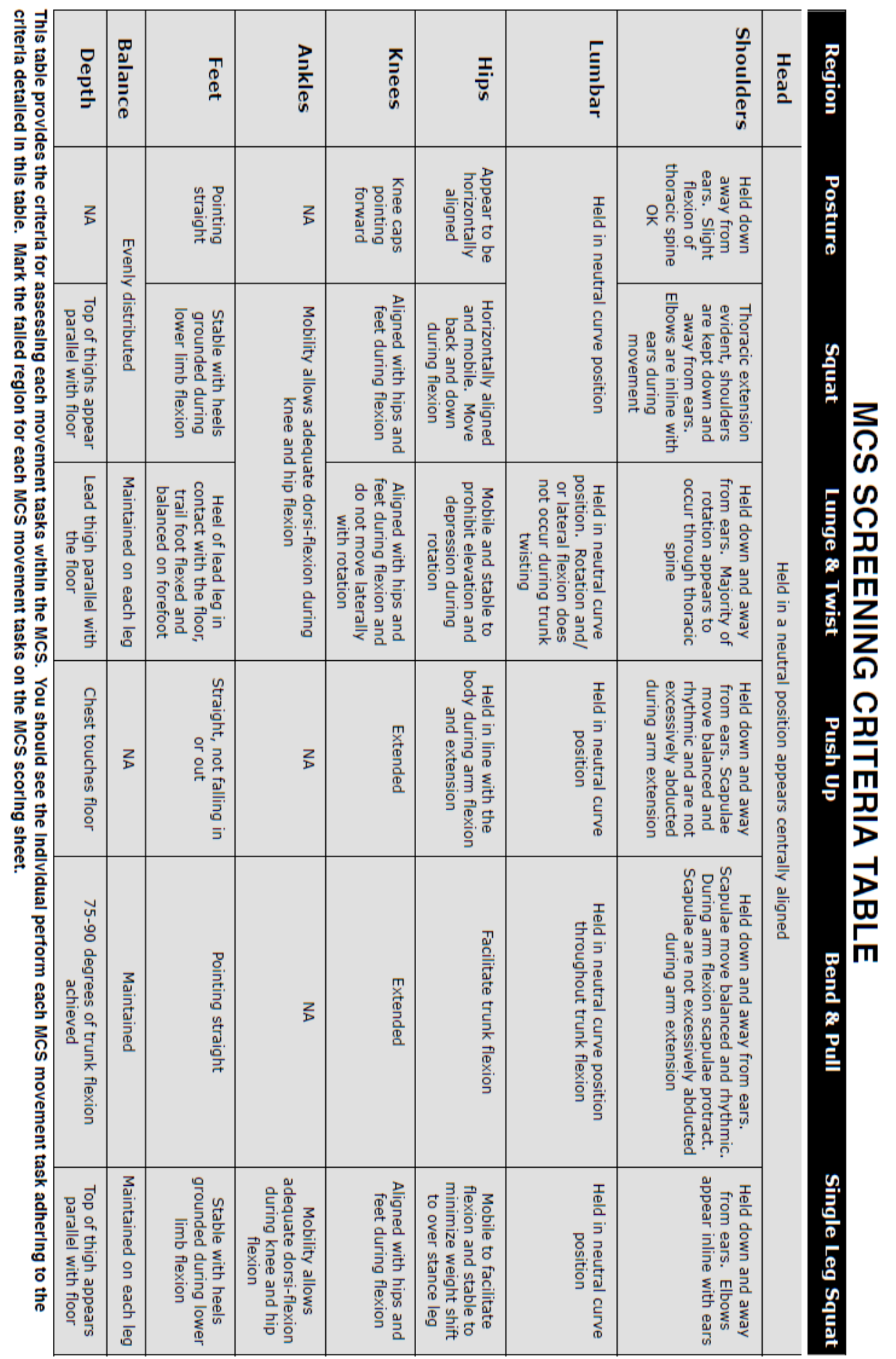




\section{Appendix 6}

\section{Logistic regression: New low back pain as Dependent variable}

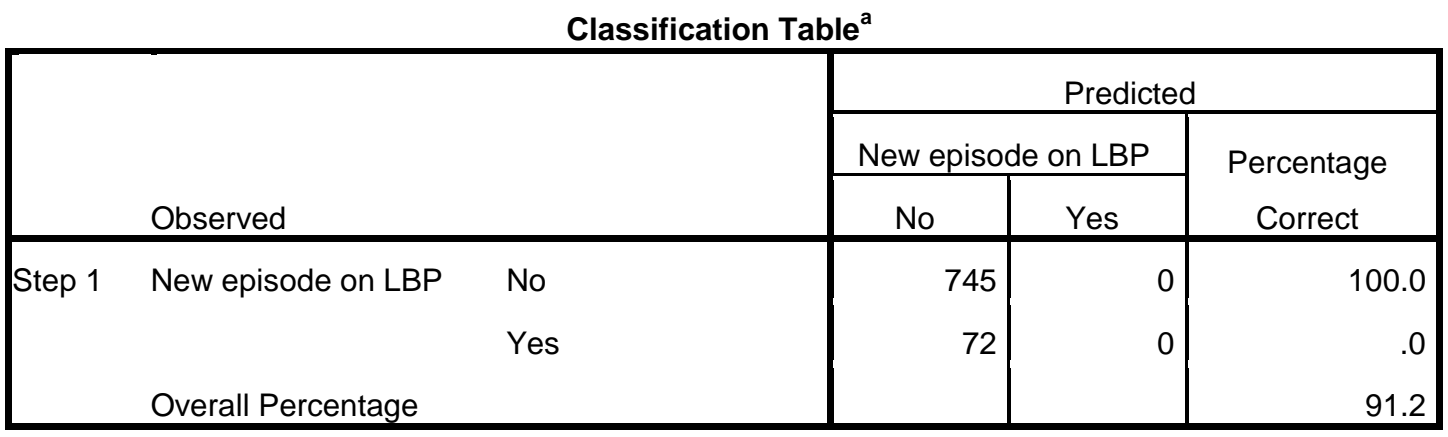

a. The cut value is .500

(i) Independent variable: Age

\begin{tabular}{|c|c|c|c|c|c|c|c|}
\hline \multicolumn{8}{|c|}{ Variables in the Equation } \\
\hline & & $\mathrm{B}$ & S.E. & Wald & df & Sig. & $\operatorname{Exp}(B)$ \\
\hline \multirow[t]{2}{*}{ Step $1^{a}$} & AGE & .073 & .030 & 5.805 & 1 & .016 & 1.076 \\
\hline & Constant & -3.984 & .709 & 31.613 & 1 & .000 & .019 \\
\hline
\end{tabular}

a. Variable(s) entered on step 1: AGE.

(ii) Independent variable: Gender

Variables in the Equation

\begin{tabular}{|rl|r|r|r|r|r|r|}
\hline & & \multicolumn{1}{c|}{ B } & \multicolumn{1}{|c|}{ S.E. } & \multicolumn{1}{c|}{ Wald } & df & \multicolumn{1}{c|}{ Sig. } & \multicolumn{1}{c|}{$\operatorname{Exp}(\mathrm{B})$} \\
\hline Step $1^{\mathrm{a}}$ & AGE & .071 & .031 & 5.321 & 1 & .021 & 1.074 \\
& GENDER & .105 & .263 & .158 & 1 & .691 & 1.110 \\
& Constant & -4.107 & .775 & 28.094 & 1 & .000 & .016 \\
\hline
\end{tabular}

a. Variable(s) entered on step 1: AGE, GENDER.

(iii) Independent variable: BMI

\begin{tabular}{|rl|r|r|r|r|r|r|}
\hline \multicolumn{1}{|c|}{} & \multicolumn{1}{c|}{ B } & \multicolumn{1}{c|}{ S.E. } & Wald & df & \multicolumn{1}{c|}{ Sig. } & \multicolumn{1}{c|}{$\operatorname{Exp}(\mathrm{B})$} \\
\hline Step $1^{\mathrm{a}}$ & AGE & .072 & .031 & 5.562 & 1 & .018 & 1.075 \\
& BMI & .024 & .071 & .116 & 1 & .733 & 1.024 \\
& Constant & -4.533 & 1.758 & 6.649 & 1 & .010 & .011 \\
\hline
\end{tabular}

a. Variable(s) entered on step 1: AGE, BMI. 
(iv) Independent variable: Age began rowing

Variables in the Equation

\begin{tabular}{|rl|r|r|r|r|r|r|}
\hline & & \multicolumn{1}{c|}{ B } & \multicolumn{1}{c|}{ S.E. } & \multicolumn{1}{c|}{ Wald } & df & \multicolumn{1}{c|}{ Sig. } & \multicolumn{1}{|c|}{$\operatorname{Exp(B)}$} \\
\hline Step $1^{\mathrm{a}}$ & AGE & .077 & .031 & 6.029 & 1 & .014 & 1.080 \\
& AGEBGAN & -.041 & .083 & .238 & 1 & .626 & .960 \\
& Constant & -3.459 & 1.294 & 7.150 & 1 & .007 & .031 \\
\hline
\end{tabular}

a. Variable(s) entered on step 1: AGE, AGEBGAN.

(v) Independent variable: Years rowing experience

Variables in the Equation

\begin{tabular}{|rl|r|r|r|r|r|r|}
\hline & & \multicolumn{1}{c|}{ B } & \multicolumn{1}{c|}{ S.E. } & Wald & df & \multicolumn{1}{c|}{ Sig. } & \multicolumn{1}{c|}{$\operatorname{Exp}(\mathrm{B})$} \\
\hline Step $1^{\mathrm{a}}$ & AGE & .036 & .083 & .188 & 1 & .664 & 1.037 \\
& YRSROW & .041 & .083 & .238 & 1 & .626 & 1.041 \\
& Constant & -3.459 & 1.294 & 7.150 & 1 & .007 & .031 \\
\hline
\end{tabular}

a. Variable(s) entered on step 1: AGE, YRSROW.

(vi) Independent variable: Competition level

\begin{tabular}{|rl|r|r|r|r|r|r|}
\multicolumn{1}{|c|}{ Variables in the Equation } \\
\hline Step $1^{\mathrm{a}}$ & \multicolumn{1}{c|}{$\mathrm{B}$} & \multicolumn{1}{c|}{ S.E. } & Wald & df & \multicolumn{1}{c|}{ Sig. } & \multicolumn{1}{c|}{$\operatorname{Exp(B)}$} \\
& AGE & .090 & .044 & 4.298 & 1 & .038 & 1.094 \\
& GRDE1 & .196 & .364 & .290 & 1 & .590 & 1.217 \\
& Constant & -4.643 & 1.418 & 10.726 & 1 & .001 & .010 \\
\hline
\end{tabular}

a. Variable(s) entered on step 1: AGE, GRDE1.

(vii) Independent variable: Rowing discipline

Variables in the Equation

\begin{tabular}{|rl|r|r|r|r|r|r|}
\hline & & \multicolumn{1}{|c|}{ B } & \multicolumn{1}{c|}{ S.E. } & Wald & df & \multicolumn{1}{c|}{ Sig. } & Exp(B) \\
\hline Step $1^{\mathrm{a}}$ & AGE & .074 & .031 & 5.802 & 1 & .016 & 1.076 \\
& DISIPLINE & -.166 & .248 & .446 & 1 & .504 & .847 \\
& Constant & -3.737 & .798 & 21.931 & 1 & .000 & .024 \\
\hline
\end{tabular}

a. Variable(s) entered on step 1: AGE, DISIPLINE. 
(viii) Independent variable: Previous history of back pain Variables in the Equation

\begin{tabular}{|rl|r|r|r|r|r|r|}
\hline & \multicolumn{1}{|c|}{ B } & \multicolumn{1}{c|}{ S.E. } & \multicolumn{1}{c|}{ Wald } & df & \multicolumn{1}{c|}{ Sig. } & \multicolumn{1}{c|}{$\operatorname{Exp}(\mathrm{B})$} \\
\hline Step $1^{\mathrm{a}}$ & AGE & .067 & .031 & 4.667 & 1 & .031 & 1.069 \\
& HxLBP & .716 & .264 & 7.342 & 1 & .007 & 2.047 \\
& Constant & -4.983 & .821 & 36.805 & 1 & .000 & .007 \\
\hline
\end{tabular}

a. Variable(s) entered on step 1: AGE, HxLBP.

(ix) Independent variable: MCS score

Variables in the Equation

\begin{tabular}{|rl|r|r|r|r|r|r|}
\hline & \multicolumn{1}{|c|}{ B } & \multicolumn{1}{c|}{ S.E. } & \multicolumn{1}{c|}{ Wald } & df & \multicolumn{1}{c|}{ Sig. } & Exp(B) \\
\hline Step $1^{\mathrm{a}}$ & AGE & .075 & .032 & 5.673 & 1 & .017 & 1.078 \\
& .734 & .265 & 7.665 & 1 & .006 & 2.084 \\
& HxLBP & .436 & .255 & 2.919 & 1 & .088 & 1.547 \\
MCSHIGHLOW & -5.872 & .983 & 35.689 & 1 & .000 & .003 \\
\hline
\end{tabular}

a. Variable(s) entered on step 1: AGE, HxLBP, MCSHIGHLOW.

(x) Independent variable: Active SLR

Variables in the Equation

\begin{tabular}{|rl|r|r|r|r|r|r|}
\hline & \multicolumn{1}{c|}{ B } & \multicolumn{1}{c|}{ S.E. } & Wald & df & \multicolumn{1}{c|}{ Sig. } & Exp(B) \\
\hline Step $1^{\mathrm{a}}$ & AGE & .073 & .032 & 5.119 & 1 & .024 & 1.076 \\
& HxLBP & .735 & .265 & 7.668 & 1 & .006 & 2.085 \\
& MCSHIGHLOW & .442 & .256 & 2.989 & 1 & .084 & 1.556 \\
& ASLRHIGHLOW & -.111 & .254 & .189 & 1 & .664 & .895 \\
& Constant & -5.663 & 1.094 & 26.799 & 1 & .000 & .003 \\
\hline
\end{tabular}

a. Variable(s) entered on step 1: AGE, HxLBP, MCSHIGHLOW, ASLRHIGHLOW.

(xi) Independent variable: Core strength endurance ratio

\begin{tabular}{|ll|r|r|r|r|r|r|}
\hline \multicolumn{1}{|c|}{ Variables in the Equation } \\
\hline Step 1 & B & \multicolumn{1}{c|}{ S.E. } & \multicolumn{1}{c|}{ Wald } & df & Sig. & Exp(B) \\
& AGE & .111 & .075 & 2.223 & 1 & .136 & 1.118 \\
& HxLBP & 1.486 & .713 & 4.344 & 1 & .037 & 4.419 \\
MCSHIGHLOW & .486 & .603 & .649 & 1 & .420 & 1.625 \\
RATIO & .968 & 1.628 & .353 & 1 & .552 & 2.632 \\
Constant & -8.044 & 2.606 & 9.526 & 1 & .002 & .000 \\
\hline
\end{tabular}


Variables in the Equation

\begin{tabular}{|c|c|c|c|c|c|c|c|}
\hline & & $\mathrm{B}$ & S.E. & Wald & $\mathrm{df}$ & Sig. & $\operatorname{Exp}(B)$ \\
\hline \multirow[t]{5}{*}{ Step $1^{a}$} & AGE & .111 & .075 & 2.223 & 1 & .136 & 1.118 \\
\hline & HxLBP & 1.486 & .713 & 4.344 & 1 & .037 & 4.419 \\
\hline & MCSHIGHLOW & .486 & .603 & .649 & 1 & .420 & 1.625 \\
\hline & RATIO & .968 & 1.628 & .353 & 1 & .552 & 2.632 \\
\hline & Constant & -8.044 & 2.606 & 9.526 & 1 & .002 & .000 \\
\hline
\end{tabular}

a. Variable(s) entered on step 1: AGE, HxLBP, MCSHIGHLOW, RATIO. 


\section{Appendix 7}

\section{Logistic regression: Any low back pain as the Dependent variable}

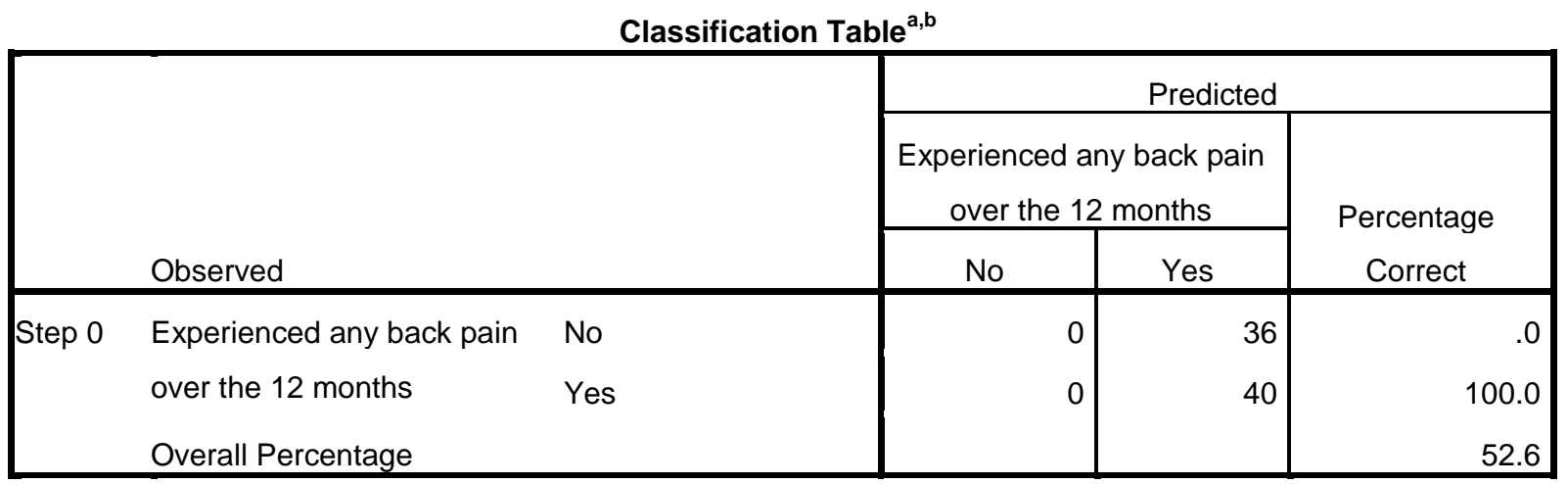

a. Constant is included in the model.

b. The cut value is .500

Variables in the Equation

\begin{tabular}{|rl|r|r|r|r|r|r|}
\hline & & \multicolumn{1}{c|}{ B } & \multicolumn{1}{c|}{ S.E. } & Wald & df & \multicolumn{1}{c|}{ Sig. } & \multicolumn{1}{c|}{$\operatorname{Exp}(\mathrm{B})$} \\
\hline Step $1^{\mathrm{a}}$ & AGE & .087 & .061 & 2.044 & 1 & .153 & 1.091 \\
& Constant & -1.806 & 1.351 & 1.785 & 1 & .182 & .164 \\
\hline
\end{tabular}

a. Variable(s) entered on step 1: AGE.

Variables in the Equation

\begin{tabular}{|rl|r|r|r|r|r|r|}
\hline & & \multicolumn{1}{c|}{ B } & \multicolumn{1}{c|}{ S.E. } & \multicolumn{1}{c|}{ Wald } & \multicolumn{1}{c|}{ df } & \multicolumn{1}{c|}{ Sig. } & \multicolumn{1}{c|}{$\operatorname{Exp(B)}$} \\
\hline Step $1^{\mathrm{a}}$ & AGE & .093 & .063 & 2.215 & 1 & .137 & 1.098 \\
& GENDER & -.215 & .490 & .193 & 1 & .661 & .807 \\
& Constant & -1.594 & 1.433 & 1.238 & 1 & .266 & .203 \\
\hline
\end{tabular}

a. Variable(s) entered on step 1: AGE, GENDER.

Variables in the Equation

\begin{tabular}{|rl|r|r|r|r|r|r|}
\hline & & \multicolumn{1}{c|}{ B } & \multicolumn{1}{c|}{ S.E. } & Wald & df & \multicolumn{1}{c|}{ Sig. } & Exp(B) \\
\hline Step $1^{\mathrm{a}}$ & AGE & .087 & .061 & 2.034 & 1 & .154 & 1.091 \\
& BMI & .013 & .130 & .011 & 1 & .918 & 1.013 \\
& Constant & -2.119 & 3.339 & .403 & 1 & .526 & .120 \\
\hline
\end{tabular}

a. Variable(s) entered on step 1: AGE, BMI.

Variables in the Equation

\begin{tabular}{|rl|r|r|r|r|r|r|}
\hline & & \multicolumn{1}{c|}{ B } & \multicolumn{1}{c|}{ S.E. } & \multicolumn{1}{c|}{ Wald } & \multicolumn{1}{c|}{ df } & \multicolumn{1}{c|}{ Sig. } & Exp(B) \\
\hline Step $1^{\mathrm{a}}$ & AGE & .087 & .063 & 1.927 & 1 & .165 & 1.091 \\
& AGEBGAN & .000 & .120 & .000 & 1 & .997 & 1.000
\end{tabular}




\begin{tabular}{|l|l|l|l|l|l|l|}
\hline Constant & -1.801 & 1.943 & .859 & 1 & .354 & .165 \\
\hline
\end{tabular}

a. Variable(s) entered on step 1: AGE, AGEBGAN.

Variables in the Equation

\begin{tabular}{|rl|r|r|r|r|r|r|}
\hline & & \multicolumn{1}{c|}{ B } & \multicolumn{1}{c|}{ S.E. } & \multicolumn{1}{c|}{ Wald } & \multicolumn{1}{c|}{ df } & \multicolumn{1}{c|}{ Sig. } & \multicolumn{1}{|c|}{$\operatorname{Exp(B)}$} \\
\hline Step $1^{\mathrm{a}}$ & AGE & .087 & .121 & .511 & 1 & .475 & 1.091 \\
& YRSROW & .000 & .120 & .000 & 1 & .997 & 1.000 \\
& Constant & -1.801 & 1.943 & .859 & 1 & .354 & .165 \\
\hline
\end{tabular}

a. Variable(s) entered on step 1: AGE, YRSROW.

\begin{tabular}{|rl|r|r|r|r|r|r|}
\hline & \multicolumn{1}{|c|}{ V } & \multicolumn{1}{c|}{ S.E. } & \multicolumn{1}{c|}{ Wald } & \multicolumn{1}{c|}{ df } & \multicolumn{1}{c|}{ Sig. } & \multicolumn{1}{c|}{$\operatorname{Exp}(\mathrm{B})$} \\
\hline Step 1 ${ }^{\mathrm{a}}$ & AGE & .110 & .083 & 1.777 & 1 & .183 & 1.116 \\
& GRDE1 & .265 & .628 & .179 & 1 & .672 & 1.304 \\
& Constant & -2.701 & 2.530 & 1.140 & 1 & .286 & .067 \\
\hline
\end{tabular}

a. Variable(s) entered on step 1: AGE, GRDE1.

Variables in the Equation

\begin{tabular}{|rl|r|r|r|r|r|r|}
\hline & & \multicolumn{1}{c|}{ B } & \multicolumn{1}{c|}{ S.E. } & \multicolumn{1}{c|}{ Wald } & df & \multicolumn{1}{c|}{ Sig. } & \multicolumn{1}{c|}{$\operatorname{Exp(B)}$} \\
\hline Step $1^{\text {a }}$ & AGE & .071 & .063 & 1.266 & 1 & .261 & 1.074 \\
& HxLBP & 1.246 & .489 & 6.488 & 1 & .011 & 3.477 \\
& Constant & -3.356 & 1.556 & 4.650 & 1 & .031 & .035 \\
\hline
\end{tabular}

a. Variable(s) entered on step 1: AGE, HxLBP.

\begin{tabular}{|rl|r|r|r|r|r|r|}
\hline & \multicolumn{1}{|c|}{ Variables in the Equation } \\
\hline Step 1 ${ }^{\mathrm{a}}$ & B & \multicolumn{1}{c|}{ S.E. } & \multicolumn{1}{c|}{ Wald } & df & \multicolumn{1}{c|}{ Sig. } & Exp(B) \\
& AGE & .097 & .066 & 2.118 & 1 & .146 & 1.102 \\
& HxLBP & 1.237 & .512 & 5.827 & 1 & .016 & 3.444 \\
MCSHIGHLOW & .889 & .517 & 2.956 & 1 & .086 & 2.434 \\
Constant & -5.280 & 1.954 & 7.301 & 1 & .007 & .005 \\
\hline
\end{tabular}

a. Variable(s) entered on step 1: AGE, HxLBP, MCSHIGHLOW.

Variables in the Equation

\begin{tabular}{|rl|r|r|r|r|r|r|}
\hline & \multicolumn{1}{|c|}{ B } & \multicolumn{1}{c|}{ S.E. } & \multicolumn{1}{c|}{ Wald } & df & \multicolumn{1}{c|}{ Sig. } & Exp(B) \\
\hline Step $1^{\mathrm{a}}$ & AGE & .107 & .069 & 2.419 & 1 & .120 & 1.113 \\
& & 1.231 & .514 & 5.741 & 1 & .017 & 3.426 \\
& HxLBP & .888 & .519 & 2.930 & 1 & .087 & 2.430 \\
& MCSHIGHLOW & .382 & .520 & .540 & 1 & .463 & 1.465 \\
& ASLRHIGHLOW & -6.083 & 2.276 & 7.141 & 1 & .008 & .002 \\
\hline
\end{tabular}


Variables in the Equation

\begin{tabular}{|rl|r|r|r|r|r|r|}
\hline & & \multicolumn{1}{c|}{ B } & \multicolumn{1}{c|}{ S.E. } & Wald & df & \multicolumn{1}{c|}{ Sig. } & \multicolumn{1}{c|}{$\operatorname{Exp}(\mathrm{B})$} \\
\hline Step 1 ${ }^{\mathrm{a}}$ & AGE & .087 & .061 & 2.044 & 1 & .153 & 1.091 \\
& Constant & -1.806 & 1.351 & 1.785 & 1 & .182 & .164 \\
\hline
\end{tabular}

a. Variable(s) entered on step 1: AGE, HxLBP, MCSHIGHLOW, ASLRHIGHLOW.

Variables in the Equation

\begin{tabular}{|ll|r|r|r|r|r|r|}
\hline & \multicolumn{1}{|c|}{ B } & \multicolumn{1}{c|}{ S.E. } & \multicolumn{1}{c|}{ Wald } & df & \multicolumn{1}{c|}{ Sig. } & Exp(B) \\
\hline Step $1^{\mathrm{a}}$ & AGE & .093 & .067 & 1.962 & 1 & .161 & 1.098 \\
& 1.197 & .515 & 5.411 & 1 & .020 & 3.310 \\
& HxLBP & .858 & .520 & 2.718 & 1 & .099 & 2.358 \\
MCSHIGHLOW & .465 & 1.394 & .111 & 1 & .739 & 1.591 \\
RATIO & -5.440 & 2.122 & 6.575 & 1 & .010 & .004 \\
Constant & &
\end{tabular}

a. Variable(s) entered on step 1: AGE, HxLBP, MCSHIGHLOW, RATIO. 


\section{References}

Adams, M. A., \& Dolan, P. (1995). Recent advances in lumbar spinal mechanics and their clinical significance. Clinical Biomechanics, 10(1), 3-19.

Bahr, R., Andersen, S., Loken, S., Fossan, B., Hansen, T., \& Holme, I. (2004). Low back pain among endurance athletes with and without specific back loading-a cross-sectional survey of crosscountry skiers, rowers, orienteerers, and nonathletic Controls. Spine, 29(4), 449-454.

Bahr, R., \& Holme, I. (2003). Risk factors for sports injuries - a methodological approach. British Journal of Sports Medicine, 37(5), 384-392.

Batt, M. E., Jaques, R., \& Stone, M. (2004). Preparticipation examination (screening): practical issues as determined by sport. A United Kingdom perspective. Clinical Journal of Sport Medicine, 14, $178-182$.

Beutler, A. I., de la Motte, S. J., Marshall, S. W., Padua, D. A., \& Boden, B. P. (2009). Muscle strength and qualitative jump-landing differences in male and female military cadets: The jump-ACL study. Journal of Sports Science \& Medicine, 8(4), 663-671.

Biering-Sorensen, F. (1984). Physical measurements as risk indicators for low-back trouble over a oneyear period. Spine, 9(2), 106-119.

Brukner, P., \& Khan, K. (2011). Clinical sports medicine: McGraw Hill.

Budgett, R., \& Fuller, G. (1989). Illness and injury in international oarsmen. Clinical Sports Medicine, 1, 55-61.

Butler, R. J., Plisky, P. J., \& Kiesel, K. B. (2012). Interrater reliability of videotaped performance on the functional movement screen using the 100-point scoring scale. Athletic Training \& Sports Health Care, 4(3), 103-109.

Caldwell, J. S., McNair, P. J., \& Williams, M. (2003). The effects of repetitive motion on lumbar flexion and erector spinae muscle activity in rowers. Clinical Biomechanics, 18(8), 704-711.

Childs, J. D., Piva, S. R., \& Fritz, J. M. (2005). Responsiveness of the numeric pain rating scale in patients with low back pain. Spine, 30(11), 1331-1334

Chorba, R. S., Chorba, D. J., Bouillon, L. E., Overmyer, C. A., \& Landis, J. A. (2010). Use of a functional movement screening tool to determine injury risk in female collegiate athletes. North American Journal of Sports Physical Therapy, 5(2), 47-54.

Comerford, M. J. (2006). Screening to identify injury and performance risk: movement control testing -the missing piece of the puzzle. SportEX Medicine(29), 21-26.

Cook, G., Burton, L., \& Hoogenboom, B. (2006). Pre-participation screening: The use of fundamental movements as an assessment of function-part 1. North American Journal of Sports Physical Therapy, 1(2), 62 .

Duggleby, T., \& Kumar, S. (1997). Epidemiology of juvenile low back pain: a review. Disability \& Rehabilitation, 19(12), 505-512.

Foss, I. S., Holme, I., \& Bahr, R. (2012). The Prevalence of Low Back Pain Among Former Elite CrossCountry Skiers, Rowers, Orienteerers, and Nonathletes: A 10-Year Cohort Study. The American Journal of Sports Medicine, 40(11), 2610-2616.

Frohm, A., Heijne, A., Kowalski, J., Svensson, P., \& Myklebust, G. (2012). A nine-test screening battery for athletes: a reliability study. Scandinavian Journal of Medicine \& Science in Sports, 22(3), 306-315.

Gajdosik, R. L., Albert, C. R., \& Mitman, J. J. (1994). Influence of hamstring length on the standing position and flexion range of motion of the pelvic angle, lumbar angle, and thoracic angle. The Journal of Orthopaedic and Sports Physical Therapy, 20(4), 213.

Garrick, J. G. (2004). Preparticipation orthopedic screening evaluation. Clinical Journal of Sport Medicine, 14(3), 123-126.

Gill, N. W., Mason, B. E., \& Gerber, J. P. (2012). Lateral abdominal muscle symmetry in collegiate single-sided rowers. International Journal of Sports Physical Therapy, 7(1), 13-19.

Goss, D., Christopher, G., Faulk, R., \& Moore, J. (2009). Functional training program bridges rehabilitation and return to duty. Journal of Special Operations Medicine, 9(2), 29.

Hagerman, F., Fielding, R., Fiatarone, M., Gault, J., Kirkendall, D., Ragg, K., \& Evans, W. (1996). A 20yr longitudinal study of Olympic oarsman. Medicine and Science in Sports and Exercise., 28(9), 1150-1156.

Hestbaek, L., Leboeuf-Yde, C., Kyvik, K. O., \& Manniche, C. (2006). The course of low back pain from adolescence to adulthood: eight-year follow-up of 9600 twins. Spine, 31(4), 468-472. 
Hickey, G. J., Fricker, P. A., \& McDonald, W. A. (1997). Injuries to elite rowers over a 10-year period. Medicine \& Science in Sports \& Exercise, 29(12), 1567-1572.

Hill, J. J., \& Keating, J. L. (2009). A systematic review of the incidence and prevalence of low back pain in children. Physical Therapy Reviews, 14(4), 272-284.

Holt, P. J. E., Bull, A. M. J., Cashman, P. M. M., \& McGregor, A. H. (2003). Kinematics of spinal motion during prolonged rowing. International Journal of Sports Medicine, 24(8), 597-602.

Hoover, D., Killian, C. B., Bourcier, B., Shannon, L., Jenny, T., \& Willis, R. (2008). Predictive validity of the functional movement screen in a population of recreational runners training for a half marathon. Medicine \& Science in Sports \& Exercise, 40(5), S219.

Howell, D. W. (1984). Musculoskeletal profile and incidence of musculoskeletal injuries in lightweight women rowers. American Journal of Sports Medicine, 12(4), 278-282.

Hoy, D., Brooks, P., Blyth, F., \& Buchbinder, R. (2010). The epidemiology of low back pain. Bailliere's Best Practice \& Research in Clinical Rheumatology, 24(6), 769-781.

Kiesel, K., Plisky, P., \& Butler, R. (2011). Functional movement test scores improve following a standardized off-season intervention program in professional football players. Scandinavian Journal of Medicine \& Science in Sports, 21(2), 287-292.

Kiesel, K., Plisky, P. J., \& Voight, M. L. (2007). Can serious injury in professional football be predicted by a preseason functional movement screen? North American Journal of Sports Physical Therapy, 2(3), 147-158.

Kritz, M. (2012). Development, reliability and effectiveness of the Movement Competency Screen (MCS) (Unpublished doctoral thesis). Auckland University of Technology, Auckland.

Kritz, M., Cronin, J., \& Hume, P. (2009a). The bodyweight squat: a movement screen for the squat pattern. Strength \& Conditioning Journal 31(1), 76-85.

Kritz, M., Cronin, J., \& Hume, P. (2009b). The bodyweight squat: A movement screen for the squat pattern. Strength \& Conditioning Journal, 31(1), 76.

Kritz, M., Cronin, J., \& Hume, P. (2009c). Using the body weight forward lunge to screen an athlete's lunge pattern. Strength \& Conditioning Journal, 31(6), 15-24.

Kritz, M., Cronin, J., \& Hume, P. (2010). Screening the Upper-Body Push and Pull Patterns Using Body Weight Exercises. Strength \& Conditioning Journal, 32(3), 72.

Kuczmarski, R. J., Carroll, M. D., Flegal, K. M., \& Troiano, R. P. (1997). Varying body mass index cutoff points to describe overweight prevalence among US adults: NHANES III (1988 to 1994). Obesity Research, 5(6), 542-548.

Kuorinka, I., Jonsson, B., Kilbom, A., Vinterberg, H., Biering-Sørensen, F., Andersson, G., \& Jørgensen, K. (1987). Standardised Nordic questionnaires for the analysis of musculoskeletal symptoms. Applied ergonomics, 18(3), 233-237.

Leboeuf-Yde, C., \& Kyvik, K. O. (1998). At what age does low back pain become a common problem?: A study of 29,424 individuals aged 12-41 Years. Spine, 23(2), 228-234.

Lederman, E. (2011). The fall of the postural-structural-biomechanical model in manual and physical therapies: Exemplified by lower back pain. Journal of Bodywork \& Movement Therapies, 15, $131-138$.

Leetun, D. T., Ireland, M. L., Willson, J. D., Ballantyne, B. T., \& Davis, I. M. (2004). Core stability measures as risk factors for lower extremity injury in athletes. Medicine \& Science in Sports \& Exercise, 36(6), 926-934.

McGill, S. M., Childs, A., \& Liebenson, C. (1999). Endurance times for low back stabilization exercises: Clinical targets for testing and training from a normal database. Archives of Physical Medicine and Rehabilitation, 80(8), 941-944.

McGregor, A., Anderton, L., \& Gedroyc, W. (2002). The assessment of intersegmental motion and pelvic tilt in elite oarsmen. Medicine \& Science in Sports \& Exercise, 34(7), 1143-1149.

McGregor, A., Bull, A. M. J., \& Byng-Maddick, R. (2004). A comparison of rowing technique at different stroke rates: a description of sequencing force production and kinematics. International Journal of Sports Medicine, 25(6), 465-470.

McGregor, A. H., Patankar, Z. S., \& Bull, A. (2005). Spinal kinematics in elite oarswomen during a routine physiological "step test". Medicine \& Science in Sports \& Exercise, 37(6), 1014-1020.

McMeeken, J., Tully, E., Stillman, B., Nattrass, C., Bygott, I. L., \& Story, I. (2001). The experience of back pain in young Australians. Manual Therapy, 6(4), 213-220.

Minick, K. I., Kiesel, K. B., Burton, L., Taylor, A., Plisky, P., \& Butler, R. J. (2010). Interrater reliability of the functional movement screen. The Journal of Strength \& Conditioning Research, 24(2), 479.

Minkler, S., \& Patterson, P. (1994). The validity of the modified sit-and-reach test in college-age students. Research Quarterly for Exercise and Sport, 65(2), 189-192.

Morgan, B. E., \& Oberlander, M. A. (2001). An examination of injuries in major league soccer. The American Journal of Sports Medicine, 29(4), 426-430. 
Mottram, S., \& Comerford, M. (2008). A new perspective on risk assessment. Physical Therapy in Sport, 9(1), 40-51.

O'Connor, F. G., Deuster, P. A., Davis, J., Pappas, C. G., \& Knapik, J. J. (2011). Functional movement screening: predicting injuries in officer candidates. Medicine \& Science in Sports \& Exercise, 43(12), 2224-2230.

O'Kane, J. W., Teitz, C. C., \& Lind, B. K. (2003). Effect of preexisting back pain on the incidence and severity of back pain in intercollegiate rowers. American Journal of Sports Medicine, 31(1), 8082.

Okada, T., Huxel, K. C., \& Nesser, T. W. (2011). Relationship between core stability, functional movement, and performance. Journal of Strength \& Conditioning Research 25(1), 252-261.

Onate, J., Cortes, N., Welch, C., \& van Lunen, B. (2010). Expert versus novice interrater reliability and criterion validity of the landing error scoring system. Journal of Sport Rehabilitation, 19(1), 4156.

Onate, J. A., Dewey, T., Kollock, R. O., Thomas, K. S., Van Lunen, B. L., DeMaio, M., \& Ringler, S. I. (2012). Real-time intersession and interrater reliability of the functional movement screen. Journal of Strength \& Conditioning Research, 26(2), 408-415.

Padua, D. A., Marshall, S. W., Boling, M. C., Thigpen, C. A., Garrett, W. E., \& Beutler, A. I. (2009). The landing error scoring system (LESS) is a valid and reliable clinical assessment tool of jumplanding biomechanics: the jump-ACL study. The American Journal of Sports Medicine, 37(10), 1996-2002.

Parchmann, C. J., \& McBride, J. M. (2011). Relationship between functional movement screen and athletic performance. Journal of Strength \& Conditioning Research, 25(12), 3378-3384.

Parkkari, J., Kannus, P., Natri, A., Lapinleimu, I., Palvanen, M., Heiskanen, M., ... Jarvinen, M. (2004). Active living and injury risk. International Journal of Sports Medicine, 25(03), 209-216.

Peate, W., Bates, G., Lunda, K., Francis, S., \& Bellamy, K. (2007). Core strength: A new model for injury prediction and prevention. J Occup Med Toxicol, 2(3), 1-9.

Perich, D., Burnett, A., \& O'Sullivan, P. (2006). Low back pain in adolescent female rowers and the associated factors. In In International Society of Biomechanics in Sports, Proceedings of XXIV International Symposium on Biomechanics in Sports 2006, Salzburg, Austria, University of Salzburg, c2006, p.355-358. Austria

Perich, D., Burnett, A., O’Sullivan, P., \& Perkin, C. (2011). Low back pain in adolescent female rowers: a multi-dimensional intervention study. Knee Surgery, Sports Traumatology, Arthroscopy, 19(1), 20-29.

Reid, D., \& McNair, P. (2000). Factors contributing to low back pain in rowers. . British Journal of Sports Medicine, 34(5), 321-322.

Roy, S. H., De Luca, C. J., Snyder-Mackler, L., Emley, M. S., Crenshaw, R. L., \& Lyons, J. P. (1990). Fatigue, recovery, and low back pain in varsity rowers. / Fatigue, recuperation et lombalgie chez des rameurs universitaires. Medicine \& Science in Sports \& Exercise, 22(4), 463-469.

Rumball, J. S., Lebrun, C. M., Ciacca, S. R. D., \& Orlando, K. (2005). Rowing Injuries. Sports Medicine, 35, 537-555.

Schneiders, A. G., Davidsson, A., Horman, E., \& Sullivan, S. J. (2011). Functional movement screen normative values in a young, active population. International Journal of Sports Physical Therapy, 6(2), 75-82.

Shultz, R., Mooney, K., Anderson, S., Marcello, B., Garza, D., Matheson, G. O., \& Besier, T. (2011). Functional movement screen: inter-rater and subject reliability. British Journal of Sports Medicine, 45(4), 374-374.

Smith, H. C., Johnson, R. J., Shultz, S. J., Tourville, T., Holterman, L. A., Slauterbeck, J., ... Beynnon, B. D. (2012). A prospective evaluation of the landing error scoring system (LESS) as a screening tool for anterior cruciate ligament injury risk. American Journal of Sports Medicine, 40(3), 521 526.

Smoljanovic, T., Bojanic, I., Hannafin, J. A., Hren, D., Delimar, D., \& Pecina, M. (2009). Traumatic and overuse injuries among international elite junior rowers. American Journal of Sports Medicine, 37(6), 1193-1199.

Song, J. W., \& Chung, K. C. (2010). Observational studies: cohort and case-control studies. Plastic and reconstructive surgery, 126(6), 2234.

Sorenson, E. A. (2009). Functional movement screen as a predictor of injury in high school basketball athletes (Dissertation). University of Oregon. doi:https://scholarsbank.uoregon.edu/xmlui/bitstream/handle/1794/10594/Sorenson_Eric_A_phd 2009fa.pdf?sequence $=1$

Stanton, T. R., Henschke, N., Maher, C. G., Refshauge, K. M., Latimer, J., \& McAuley, J. H. (2008). After an episode of acute low back pain, recurrence is unpredictable and not as common as previously thought. Spine, 33(26), 2923-2928. 
Strahan, A. D., Burnett, A. F., Caneiro, J. P., Doyle, M. M., O'Sullivan, P. B., \& Goodman, C. (2011). Differences in spinopelvic kinematics in sweep and scull ergometer rowing. Clinical Journal of Sport Medicine, 21(4), 330-336.

Stutchfield, B. M., \& Coleman, S. (2006). The relationships between hamstring flexibility, lumbar flexion, and low back pain in rowers. European Journal of Sport Science, 6(4), 255-260.

Teitz, C. C., O'Kane, J., Lind, B. K., \& Hannafin, J. A. (2002). Back pain in intercollegiate rowers. American Journal of Sports Medicine, 30(5), 674.

Teitz, C. C., O'Kane, J. W., \& Lind, B. K. (2003). Back pain in former intercollegiate rowers: a long-term follow-up study. American Journal of Sports Medicine, 31(4), 590-595.

Teyhen, D. S., Shaffer, S. W., Lorenson, C. L., Halfpap, J. P., Donofry, D. F., Walker, M. J., ... Childs, J. D. (2012). The functional movement screen: a reliability study. Journal of Orthopaedic \& Sports Physical Therapy, 42(6), 530-540.

Thorpe, A., O'Sullivan, P., Burnett, A., \& Caneiro, J. P. (2009). Assessing the efficacy of a specific physiotherapy intervention for the prevention of low back pain in female adolescent rowers: A field study. New Zealand Journal of Sports Medicine, 36(2), 38 - 46.

Timm, K. (1999). Sacroiliac Joint dysfunction in elite rowers. Journal of Orthopaedic and Sports Physical Therapy, 29(5), 288-293.

Warden, S. J., Gutschlag, F. R., Wajswelner, H., \& Crossley, K. M. (2002). Aetiology of rib stress fractures in rowers. Sports Medicine, 32, 819-836.

Whatman, C., Hing, W., \& Hume, P. (2012). Physiotherapist agreement when visually rating movement quality during lower extremity functional screening tests. Physical Therapy in Sport, 13(2), 8796.

Wieczorkowski, M. P. (2010). Functional movement screening as a predictor of injury in high school basketball athletes (Masters Thesis). University of Toledo, Toledo.

Wilson, F., Gissane, C., Gormley, J., \& Simms, C. (2010). A 12-month prospective cohort study of injury in international rowers. British journal of sports medicine, 44(3), 207-214.

Wilson, F., Kennedy, F., \& Meehan, K. (2004). The incidence and management of rowing injuries. (Abstract). Journal of Sports Sciences, 22(3), 261-262. 